\title{
Is the Permeability of Naturally Fractured Rocks Scale Dependent?
}

\section{Siroos Azizmohammadi}

Department of Petroleum Engineering, Montanuniversität Leoben, Parkstrasse 27, 8700

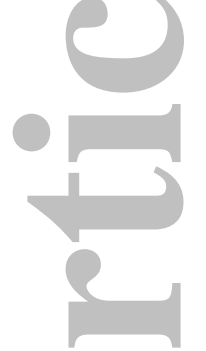

Leoben, Austria

siroos.azizmohammadi@unileoben.ac.at

Department of Infrastructure Engineering, Melbourne School of Engineering, the University

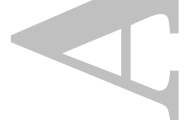
of Melbourne, Victoria 3010, Australia

stephan.matthai@unimelb.edu.au

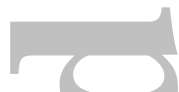

\section{Key points}

1. Multi-scale analysis of the magnitude of the full equivalent (fracture + matrix homogenization-derived) permeability tensor of layered permeable sedimentary rocks where fracture aperture was computed from in situ stress.

2. First maps of fracture-matrix ensemble permeability tensors juxtaposed on fracture patterns highlighting strong anisotropy.

3. Analysis of permeability tensor orientation and its variation with scale. The REV is shown to be related to the size of dilated fracture segments as opposed to fracture length.

4. Tensor orientation varies spatially indicating the heterogeneity of the studied fracture patterns.

This is the author manuscript accepted for publication and has undergone full peer review but has not been through the copyediting, typesetting, pagination and proofreading process, which may lead to differences between this version and the Version record. Please cite this article as doi:10.1002/ 2016WR019764. 


\section{Abstract}

The equivalent permeability, $\mathbf{k}^{e q}$ of stratified fractured porous rocks and its anisotropy is important for hydrocarbon reservoir engineering, groundwater hydrology, and subsurface contaminant transport. However, it is difficult to constrain this tensor property as it is strongly influenced by infrequent large fractures. Boreholes miss them and their directional sampling bias affects the collected geostatistical data. Samples taken at any scale smaller than that of interest truncate distributions and this bias leads to an incorrect characterization and property upscaling.

To better understand this sampling problem, we have investigated a collection of outcropdata based Discrete Fracture and Matrix (DFM) models with mechanically constrained fracture aperture distributions, trying to establish a useful Representative Elementary Volume (REV). Finite-element analysis and flow-based upscaling have been used to determine $\mathbf{k}^{e q}$ eigenvalues and anisotropy.

While our results indicate a convergence towards a scale-invariant $\mathbf{k}^{e q} \mathrm{REV}$ with increasing sample size, $\mathbf{k}^{e q}$ magnitude can have multi-modal distributions. REV size relates to the length of dilated fracture segments as opposed to overall fracture length. Tensor orientation and degree of anisotropy also converge with sample size. However, the REV for $\mathbf{k}^{e q}$ anisotropy is larger than that for $\mathbf{k}^{e q}$ magnitude. Across scales, tensor orientation varies spatially, reflecting inhomogeneity of the fracture patterns. Inhomogeneity is particularly pronounced where the ambient stress selectively activates late- as opposed to early (throughgoing) fractures. While we cannot detect any increase of $\mathbf{k}^{e q}$ with sample size as postulated in some earlier studies, our results highlight a strong $\mathbf{k}^{e q}$ anisotropy that influences scale dependence. 


\section{List of symbols}

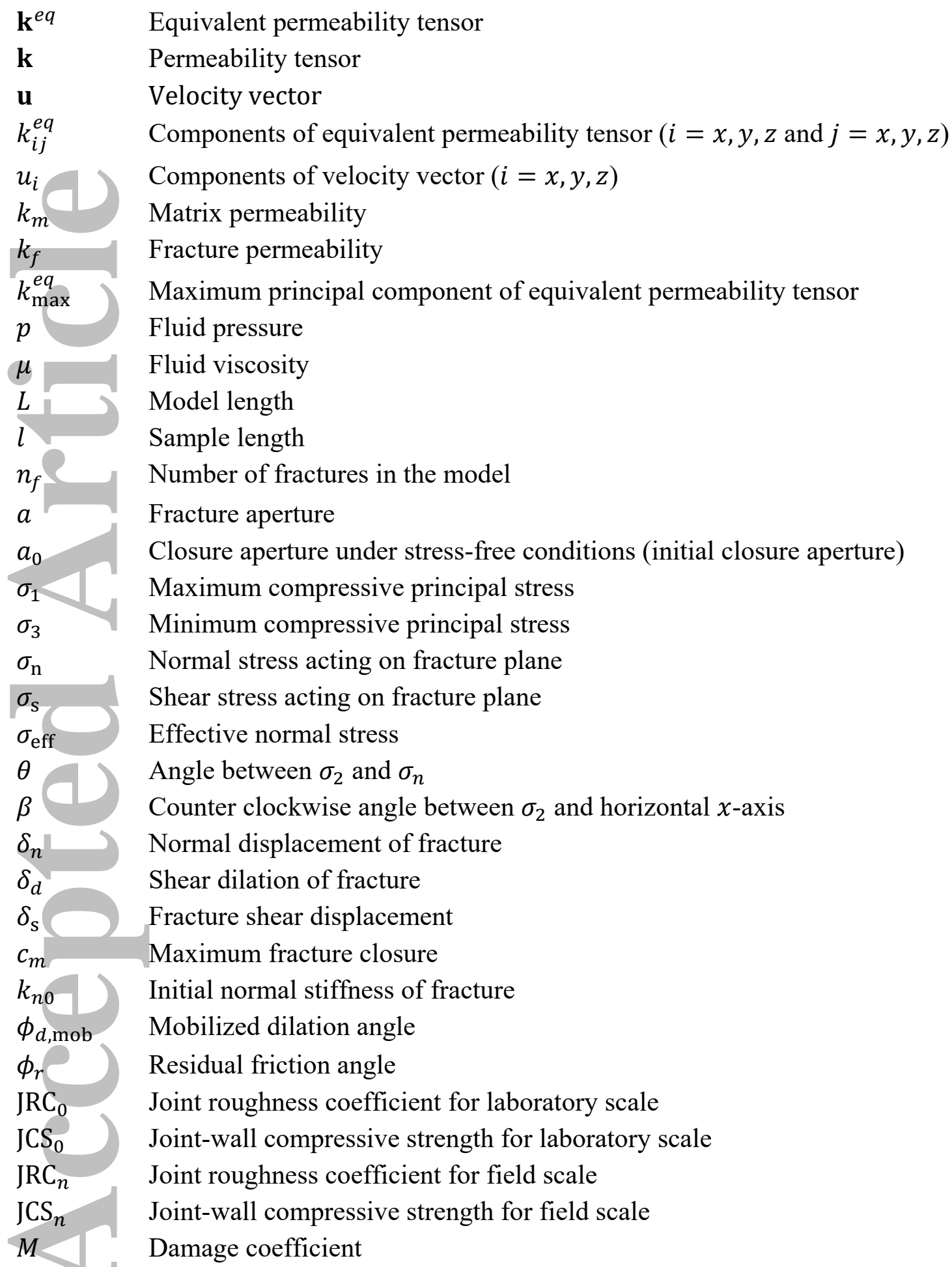




\section{Introduction}

Understanding the impact of fractures on the flow properties of layered sedimentary rocks in the subsurface (1-5 km depth), is important not only because more than $50 \%$ of the world's remaining conventional oil reservoirs are hosted by naturally fractured (Roehl and Choquette, 1985; Pirker et al., 2008; Tran, 2009), but also because production of coal seam gas, coal bed methane or shale oil would not be possible in the absence of fractures (e.g., Turcotte et al., 2014). Moreover, fractured sedimentary rocks are good candidates for geological carbon sequestration (Annewandter et al., 2013; Ringrose et al., 2013).

The flow properties of subsurface strata are usually inferred from information collected on a wide range of length scales, from the centimeter scale (e.g., core samples) over the well log (Wu and Pollard, 2002) to the kilometer scale (e.g., seismic studies). Since fracture length cannot be measured in borehole, such measurements require length-frequency distributions from outcrops (e.g., Bonnet et al., 2001). These are either power law or follow a negative exponential (Bonnet et al., 2001; Olson, 2003). Given this (pseudo) fractal nature, it is questionable that an REV concept can be applied. Even raw fracture density estimates are somewhat arbitrary as they strongly depend on where the lower cut-off value imposed on fracture length is set.

Highly resolved well data are nevertheless sparse and computational constraints demand that property modeling is carried out on the scale of structured simulation grids (typical cell size $\sim 10-300 \mathrm{~m})$. Volumetric averaging yields equivalent properties on this scale. More sophisticated "flow-based" upscaling methods compute the equivalent permeability, ascertaining that each grid block behaves similar to the underpinning fine-scale model if similar boundary conditions are imposed (e.g., Durlofsky, 1991). For fractured impermeable rock masses the resultant equivalent permeability is estimated from stochastic Discrete Fracture Network (DFN) models. For fractured permeable rocks Discrete Fracture and Matrix 
(DFM) models informed by statistics extracted from well logs and cores represent a superior alternative because they also consider the interactions of the fractures with the rock matrix (Min et al., 2004; Ahmed-Elfeel and Geiger, 2012).

Homogenization techniques try to model the heterogeneous medium as a simpler equivalent continuous medium. This simplification is assumed valid at a scale much larger than that of the heterogeneities (Auriault et al., 2009). Numerous other upscaling techniques have been proposed and analyzed (e.g., Qi and Hesketh, 2005, and references therein). They all assume that it is possible to perform such a separation of length scales, and that there is a Representative Elementary Volume (REV): a sample size above which the measured values of the property neither vary significantly from sample to sample nor change if sample size is further increased (Bear, 1972). Qi and Hesketh (2005) stress that the REV imposes a fielddata based selection criterion for the upscaling method of choice. Finding such an REV for the permeability of fractured sedimentary rocks is not trivial: permeability values often vary by many orders of magnitude between wells or even along them (Aguilera, 1995; Nelson, 1985). Already in 1975, Kiraly compiled field evidence that the permeability of fractured limestones appears to vary with scale (Figure 1). He argued that this is due to nested geologic features with scale variant properties (pores/micro fractures, macro fractures and karst, faults).

Since then, many researchers have observed such a dependence (Brace, 1994; Neumann, 1994; Hsieh, 1998; Schulze-Makuch et al., 1999; Martiez-Landa and Carrera, 2005). Neumann (1994) fitted a power law to the scaling he obtained from hydraulic tests from a number of sites described in Gelhar (1993). Schulze-Makuch et al. (1999) noticed a similar relationship up to an intermediate volume scale $\left(10^{4} \mathrm{~m}^{3}\right)$. In their investigation of 39 different lithotypes the documented permeability increase with scale was most prominent in the fractured ones and absent only from nearly homogeneous quartz sandstones with an REV at the laboratory specimen scale $\left(10^{-4} \mathrm{~m}^{3}\right)$. These findings are corroborated by the pulse-, 
recovery-, cross-hole-, and inflow tests of Martinez-Landa and Carrera (2005) carried out on fractured granite during the FEBEX experiment at the Grimsel Pass underground laboratory in Switzerland. There, equivalent permeability increases with analyzed rock volume.

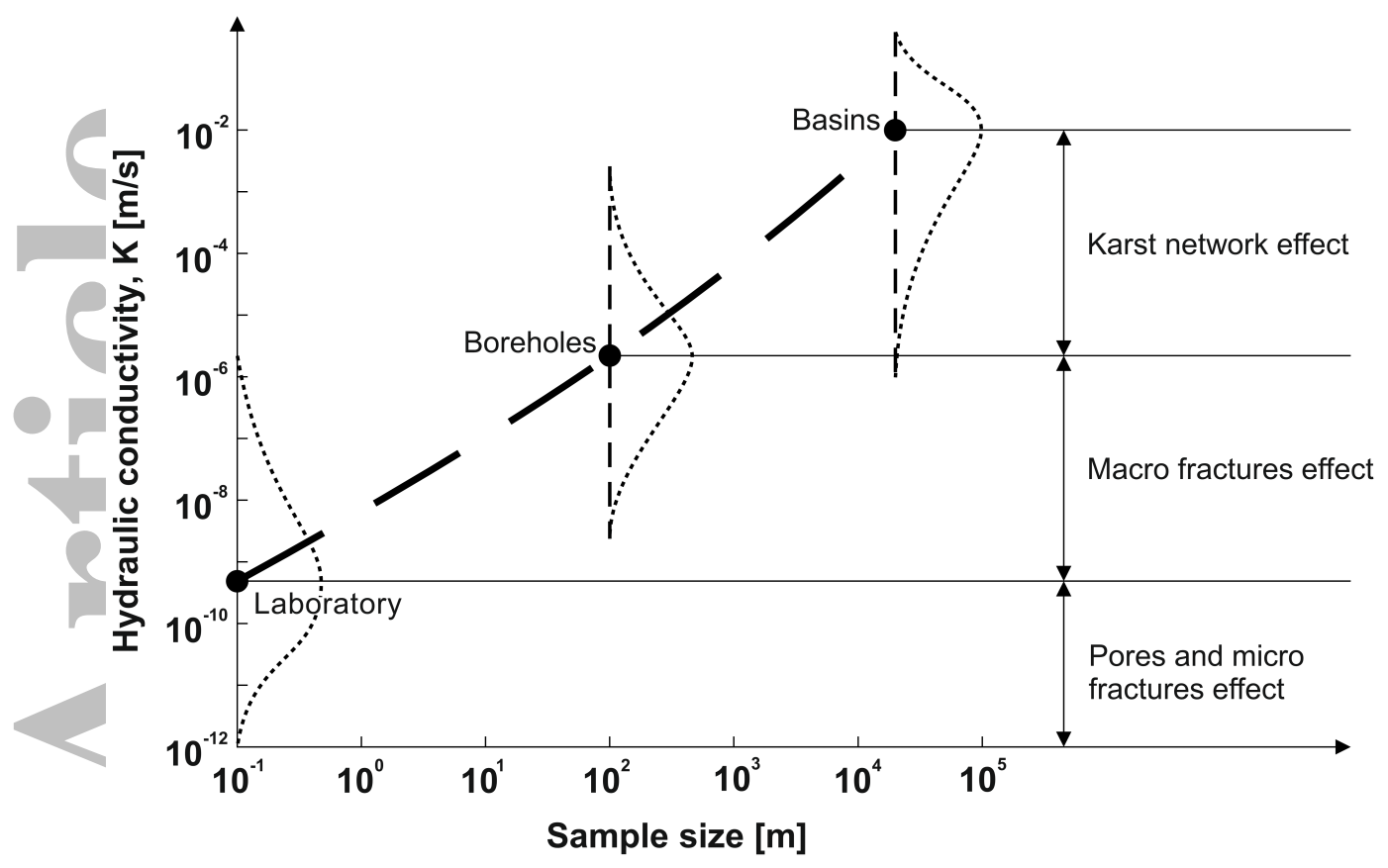

Figure 1. Variation of hydraulic conductivity with sample size as determined from different types and length scales of measurements carried out on fractured and karstified carbonate rocks in the Swiss Jura mountains (Kiraly, 1975). Dotted lines give qualitative estimates on observed value distributions.

A scale dependent equivalent permeability has also been observed in DFN/DFM models (Long et al., 1982; Min et al., 2004; Bogdanov et al., 2007). Long et al. (1982) report that samples smaller than the length of the fractures, indicate a homogeneous, yet anisotropic medium. With increasing sample size, the permeability becomes less predictable and tensor measurements indicate anisotropy. Min et al. (2004), show that the variance of computed permeability components decreases with scale, hinting at the existence of an REV.

Renshaw and Park (1997) highlight fracture aperture as an additional important parameter that shows a complex dependence on fracture length, orientation, state of stress, fluid pressure and the mechanical properties of the fractured rock. In most published stochastic modeling studies, however, aperture is treated as constant (e.g. Hardebol et al., 2015). Where it is varied with fracture length, this pre-imposes a scale variance. There are several studies that address the impact of geo-mechanical aperture on equivalent permeability (Paluszny and 
Matthai, 2010; Nick et al., 2011; Bisdom et al., 2016a, 2016b, 2016c). Yet, they do not consider the full tensor of equivalent permeability and its potential variation with direction and scale. Recently, Bisdom et al. (2017) also introduced a workflow for integrating geomechanics and full-tensor permeability calculations into outcrop modeling studies. Arguably, these studies may not have investigated sufficiently large samples of the fracture population to reproduce the statistics seen in the field (Paluszny and Matthai, 2010; Nick et al., 2011; Bisdom et al., 2016a, 2016b, 2016c). While studies like Bogdanov et al. (2007) and Chen et al. (2015) address the upscaling of the fracture-matrix ensemble, the impact of a variable fracture aperture on permeability anisotropy and its potential variation with scale and the state of stress has yet to be clarified.

This study applies fracture-and-permeable-rock-matrix numerical analysis (Bogdanov et al., 2007; Matthäi and Belayneh, 2004), later termed Discrete Fracture and Matrix (DFM) method (e.g., Matthäi et al., 2010; Ahmed-Elfeel and Geiger, 2012, Lang et al., 2014) to investigate the anisotropy and potential scale dependence of the equivalent permeability of layered fractured sedimentary rocks. For this purpose, a spectrum of complex natural fracture patterns has been reproduced in highly detailed finite-element DFMs. Plausible in situ fracture aperture distributions were computed using the Barton and Bandis mechanical model (Barton and Choubey, 1977; Barton and Bandis, 1982; Bandis et al., 1983; Barton et al., 1985). The flow-based upscaling approach developed by Durlofsky (1991) is used herein to compute equivalent permeability tensors for the complex natural fracture patterns. This is followed by REV analysis based on a new sampling technique that will be explained in the methodology.

The novelty of this study can be summarized as: (1) a new stress-induced aperture modeling that allows aperture (therefore fracture permeability) to vary along (curved) fractures, (2) a new sampling and REV analysis technique, (3) the first multi-scale plots of permeability 
tensors juxtaposed on fracture permeability maps, illustrating the strong anisotropy of naturally fractured rocks and the spatial variation of tensor orientation.

The paper proceeds as follows: first, the characteristics of the permeability tensor in naturally fractured porous media are reviewed. Second, the aperture modeling is presented. Third, the governing equations and boundary conditions used in the finite element analysis are explained, followed by the sampling and the equivalent permeability calculation procedures. A verification of these methods are added. The methodology is followed by a description of the outcrop models. While key results are reported in the body of this paper, a digital appendix provides the full suite of simulation results.

\section{Methodology}

This study focuses on permeable layered sedimentary rocks with open natural fractures mapped in outcrops in two dimensions. We ignore stereological effects (cf., Darcel et al., 2003) because the majority of fractures in the studied horizontal pavements dip perpendicular to bedding, fully penetrating the sedimentary layers. Thus, the fractures are largely bed confined intersecting only the single layer. Also, fracturing is restricted to brittle layers sandwiched between more shale-rich layers above and below. In this scenario, fluid flow is largely confined to the fractured beds.

To build the flow models, fracture line tracings were converted into $3^{\text {rd }}$-order Non-UniformRational B-Spline curves (NURBS) because these are well suited for spatially adaptive meshing. These curves and their intersection points define the input geometry for finiteelement meshing carried out with a commercial software package, creating constrained conforming triangulations with discrete (lower-dimensional) line-element representations of the fractures. The spatially adaptive refinement was used to keep element numbers down while capturing the intricate patterns with more than 1000 fractures per model, see below. The Complex Systems Modeling Platform (CSMP++, Matthäi et al., 2007) was used to 
calculate pressure and velocity fields on these meshes using the Bubnov-Galerkin finiteelement method, see Matthäi and Belayneh (2004).

\subsection{Fracture aperture and permeability calculation}

The permeability of the rock matrix, $k_{m}$, is treated as constant and isotropic. Although rarely constant, fixing $k_{m}$ helps to discern fracture related inhomogeneity. The permeability of each fracture segment (every single finite element that represents a fracture) is computed from its aperture, $a$, by the parallel plate law (Snow, 1969)

$$
k_{f}=\frac{a^{2}}{12}
$$

This is suitable for the calculation of ensemble permeabilities, but assumes that flow is laminar and inertia effects can be neglected (cf., Zimmerman and Bodvarsson, 1996; Meheust and Schmittbuhl, 2003).

Local fracture aperture is computed from the far-field stress and fluid pressure acting on each fracture segment. Using Cauchy's equation, this stress is resolved into a fracture normal- and a parallel shear stress component (e.g, Pollard and Fletcher, 2005; Beer et al., 2011)

$$
\begin{aligned}
& \sigma_{n}=\sigma_{1} \cos ^{2} \theta+\sigma_{3} \sin ^{2} \theta \\
& \sigma_{s}=\left(\sigma_{3}-\sigma_{1}\right) \sin \theta \cos \theta
\end{aligned}
$$

where $\sigma_{1}$ and $\sigma_{3}$ represent the magnitudes of the maximum and minimum compressive principal stresses acting in the plane of the sedimentary layer, respectively; $\theta$ is the angle between $\sigma_{1}$ and, $\sigma_{n}$ (Figure 2a). In the following equations, compressive stresses are treated as positive. It should be noted that equations (2) and (3) do not consider the impact of mechanical interactions of fractures close to one another (e.g. Olson, 2007).

The aperture of rough-walled natural fractures not only depends on stress, but also on shear displacement. Following Barton et al. (1985) fracture roughness can be quantified in terms of aperture variation as

$$
a=a_{0}-\delta_{n}+\delta_{d}
$$



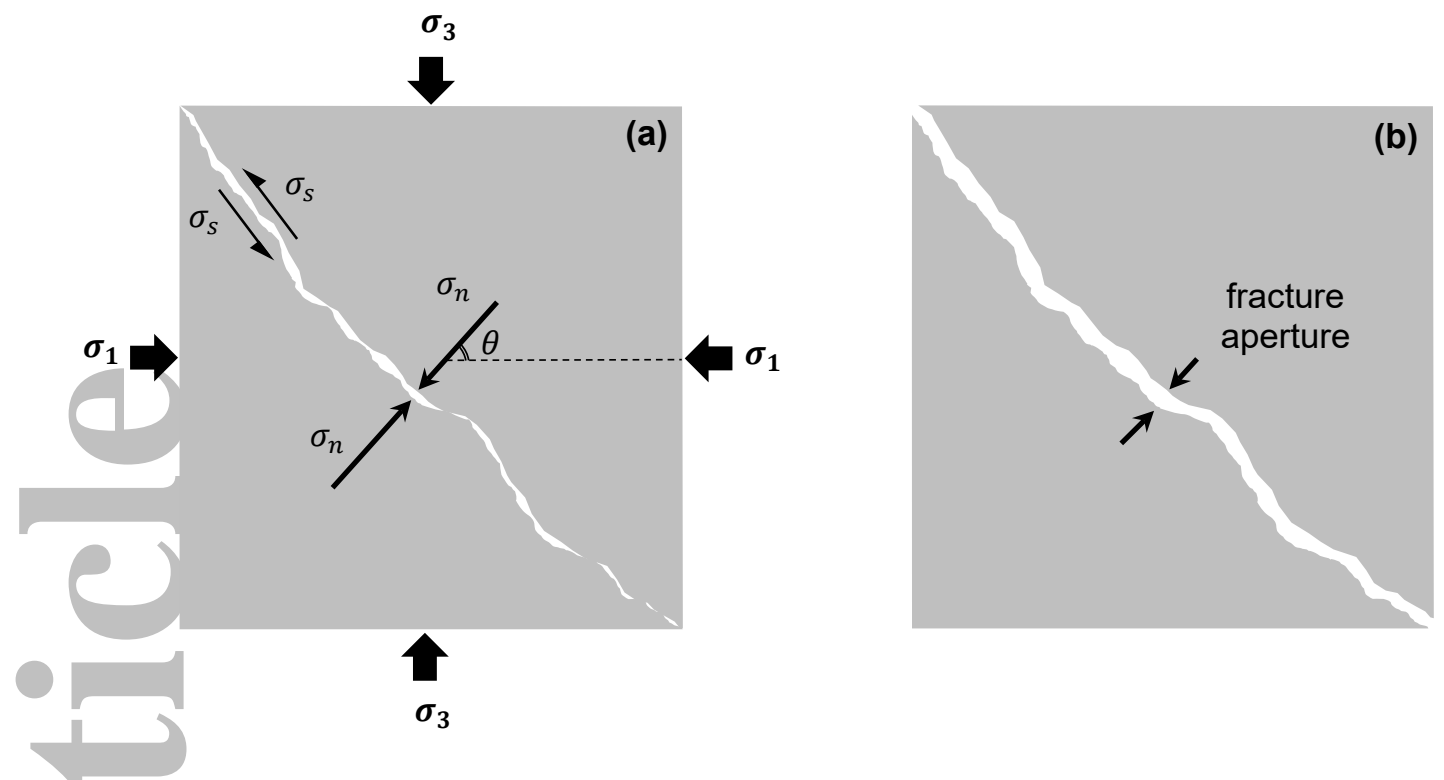

Figure 2. Fracture cross-section model of stress induced opening. (a) Normal $\sigma_{n}$ and shear $\sigma_{s}$ stresses acting on the fracture walls in response to far-field maximum and minimum principal stresses, $\sigma_{1}$ and $\sigma_{3}$, respectively. The fluid pressure counteracting the fracture-normal stress is not shown. (b) Relative normal and shear displacements of the fracture walls subjected to the far-field stress.

where $a_{0}$ is a closure aperture under stress-free conditions, measured, for instance, on core samples (Figure 2b); $\delta_{n}$ is the reduction of aperture caused by application of a normal stress, and $\delta_{d}$ the increase of aperture due to shear dilation. In this study, $a_{0}$ is assigned a small constant value to ensure that all fractures in the pattern have a non-zero aperture prior to application of stress. Normal closure, $\delta_{n}$ is then determined by using Bandis' hyperbolic model (Bandis et al., 1983)

$$
\delta_{n}=\frac{k_{n 0} c_{m}{ }^{2}}{k_{n 0} c_{m}+\sigma_{\mathrm{eff}}}
$$

where $\sigma_{\text {eff }}$ is the effective normal stress acting on the fracture plane, $c_{m}$ the maximum closure, and $k_{n 0}$ the initial fracture normal stiffness. These parameters can be estimated by using the empirical relations discussed in Bandis et al. (1983). Central to these rules is that asperity gliding "when the joint roughness is mobilized" results in fracture dilation. This mobilization is experimentally constrained to occur at 30\% of peak shear displacement (Barton et al., 1985) and shear dilation can be calculated from

$$
\delta_{d}=\delta_{s} \tan \left(\phi_{d, \mathrm{mob}}\right)
$$


where $\delta_{\mathrm{s}}$ is the shear displacement and $\phi_{d, \mathrm{mob}}$ the mobilized dilation angle evaluated by

$$
\phi_{d, \mathrm{mob}}=\frac{1}{M} \mathrm{JRC}_{\mathrm{mob}} \log _{10}\left(\frac{\mathrm{JCS}_{n}}{\sigma_{\mathrm{eff}}}\right)
$$

The coefficient $M$ parameterises damage with values of 1 or 2 for shearing under low or high fracture normal stress, respectively (Olsson and Barton, 2001). It can also be obtained from Barton and Choubey (1977)

$$
M=0.7+\mathrm{JRC}_{n} /\left[12 \log _{10}\left(\frac{\mathrm{JCS}_{n}}{\sigma_{\text {eff }}}\right)\right]
$$

where JRC $\mathrm{mob}_{\mathrm{mob}}$ is the mobilized joint roughness coefficient

$$
\mathrm{JRC}_{\mathrm{mob}}=\left[\tan ^{-1}\left(\frac{\sigma_{s}}{\sigma_{\mathrm{eff}}}\right)-\phi_{r}\right] / \log _{10}\left(\frac{\mathrm{JCS}_{n}}{\sigma_{\text {eff }}}\right)
$$

and $\phi_{r}$ is the residual friction angle. A fracture length dependent joint-wall compressive strength, $\mathrm{JCS}_{n}$ was introduced by Barton and Bandis (1982) together with the $\mathrm{JRC}_{n}$ to address the influence of fracture size on surface properties. This approach was motivated by the observation, that larger fractures tend to have larger surface undulations, including rib marks, plumose textures and hackle (cf., Pollard and Aydin, 1988). This aperture calculation approach goes much beyond other modeling studies, which either assume that all fractures have similar apertures (e.g., Taylor et al., 1999; Min et al., 2004) or utilize values sampled from power-law distributions (e.g., Long et al., 1982). For carbonates, universal lengthversus-aperture correlations apply where mineral bridges preserve original openings, see Olson (2003). By contrast, the Barton and Bandis model allows $k_{f}$ to vary not only with fracture length, but also with orientation of curved fractures. Simultaneously, it considers the mechanical properties of the host rock. Arguably, this is sufficiently realistic to serve as a point of departure for the analysis of the scale dependence of the equivalent permeability of layered fractured rock. 


\subsection{Full-tensor equivalent permeability analysis}

The steady-state pressure equation serves as a prior for the determination of the equivalent permeability. It is derived by substituting Darcy's law into the continuity equation $(\nabla \cdot \mathbf{u}=0)$

$$
\nabla \cdot\left(\frac{\mathbf{k}}{\mu} \cdot \nabla p\right)=0
$$

here $\mathbf{k}$ is the permeability tensor, and $\mu$ the viscosity of the fluid. In a two-dimensional Cartesian coordinate system, the full permeability tensor is

$$
\mathbf{k}=\left[\begin{array}{ll}
k_{x x} & k_{x y} \\
k_{y x} & k_{y y}
\end{array}\right]
$$

Since this is a symmetric positive definite matrix (Bear, 1972)

$$
k_{x y}=k_{y x}
$$

The positive definite attribute implies that

$$
k_{x x} k_{y y}>\left(k_{x y}\right)^{2}, \quad k_{x x}>0, \quad k_{y y}>0
$$

These two characteristics must apply, otherwise the permeability tensor has no physical meaning because the eigenvalues of $\mathbf{k}$ are real only if it is symmetric. The positive definite attribute also implies that energy is dissipated during fluid flow (Durlofsky, 1991) as the fluid moves in the direction of the decreasing pressure gradient (Bear and Cheng, 2010). Directional permeability further implies that flow directions are not necessarily aligned with the fluid-pressure gradient. This is fundamental for the calculation of the permeability tensor in an anisotropic medium (Long et al., 1982).

Following the non-local permeability upscaling approach of Durlofsky (1991), involves solving two flow problems: In the first, we set constant pressure (Dirichlet) boundary conditions on opposite left $\left(p_{\text {in }}\right)$ and right $\left(p_{\text {out }}\right)$ edges of the overall model while no-flow (natural) boundary conditions are applied on the others, see Figure 3.

The set of linear algebraic equations arising from the finite elements equations describing the pressure field, $p(x, y)$ is solved with the algebraic multigrid method for systems of equations 
SAMG (Stüben, 2001). From the gradient of the pressure field, piecewise constant element velocities are calculated using Darcy's law. The same process is repeated for the second flow problem with constant pressures applied at top and bottom boundaries and no-flow (natural) boundary conditions applied to the others. The computed pressure and velocity fields are sampled randomly in square-shaped model subregions with a side length $l$ that is a fraction of model length, $L$ (see Figure 3c). The dimensionless sample size $l_{D}$ is defined as

$$
l_{D}=\frac{l}{L}=\frac{1}{1+r} \quad r \in R^{+}
$$

where $r$ is a set of real positive numbers, and $1 /(1+r)$ reflects the size fraction of a sample with respect to the entire model. To make the statistical assessment meaningful, the smallest $r$ is chosen so that each sample contains at least 100 elements. Sufficient model size ascertains that enough samples $(\geq 30)$ can be taken on the largest scale.

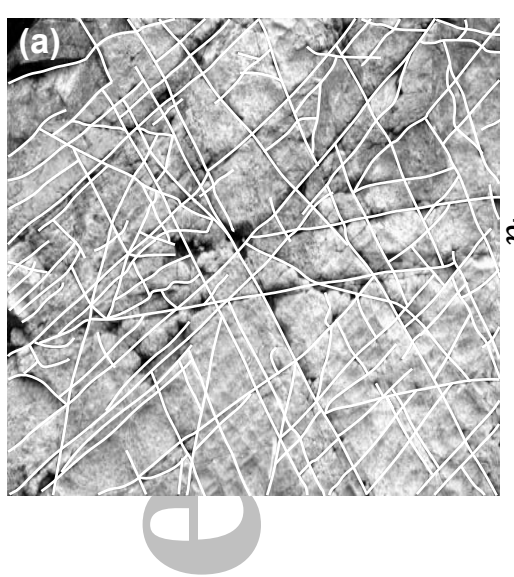

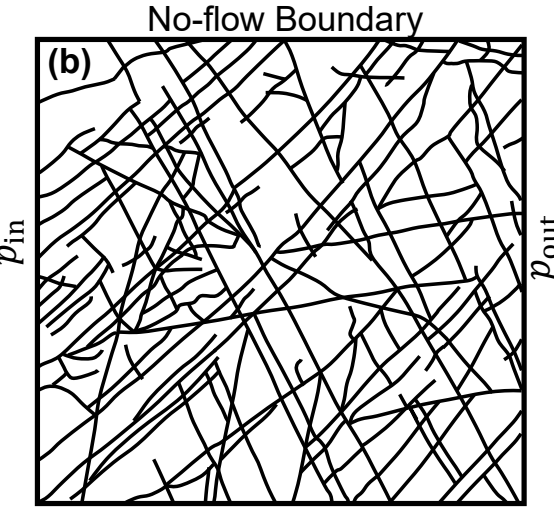

No-flow Boundary

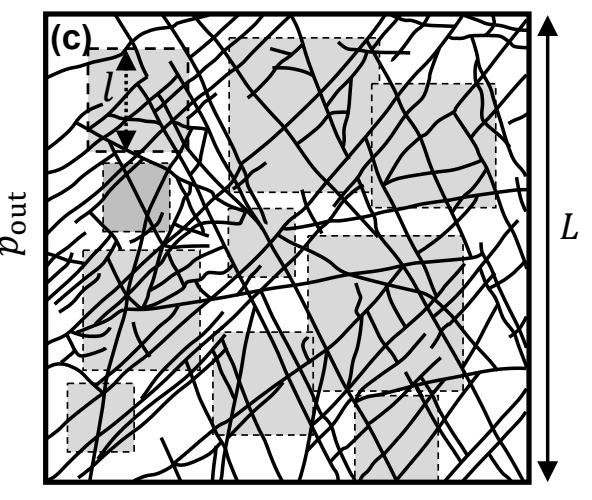

Figure 3. Photograph of fractured rock sample (a) and trace map of different fracture sets shown as white lines, (b) including boundary conditions: Uniform pressure set on left and right edges of the model; bottom and top edges are no-flow boundaries, and (c) Random sampling performed in this study: partially overlapping square-shaped box samples with edge length $l$ (inset boxes).

Figure 3c shows some typical random square-shaped samples inside a test model. Samples taken this way might overlap with each other. To quantify the effect of this, systematic random sampling avoiding any overlaps (e.g., Elzinga et al., 2001) was also carried out. For each random sample, the equivalent permeability tensor, $\mathbf{k}^{e q}$, was computed by volume averaging of fluid velocities, pressure gradients, and viscosities (Durlofsky, 1991) 


$$
\langle\mathbf{u}\rangle=-\frac{\mathbf{k}^{e q}}{\langle\mu\rangle} \cdot\langle\nabla p\rangle
$$

where \langle\rangle is the volume averaging operator. The equivalent permeability tensor, $\mathbf{k}^{e q}$, relates the averaged flow velocity $\langle\mathbf{u}\rangle$ to the averaged pressure gradient $\langle\nabla p\rangle$. Writing out matrix components in the $x$ and $y$ directions in full, this linear-algebraic relationship assumes the form

$$
\left[\begin{array}{cccc}
\left\langle\nabla p_{x}\right\rangle^{1} & \left\langle\nabla p_{y}\right\rangle^{1} & 0 & 0 \\
0 & 0 & \left\langle\nabla p_{x}\right\rangle^{1} & \left\langle\nabla p_{y}\right\rangle^{1} \\
\left\langle\nabla p_{x}\right\rangle^{2} & \left\langle\nabla p_{y}\right\rangle^{2} & 0 & 0 \\
0 & 0 & \left\langle\nabla p_{x}\right\rangle^{2} & \left\langle\nabla p_{y}\right\rangle^{2}
\end{array}\right]\left\{\begin{array}{c}
k_{x x}^{e q} \\
k_{x y}^{e q} \\
k_{y x}^{e q} \\
k_{y y}^{e q}
\end{array}\right\}=-\langle\mu\rangle\left\{\begin{array}{c}
\left\langle u_{x}\right\rangle^{1} \\
\left\langle u_{y}\right\rangle^{1} \\
\left\langle u_{x}\right\rangle^{2} \\
\left\langle u_{y}\right\rangle^{2}
\end{array}\right\}
$$

The superscripts 1 and 2 denote the two flow problems described above. The SAMG algebraic multigrid solver is used to solve this system of equations to determine the components of $\mathbf{k}^{e q}$. While $\mathbf{k}^{e q}$ computed for no-flow boundary conditions is not necessarily symmetric, the equation $k_{x y}^{e q}-k_{y x}^{e q}=0$ can be added to enforce symmetry on $\mathbf{k}^{e q}$. The flow chart (Figure 4) enlists all steps of this $\mathbf{k}^{e q}$ computation applied to the suite of outcrop analogue models.

Sampling was carried out over three orders of magnitude of length scale (from $l_{D}=0.01$ to 1), determining $\mathbf{k}^{e q}$ as a function of sample size. To obtain statistically independent (nonoverlapping) samples, the model is divided into equally spaced regions. Then in each row of these regions the $\mathbf{k}^{e q}$ of random samples is analyzed. The number of samples per row is arbitrary. For a target coverage (we used 50\%), a list of randomly selected non-overlapping samples is created and the mode and standard deviations for each sample size are calculated. This procedure is repeated across the entire scale analysis range. 

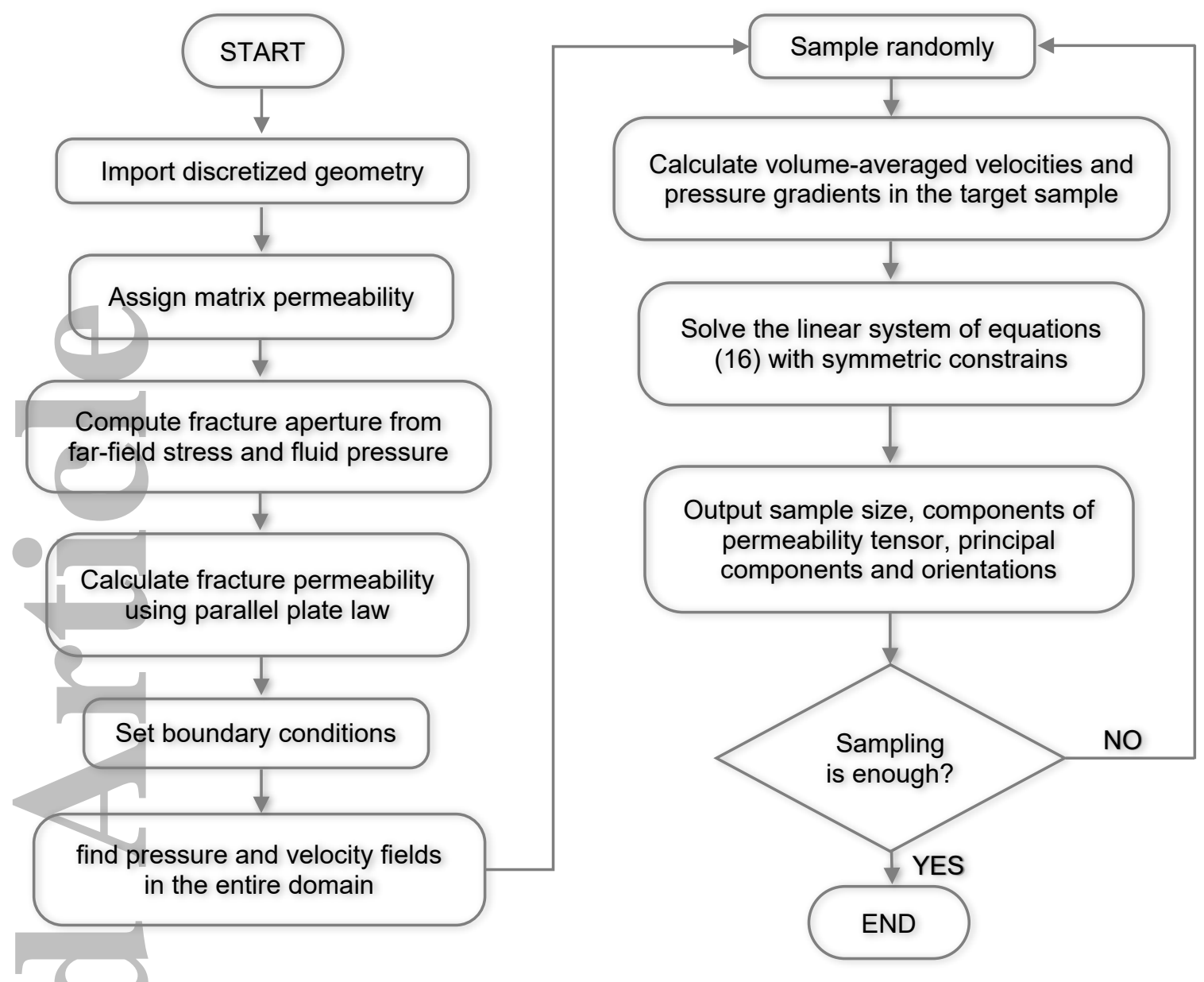

Figure 4. Flowchart of equivalent permeability tensor calculation by volume averaging of velocities and pressure gradients, following Durlofsky (1991).

\subsection{Equivalent permeability analysis: method verification}

A conceptual $28 \times 28 \mathrm{~m}$ discrete fracture model (DFMC1) with 27 through-going equally spaced fractures each with a $0.1 \mathrm{~mm}$ aperture serves to assess the accuracy of the computed $\mathbf{k}^{e q}$ values (Figure 5a). Matrix and fracture permeabilities are $10^{-15} \mathrm{~m}^{2}(1 \mathrm{mD})$ and $\left(10^{-4}\right)^{2} / 12=8.33 \times 10^{-10} \mathrm{~m}^{2}(833 \mathrm{D})$, respectively. For this model an analytical solution can be found using effective medium theory (Kasap and Lake, 1990). It is equal to the thickness-weighted arithmetic average along the fractures ( $x$-direction)

$$
k_{x x}^{e q}=k_{m}\left(1-\frac{1}{L} \sum_{j=1}^{n_{f}} a_{j}\right)+\frac{k_{f}}{L} \sum_{j=1}^{n_{f}} a_{j}
$$

Thickness-weighted harmonic averaging in the $y$-direction gives 


$$
k_{y y}^{e q}=\left[\left(1-\frac{1}{L} \sum_{j=1}^{n_{f}} a_{j}\right) / k_{m}+\left(\frac{1}{L} \sum_{j=1}^{n_{f}} a_{j}\right) / k_{f}\right]^{-1}
$$

where $a_{j}$ is the aperture of the $j$-th fracture, $n_{f}$ the number of fractures in the system and $L$ the model length. The calculated equivalent permeability tensor therefore is

$$
\mathbf{k}^{e q}=\left[\begin{array}{cc}
81.4 & 0 \\
0 & 1
\end{array}\right] \times 10^{-15} \mathrm{~m}^{2}
$$

This result is reproduced by the FEM solution with an accuracy of $\pm 0.05 \%$. This method verification also included tests where the orientation of the fractures in the model was rotated relative to the coordinate axes (Figure 5a).

(a)

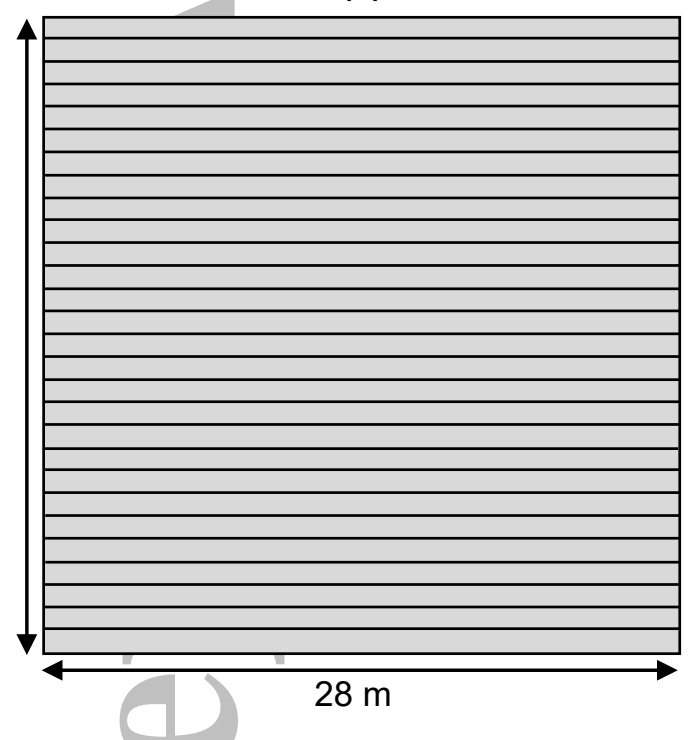

(b)

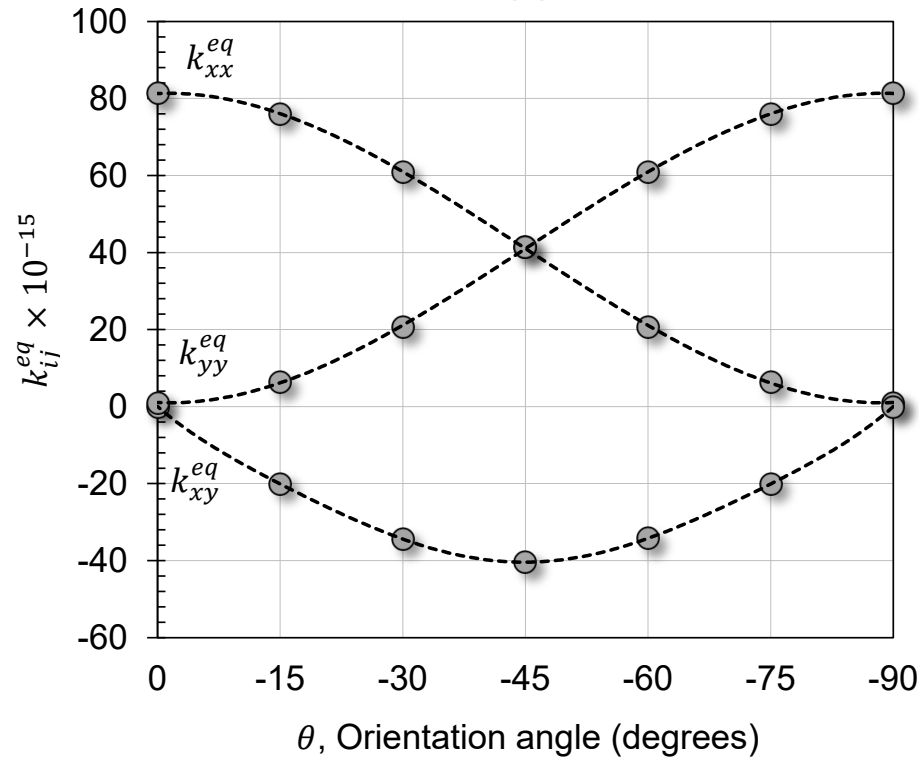

Figure 5. Method verification test: (a) DFMC1 model: A $28 \times 28 \mathrm{~m}$ discrete fracture model consisting 27 through-going equally spaced $(\theta=0)$ fractures each with a $0.1 \mathrm{~mm}$ aperture. Rock matrix (shaded gray area) with embedded fractures (horizontal black lines). Permeabilities are $10^{-15} \mathrm{~m}^{2}(1 \mathrm{mD})$ and $\left(10^{-4}\right)^{2} / 12=8.33 \times 10^{-10} \mathrm{~m}^{2}(833 \mathrm{D})$ for the matrix and fractures, respectively. (b) Comparison of analytical (dashed lines) and numerical results (circles) for different orientation angles of the verification model.

Analytical solutions for different fracture orientations are achieved by tensor rotation (Bear,

$$
\mathbf{k}^{e q}=\left[\begin{array}{ll}
k_{x x} \cos ^{2} \theta+k_{y y} \sin ^{2} \theta & \left(k_{x x}-k_{y y}\right) \sin \theta \cos \theta \\
\left(k_{x x}-k_{y y}\right) \sin \theta \cos \theta & k_{x x} \sin ^{2} \theta+k_{y y} \cos ^{2} \theta
\end{array}\right]
$$


where $\theta$ is the rotation angle in clockwise direction. For a rotation by $-45^{\circ}$, the equivalent permeability tensor becomes

$$
\mathbf{k}^{e q}=\left[\begin{array}{cc}
41.2 & -40.4 \\
-40.4 & 41.2
\end{array}\right] \times 10^{-15} \mathrm{~m}^{2}
$$

The comparison between the analytical and numerical results for different orientations (Figure 5b), yields a maximum Mean Percentage Error (MPE) for the computed $\mathbf{k}^{e q}$ of less than $0.5 \%$. Given that we are interested in fraction-of-order-of-magnitude $\mathbf{k}^{e q}$ estimates, this result indicates that the volume averaging method is sufficiently accurate for our study.

\section{Fracture Outcrop Studies}

Since fracture geometry cannot be reconstructed from well data alone because the fracture length distribution is hidden in the subsurface, this study is based on fracture trace maps of outcrops (cf., Geiger and Matthäi, 2012). We prefer these maps to geostatistics-based stochastic fracture models (e.g., Dershowitz and Einstein, 1988) because their geometry does not capture the spatial self-organization of fractures that typifies well-developed natural fracture patterns (Renshaw and Park, 1997; Pollard and Aydin, 1988; Wu and Pollard, 1995). Outcrops were selected to give a representative spectrum of fracture patterns and length scales, from the 10-meter to km-scale. All patterns are "percolating:" multiple interconnected fracture pathways connect opposite sides. All patterns formed incrementally and early fracture sets obey power-law length-frequency distributions, while younger sets have fracture length distributions that are controlled by abutting relationships with older sets. Considering all fracture sets simultaneously, multimodal length-frequency distributions result.

\subsection{Kilve outcrop, Bristol, $\mathrm{UK}$}

The model KILVE_BED3 (Figure 6) is based on an outcrop located on the southern margin of the Bristol Channel Basin, U.K., south of the village of Kilve. The outcrop exposes alternating layers of fractured limestone and intact shale. The mapped top-most $0.2 \mathrm{~m}$ thin 
micritic limestone layer contains four sets of mineralized fractures formed in the Mesozoic (Rawnsley et al., 1998). The geologic evolution of the Bristol Channel Basin has been extensively studied (Kamerling, 1979; Nemcok and Gayer, 1996; Rawnsley et al., 1998; Belayneh et al., 2006a and 2006b). The fracture pattern was mapped by Belayneh et al. (2006b) in a $18 \times 8 \mathrm{~m}$ rectangular area.
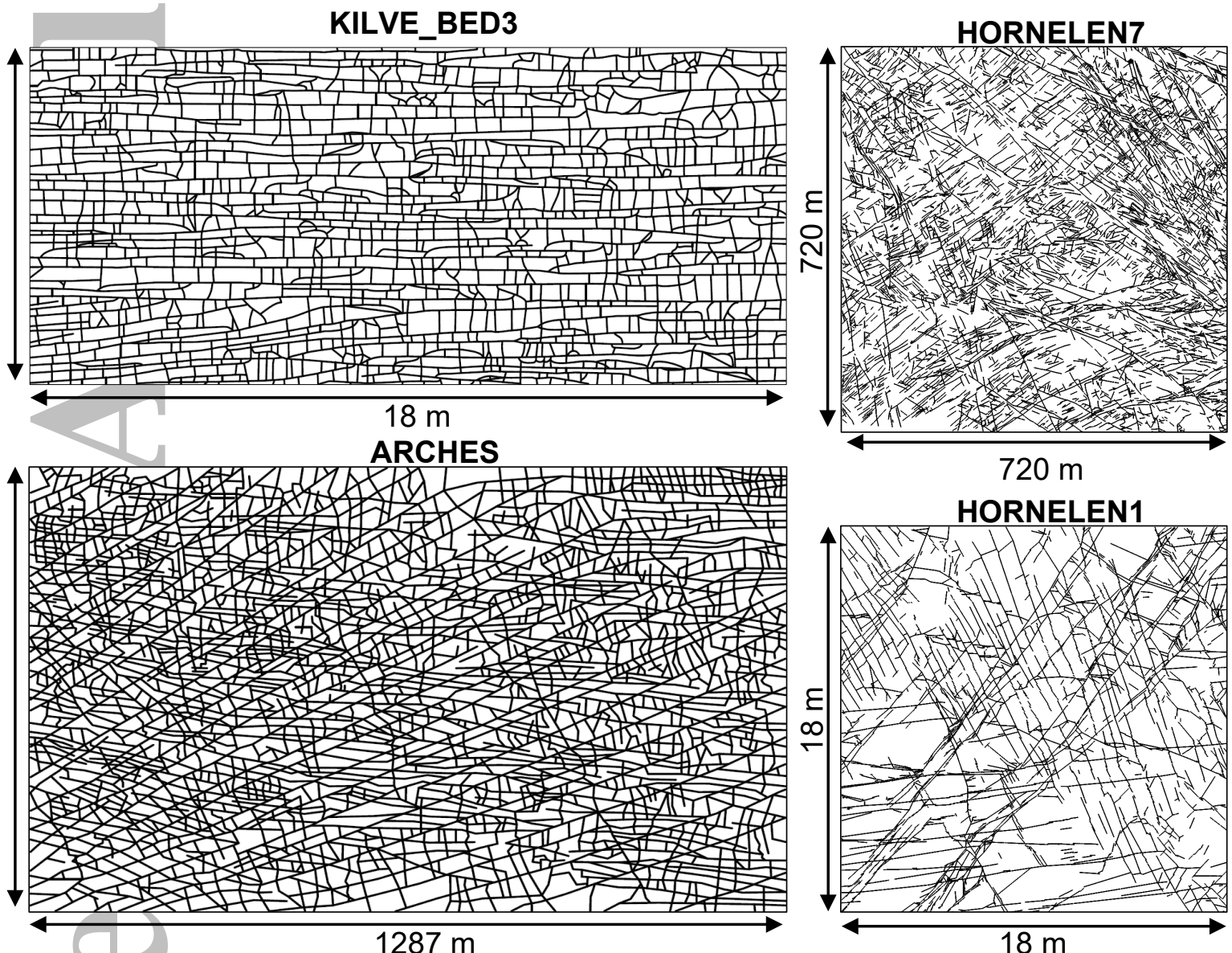

Figure 6. Fracture trace maps of KILVE_BED3, ARCHES, HORNELEN7 and HORNELEN1 models.

\subsection{Arches National Park Entrada sandstone outcrop, Utah, USA}

Using satellite imagery from Google maps, we traced a fracture pattern in the Entrada sandstone between Fiery Furnace and Freshwater Springs, Arches National Park, Utah (cf., Matthäi et al., 2012), see Figure 6. The outcrop exposes a 25-30 m thick bed of quartzsandstone (Moab member of Entrada sandstone, Johansen and Fossen, 2008) over an area of $1287 \times 834 \mathrm{~m}$. The long early fractures are Mode-I joints that formed during the flexure of the 
sandstone layer during lateral flow and diapiric rise of salt (Lorenz and Cooper, 2001). The largest fractures are on the kilometer-scale, exceeding the length of the trace map. Fracture formation at Arches has been analyzed by Cruikshank et al. (1991) who also performed aperture calculations. Furthermore, Antonellini and Aydin (1994) measured the permeability of the exhumed fractures with a mini-permeameter, finding a wide spectrum of values limited only by the range of applicability of the instrument. These, however, reflect apertures in the absence of confining stress so that we only used these measurements for a consistency check of our mechanical model.

Three different fracture sets partition the sandstone layer into blocks with a log-normal size distribution and a cross-sectional area mode of $250 \mathrm{~m}^{2}$. Square blocks with this area are roughly $15 \times 15 \mathrm{~m}$ in size. The largest blocks are roughly three times this size. These features are captured by the ARCHES model.

\subsection{Hornelen outcrop, Map 7, Nordfjord, Norway}

Noelle Odling mapped this $720 \times 720 \mathrm{~m}$ outcrop in the Hornelen basin, approximately $200 \mathrm{~km}$ north of Bergen, Norway, see Figure 6 (map 7 of Odling, 1997). The outcrop consists of fractured quartz sandstones of Devonian age with a bed thickness around $2 \mathrm{~m}$, much less than the length of the fractures represented in Model HORNELEN7. Most fractures are subvertical, perpendicular to bedding. HORNELEN7 is an idealization of the fracture pattern in the sense that - in 2D - fractures that only penetrate a single bed cannot be distinguished from those that continue into the rocks below.

\subsection{Hornelen Outcrop, Map 1, Nordfjord, Norway}

Model HORNELEN1 (Figure 6) is similar to the HORNELEN7, yet Odling (1997) recorded the fractures in more detail and on a smaller scale $(18 \times 18 \mathrm{~m})$. Therefore, the segmentation of the longer through-going fractures seen in the field is resolved. This was not possible given the quality of the imagery from which the ARCHES model was reconstructed. 


\subsection{Model Configuration}

Since no better data is available, constant far-field stress conditions were applied to the fracture patterns to compute aperture distributions. We assume the common scenario of a shallow burial depth in a normal faulting regime with a $\sigma_{1} 15 \mathrm{MPa}, \sigma_{3}$ of $10 \mathrm{MPa}$ and fluid pressure of $9 \mathrm{MPa}$.

For the computation of fracture aperture with the Barton and Bandis model, rock joint parameters are required, but are not available for the rocks in the described outcrops. Therefore, plausible, albeit constant values were taken from the literature: joint roughness coefficient, $\mathrm{JRC}_{0}$ values of 5, 15, 12, 7 for the KILVE_BED3, ARCHES, and HORNELEN7 and HORNELEN1 models, respectively; joint wall compressive strength, $\mathrm{JCS}_{0}=120 \mathrm{MPa}$ and a residual friction angle, $\phi_{r}=25^{\circ}$. Obtaining $\mathrm{JRC}_{\mathrm{mob}}$ from equation (20), the dimensionless shear stress versus shear displacement curve of Barton et al. (1985) has been used to determine shear displacements for the fracture segments. Since determining the potential variance of equivalent permeability with scale is the key goal of this study, a fracture closure aperture of $20 \mu \mathrm{m}$ was assumed to ensure that all fractures contribute to the flow. Cracks with an opening below this value, tend to seal up in the presence of a reactive pore-fluid (e.g., Roedder, 1984). A constant and isotropic matrix permeability $\left(k_{m}\right)$ of $10^{-15} \mathrm{~m}^{2}(1 \mathrm{mD})$ was assumed for all outcrop models. Table 1 enlists the mechanical parameters extracted from the literature or computed for the aperture calculations as described in the Methodology.

Table 1. Mechanical properties assigned to the outcrop models for aperture calculation.

\begin{tabular}{|l|c|c|c|c|}
\cline { 2 - 5 } \multicolumn{2}{c|}{} & \multicolumn{4}{c|}{ Outcrop model } \\
\hline Mechanical properties & $\begin{array}{c}\text { KILVE_BED3 } \\
(\mathbf{1 8 \times 8} \mathbf{~ m})\end{array}$ & $\begin{array}{c}\text { ARCHES } \\
(\mathbf{1 2 8 7 \times 8 3 4} \mathbf{~ m})\end{array}$ & $\begin{array}{c}\text { HORNELEN7 } \\
(\mathbf{7 2 0} \times \mathbf{7 2 0} \mathbf{~ m})\end{array}$ & $\begin{array}{c}\text { HORNELEN1 } \\
\mathbf{( 1 8 \times 1 8 ~ m )}\end{array}$ \\
\hline Maximum principal stress, $\sigma_{1}(\mathrm{MPa})$ & 15 & 15 & 15 & 15 \\
Minimum principal stress, $\sigma_{3}(\mathrm{MPa})$ & 10 & 10 & 10 & 10 \\
Orientation of far field stress, $\beta($ degrees $)$ & 45 & 45 & 0 & 90 \\
Fluid pressure $(\mathrm{MPa})$ & 9 & 9 & 9 & 9 \\
Joint roughness coefficient, JRC & 5 & 15 & 12 & 7 \\
Joint wall compressive strength, JCS $(\mathrm{MPa})$ & 120 & 120 & 120 & 120 \\
Residual friction angle, $\phi_{r}($ degrees $)$ & 25 & 25 & 25 & 25 \\
Initial closure aperture, $a_{0}(\mu \mathrm{m})$ & 20 & 20 & 20 & 20 \\
\hline
\end{tabular}




\section{Geometric Fracture Distribution}

The geometry of each fracture pattern is captured in full by the outcrop mapping, including the abutting relationships of the sequentially formed sets and the spatial organization of the fractures. These characteristics are presented set-by-set in Table 2 before the full equivalent permeability tensor is established in the next section.

Table 2. Fracture length and density are calculated using the area method of $\mathrm{Wu}$ and Pollard (2002).

\begin{tabular}{|c|c|c|c|c|c|}
\hline \multicolumn{2}{|l|}{ Outcrop model } & \multirow{2}{*}{$\begin{array}{c}\begin{array}{c}\text { No. of } \\
\text { fractures }\end{array} \\
78\end{array}$} & \multirow{2}{*}{$\begin{array}{c}\text { Total length } \\
\text { (m) }\end{array}$} & \multirow{2}{*}{$\begin{array}{c}\begin{array}{c}\text { Length mode } \\
\text { (m) }\end{array} \\
0.414\end{array}$} & \multirow{2}{*}{$\begin{array}{c}\begin{array}{c}\text { Fracture density (P21) } \\
\left(\mathbf{1} / \mathbf{m}^{\mathbf{2}}\right)\end{array} \\
2.112\end{array}$} \\
\hline & Set 1 & & & & \\
\hline & Set 2 & 252 & 304 & 0.137 & 2.113 \\
\hline K1L & Set 3 & 1100 & 263 & 0.232 & 1.825 \\
\hline & Set 4 & 273 & 70 & 0.167 & 0.488 \\
\hline & All sets & 1703 & 942 & 0.315 & 6.539 \\
\hline & Set 1 & 74 & 28584 & 160 & 0.027 \\
\hline & Set 2 & 442 & 48375 & 47 & 0.045 \\
\hline ARCHES & Set 3 & 946 & 35433 & 21 & 0.033 \\
\hline$(1287 \times 834 \mathrm{~m})$ & Set 4 & 8 & 1885 & 311 & 0.002 \\
\hline & All sets & 1470 & 114276 & 40 & 0.106 \\
\hline & All excl. set 4 & 1462 & 112392 & 30 & 0.105 \\
\hline $\begin{array}{l}\text { HORNELEN7 } \\
(720 \times 720 \mathrm{~m})\end{array}$ & All fractures & 4005 & 80561 & 15 & 0.155 \\
\hline $\begin{array}{l}\text { HORNELEN1 } \\
(18 \times 18 \mathrm{~m})\end{array}$ & All fractures & 2122 & 1198 & 0.189 & 3.696 \\
\hline
\end{tabular}

\subsection{Fracture length}

Fracture length - frequency distributions are either exponential, lognormal or power-law (Bonnet et al., 2001). Since fractures occur over a wide range of length scales, they are supposed to be treated as power-law (de Dreuzy et al., 2001; Darcel et al., 2003). This is true for most of the early sets in 2D fracture trace maps and satellite image analysis (Bour et al., 2002; Sahimi, 2011).

$$
n(l, L)=a L^{D} l^{-\alpha} \quad \text { for } l \in\left[l_{\min }, l_{\max }\right]
$$

where $n(l, L) d l$ is the number of fractures over the interval $[l+d l](d l \ll l)$ in a domain of size $L$, the exponent $\alpha$ describes how frequency decreases with fracture length and $a$ is a 
constant that depends on the fracture density, $D$ is the fractal dimension, $l_{\min }$ and $l_{\max }$ are the minimum and maximum fracture length $\left(l_{\min } \ll L \ll l_{\max }\right)$.

Fracture length data are often influenced by truncation (short traces cannot be captured due to a limited spatial resolution) and censoring effects (long traces are not captured due to incomplete sample size) (Odling, 1997; Bonnet et al., 2001).

Figure 7 shows the cumulative distribution of fracture length for different outcrop models described above. The power-law fit is obtained using Maximum Likelihood Estimation (MLE) method which has been shown to be the best approach to estimate powerlaw behavior of the empirical data (Clauset et al., 2009).
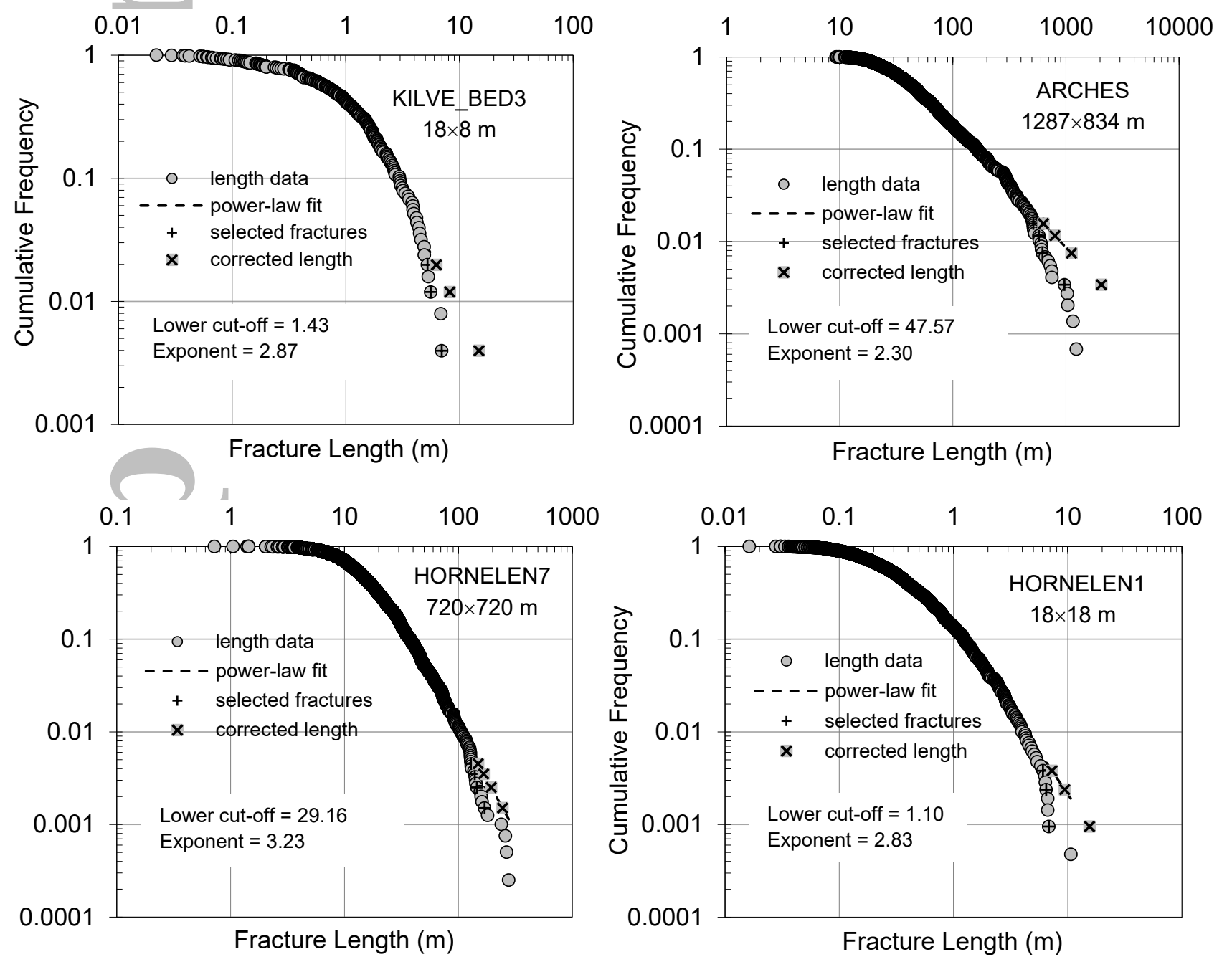

Figure 7. The cumulative frequency distribution of fracture length (light gray filled circles) for the studied outcrop patterns and associated power-law fit (black dashed lines). A lower cut-off and power-law exponent are calculated using Maximum Likelihood Estimation (MLE). Plus (+) signs are a few selected fractures, which are censored by the sample boundaries and squared filled crosses $(x)$ showing corrected length for those selected fractures. 
For HORNELEN7 model the lower cut-off calculated using MLE is in a good agreement with the work of Odling (1997) that considers $5-10 \%$ of the map size as a limit for truncated traces. Also the corrected length results for censored traces is comparable with the work of Odling (1997) that analyzed censoring effects using Kaplan-Meier estimation.

\subsection{Fracture aperture}

Apertures are calculated using Barton and Bandis model. Figure 8 shows the aperture distribution for the studied outcrops. For the differential stress applied to the models, only those fractures with an orientation giving rise to a reduced fracture-normal stress are dilated. Many fractures in the models are curved. This has the important consequence that they are not dilated over their entire length, but only favorably oriented segments are. Their length is much less than the overall fracture length.
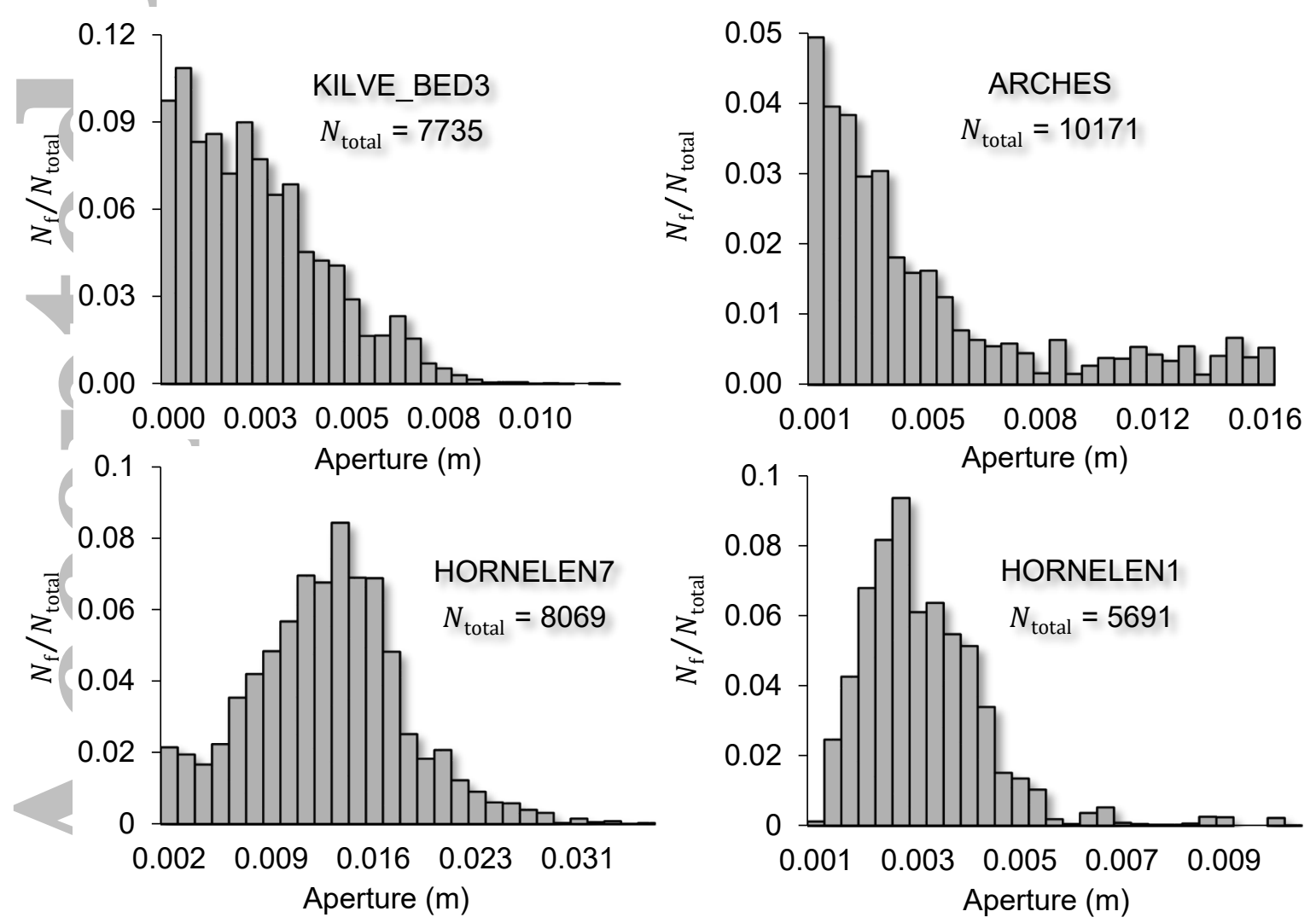

Figure 8. Normalized aperture distribution of KILVE_BED3, ARCHES, HORNELEN7, and HORNELEN1 models. $N_{\text {total }}$ refers to the number of fracture segments (elements) in the model. 


\subsection{Fracture permeability}

Figure 9 illustrates fracture permeability corresponding to the aperture distributions computed for each model. The modes correspond to fractures with a specific orientation, imparting a strong anisotropy on the medium perhaps best seen in mode KILVE_BED3. Since only a favorably oriented - critically stressed subset of all fractures is dilated, this result is less of a surprise.

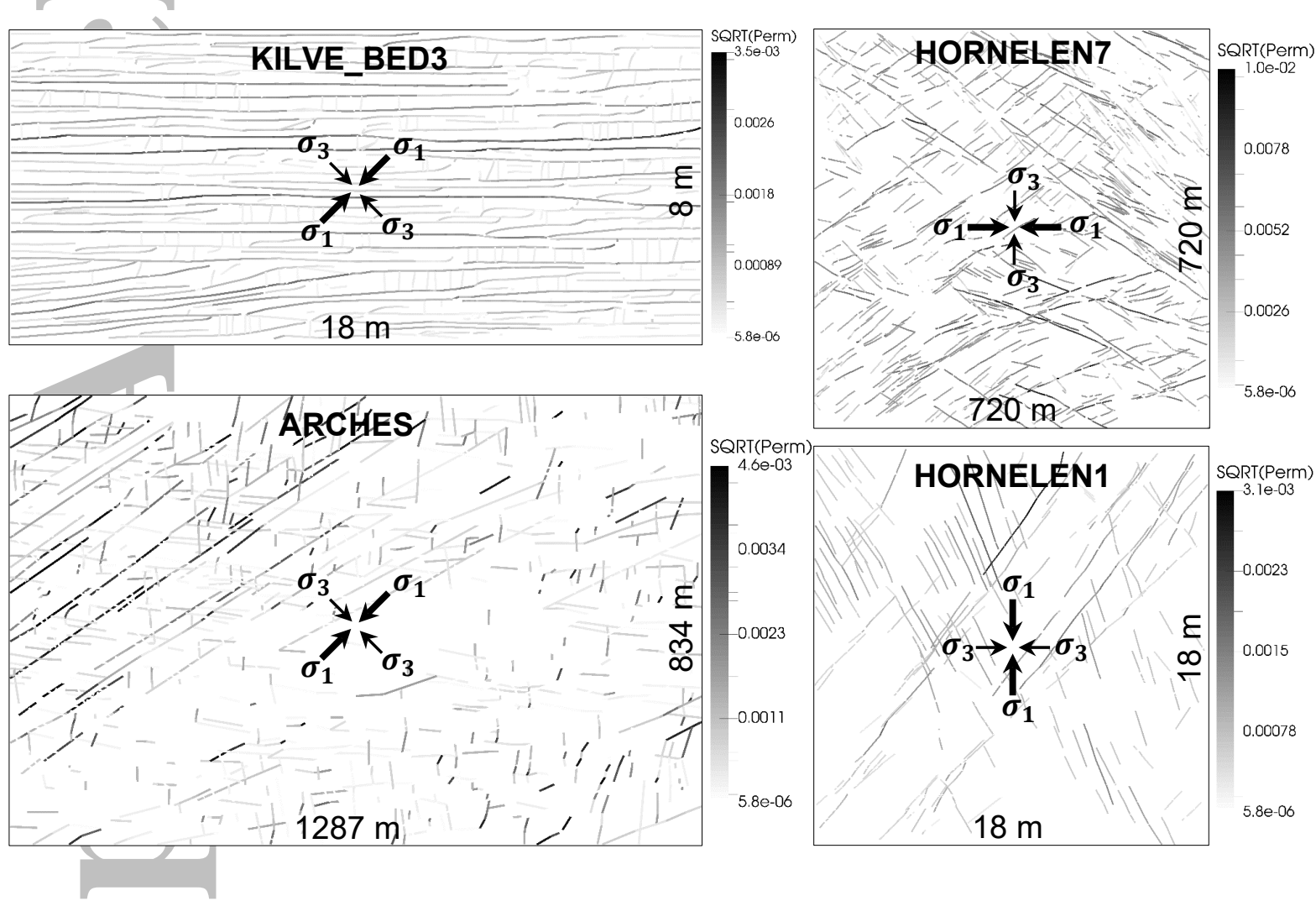

Figure 9. Fracture permeability calculated using parallel plate law shown in gray scale where aperture was calculated by Barton and Bandis model, see text; modeled apertures are given in Figure 8 and fracture trace maps are given in Figure 6.

\section{Simulation Results}

Below, the results of the computations done on the outcrop models to obtain the equivalent permeability tensor, variation of anisotropy, and REV analysis are presented.

\subsection{Equivalent permeability}

Tensorial equivalent permeability values were computed for square sample subregions, covering a wide range of sample sizes ranging from $\sim 0.44$ to $794 \mathrm{~m}$ in models KILVE_BED3 
and ARCHES, respectively. Figure 10 to Figure 13 show the variation in the magnitude of their $k_{D}=k_{\max }^{e q} / k_{m}$ (maximum principal component $k_{\max }^{e q}$, normalized by rock matrix permeability $k_{m}$ ). In these plots, selected histograms of the variation of $\log _{10} k_{D}$ for given sample sizes are displayed as insets, revealing whether there is a convergence of the maximum equivalent permeability with increasing scale.

These results indicate a gradual decrease in sample-to-sample variation with scale. The even stronger reduction at the largest scale is likely due to the increased overlap of samples. In the ARCHES and HORNELEN models (Figure 11 to Figure 13), the same trends are observed. Even at the outcrop scale the $k_{\max }^{e q}$ statistics are noisy and might be interpreted as multimodal. Model HORNELEN7 shows a distinct bimodal distribution with comparatively low standard deviations. There is nothing in the fracture geometry that rationalizes this distribution. Since all histograms display the decadic logarithm of permeability, the seemingly small standard deviation at model scale is close to $\pm 0.3 \log$ units.

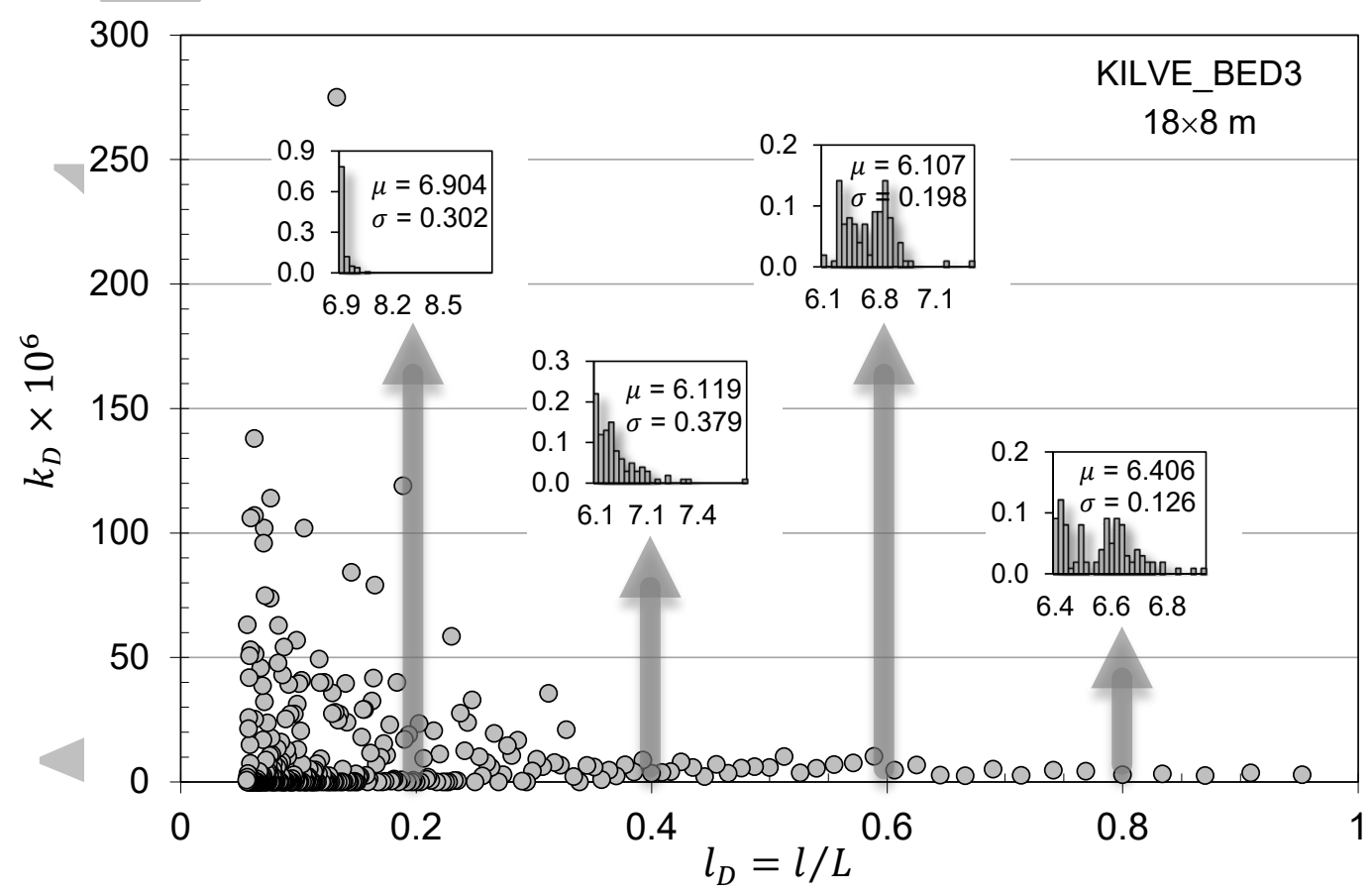

Figure 10. KILVE_BED3 model: Variation of the dimensionless maximum principal component of the equivalent permeability tensor, $k_{D}=k_{\max }^{e q} / k_{m},\left(k_{m}\right.$ is matrix permeability) for partially overlapping random samples with dimensionless sample size, $l_{D}=l / L$. Normalized frequency of $\log _{10} k_{D}$ and its statistical moments (mode, $\mu$ and standard deviation, $\sigma$ ) are shown as inset histograms at $l_{D}=0.2,0.4,0.6$, and 0.8 . 


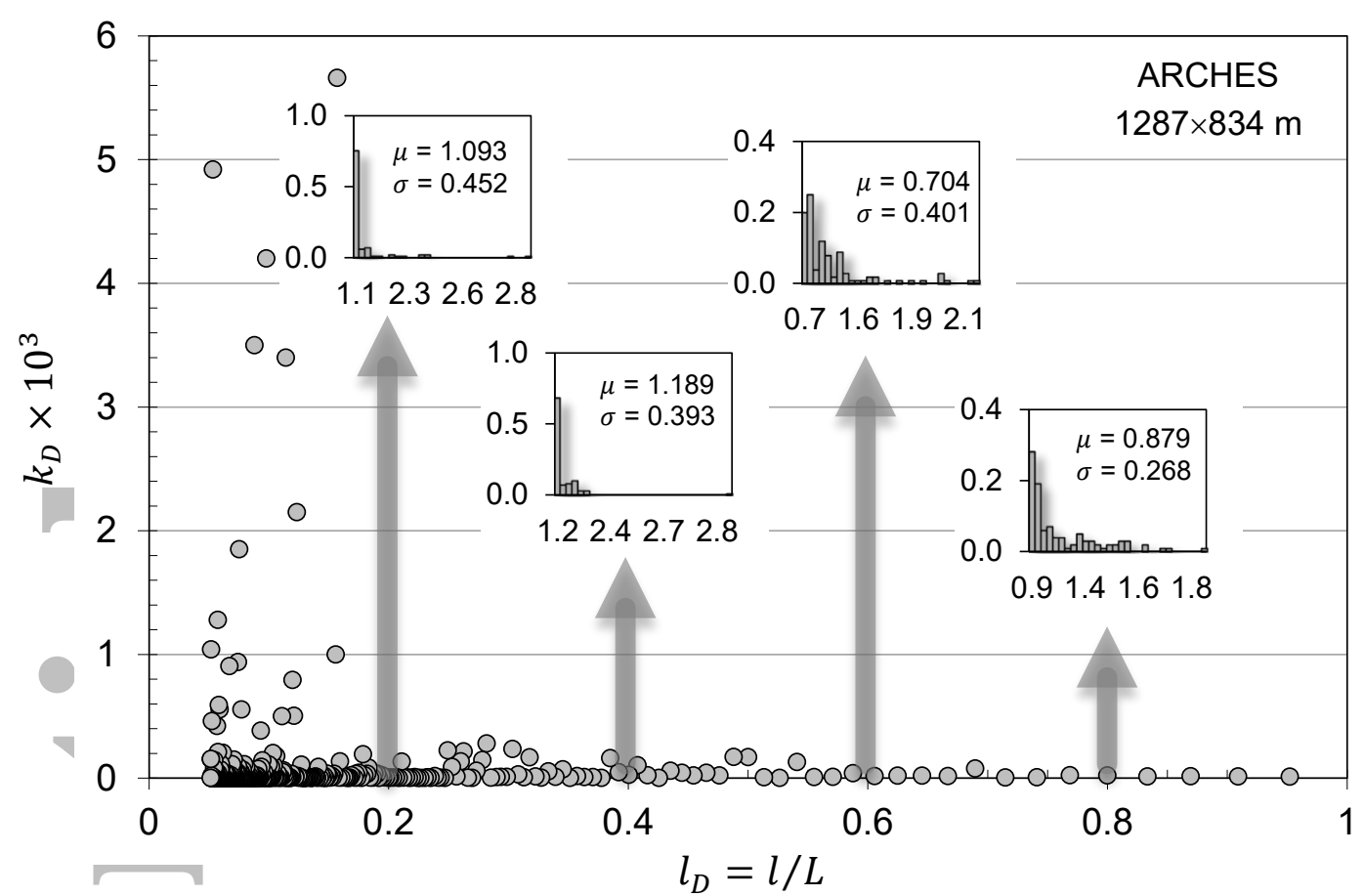

Figure 11. ARCHES model: Variation of the dimensionless maximum principal component of the equivalent permeability tensor, $k_{D}=k_{\max }^{e q} / k_{m},\left(k_{m}\right.$ is matrix permeability) for partially overlapping random samples with dimensionless sample size, $l_{D}=l / L$. Normalized frequency of $\log _{10} k_{D}$ and its statistical moments (mode, $\mu$ and standard deviation, $\sigma$ ) are shown as inset histograms at $l_{D}=0.2,0.4$, 0.6 , and 0.8

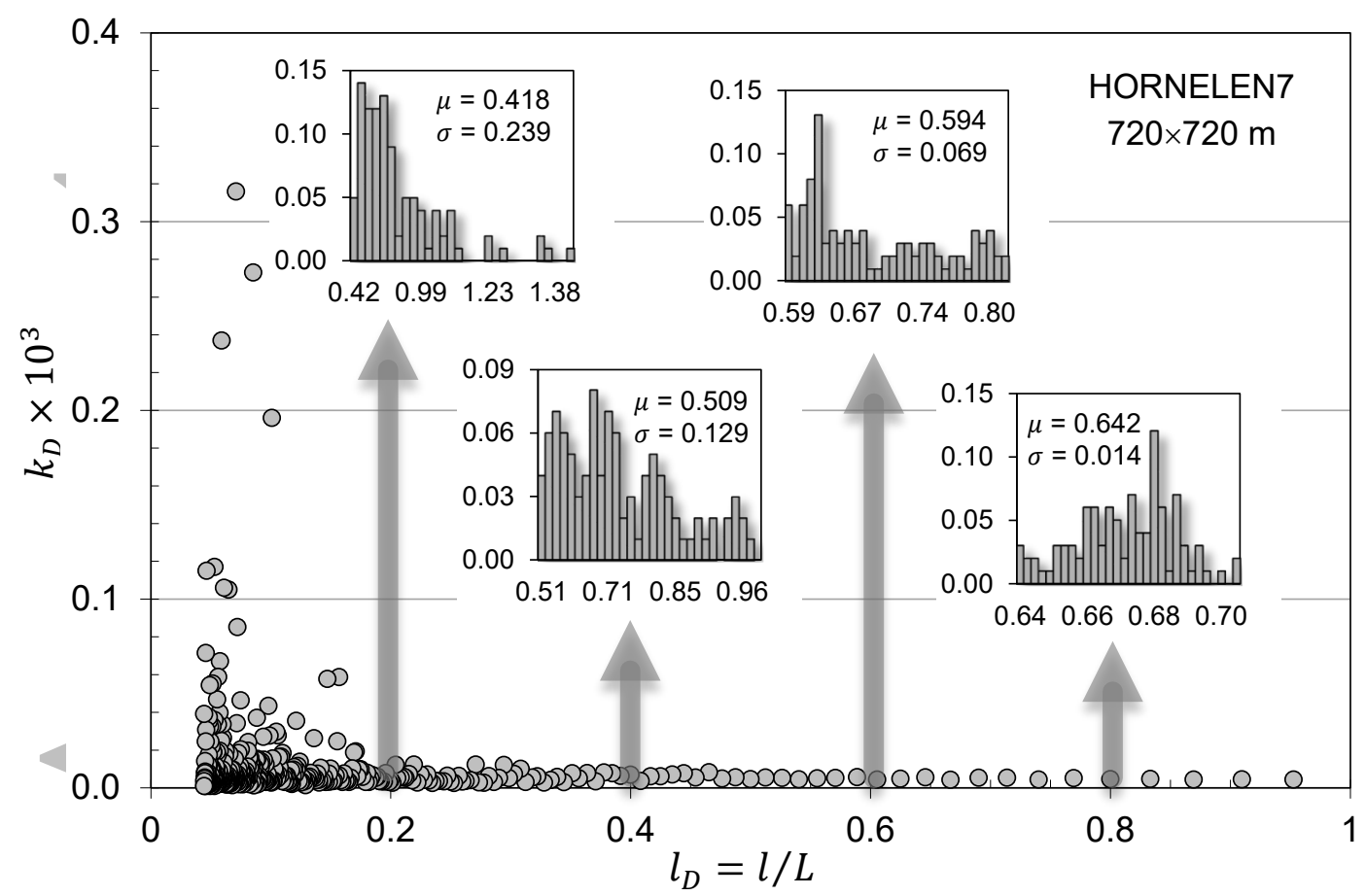

Figure 12. HORNELEN7 model: Variation of the dimensionless maximum principal component of the equivalent permeability tensor, $k_{D}=k_{\max }^{e q} / k_{m},\left(k_{m}\right.$ is matrix permeability) for partially overlapping random samples with dimensionless sample size, $l_{D}=l / L$. Normalized frequency of $\log _{10} k_{D}$ and its statistical moments (mode, $\mu$ and standard deviation, $\sigma$ ) are shown as inset histograms at $l_{D}=0.2,0.4,0.6$, and 0.8 . 


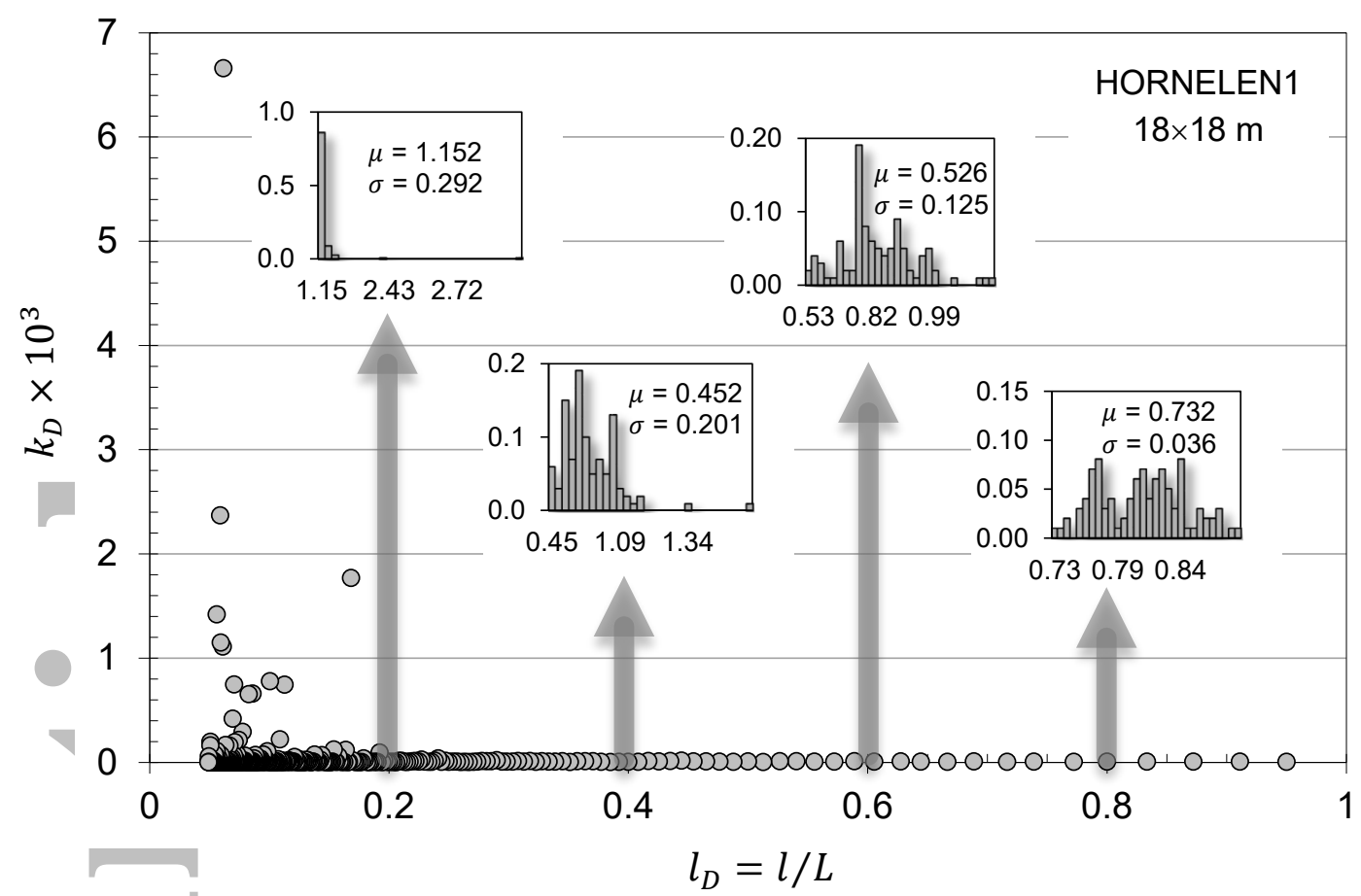

Figure 13. HORNELEN1 model: Variation of the dimensionless maximum principal component of the equivalent permeability tensor, $k_{D}=k_{\max }^{e q} / k_{m},\left(k_{m}\right.$ is matrix permeability) for partially overlapping random samples with dimensionless sample size, $l_{D}=l / L$. Normalized frequency of $\log _{10} k_{D}$ and its statistical moments (mode, $\mu$ and standard deviation, $\sigma$ ) are shown as inset histograms at $l_{D}=0.2,0.4,0.6$, and 0.8 .

The averages for any particular model are very similar for samples bigger than a certain size as is expected for samples on the REV scale. Corresponding threshold sizes that could be interpreted as $k_{\max }^{e q} \mathrm{REVs}$ are $\sim 0.2 \times 833=167 \mathrm{~m}$ for ARCHES, $\sim 0.2 \times 720=144 \mathrm{~m}$ for HORNELEN7, and $\sim 0.2 \times 18=3.6 \mathrm{~m}$ for HORNELEN1. The $k_{\max }^{e q}$ REV identified for HORNELEN1 and ARCHES can be regarded as upper and lower bounds. Constructing DFMs a small multiple of these sizes should lead to a reasonable approximation of the $\mathbf{k}^{e q}$ tensor magnitudes, although the results show spatial variations of these parameters within the studied fracture patterns.

Also, while the mode standard deviation of the equivalent permeability decreases with sample size, the statistics of the distributions at any particular size only become interpretable in terms of normal/log normal distributions when the sampling window contains a sufficiently large number of fractures. For this reason we cannot say for sure there is a characteristic trend in going from $l_{D}=0.05$ to $l_{D}=0.3$. 
Figure 14 shows the mode, standard deviation and skewness of $\log _{10} k_{D}\left(k_{D}=k_{\max }^{e q} / k_{m}\right)$ at different length scales.

The mode of $k_{D}$ varies more at small than at large scale. For HORNELEN7 and HORNELEN1 the negative skewness of $k_{D}$ is decreasing with increasing scale across the entire range of $l_{D}$. The skewness is always negative, and varies between -2 and 0 . This means that $k_{D}$ distributions on the small scale are more asymmetric than at large scale. On the small scale, the tail on the left of the $k_{D}$ mode is longer or fatter than on its right. The mean value of $k_{D}$ is therefore less than the mode value. We interpret this asymmetry as a symptom of the fact that many samples miss significant fractures and therefore have a distinctly lower permeability. For intermediate to large scale samples the tails on both sides of the $k_{D}$ mode values are similar. It is worth noting that the mode and standard deviation of $k_{D}$ are equivalent to the logarithm of the geometric mode and the multiplicative standard deviation of $k_{D}$, respectively as data are log-normally distributed (Limpert et al., 2001).
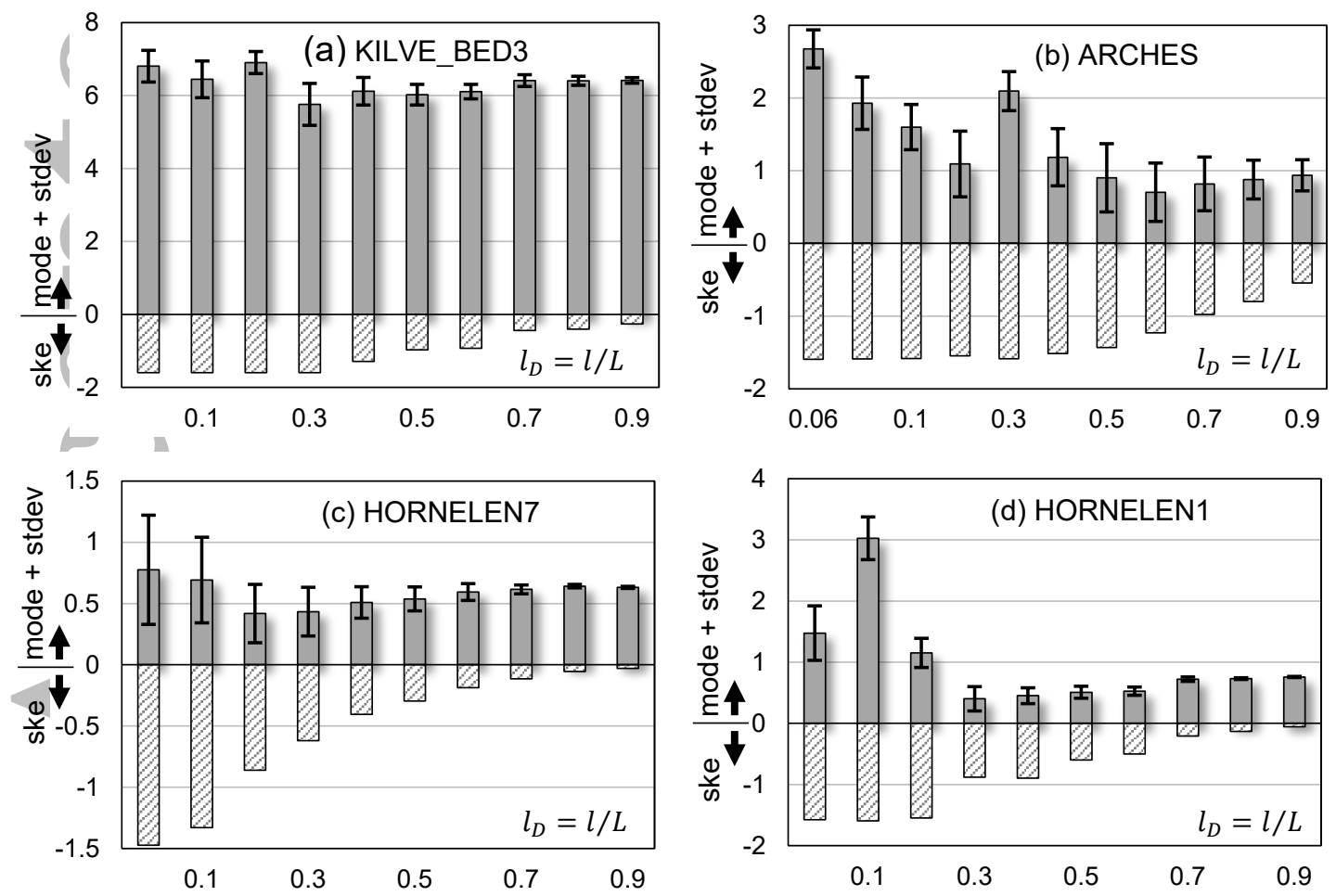

Figure 14. Variation of statistical moments of $\log _{10} k_{D}\left(k_{D}=k_{\max }^{e q} / k_{m}\right)$ with dimensionless sample size, $l_{D}=l / L$ for (a) KILVE_BED3, (b) ARCHES, and (c) HORNELEN7 and (d) HORNELEN1 models respectively. Positive y-direction: mode, error bars: standard deviation, and negative ydirection: skewness. 


\subsection{Permeability anisotropy}

Figure 15 illustrates the degree of permeability anisotropy varying from model to model and with sampling scale: for KILVE_BED3, a maximum value of $27.9 \times 10^{6}$ is reached. By contrast, in HORNELEN1, locally, permeability is isotropic.
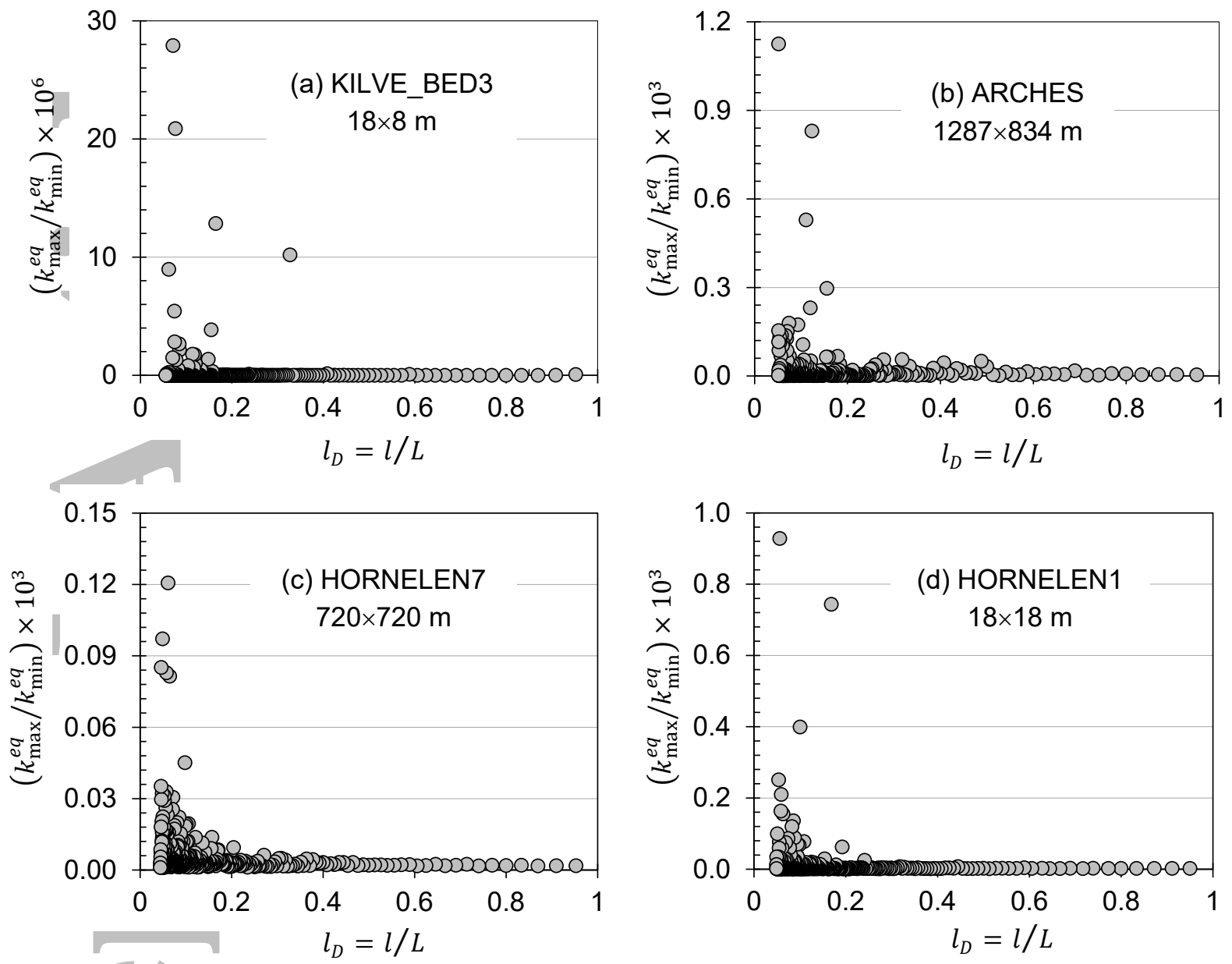

Figure 15. Variation of anisotropy of equivalent permeability tensor $\left(k_{\max }^{e q} / k_{\min }^{e q}\right.$, ratio between maximum and minimum principal components) with dimensionless sample size, $l_{D}=l / L$ for (a) KILVE_BED3, (b) ARCHES, (c) HORNELEN7 and (d) HORNELEN1 models respectively using overlapping random sampling method as described in the paper.

The variation of permeability anisotropy, expressed as the ratio of the maximum and minimum principal components as a function of dimensionless sample size highlights that the fracture patterns are inhomogeneous and - again - there is a size threshold above which sampled anisotropy values converge (Figure 15). This threshold varies from model to model, but decreases with increasing fracture density, being highest in the KILVE_BED3 model. 


\subsection{Non-overlapping samples}

Figure 16 shows the variation of $k_{D}=k_{\max }^{e q} / k_{m}$ with dimensionless sample size $l_{D}=l / L$ as determined from non-overlapping random square samples. The stippled lines show the trend of $k_{D}$ with sample size $l_{D}$. The same trends are seen as for the partially overlapping samples, but the standard deviation does not get as small for the largest samples, confirming that sample overlap increasing with sample size is at least partially responsible for the reduction of the standard deviation with scale.
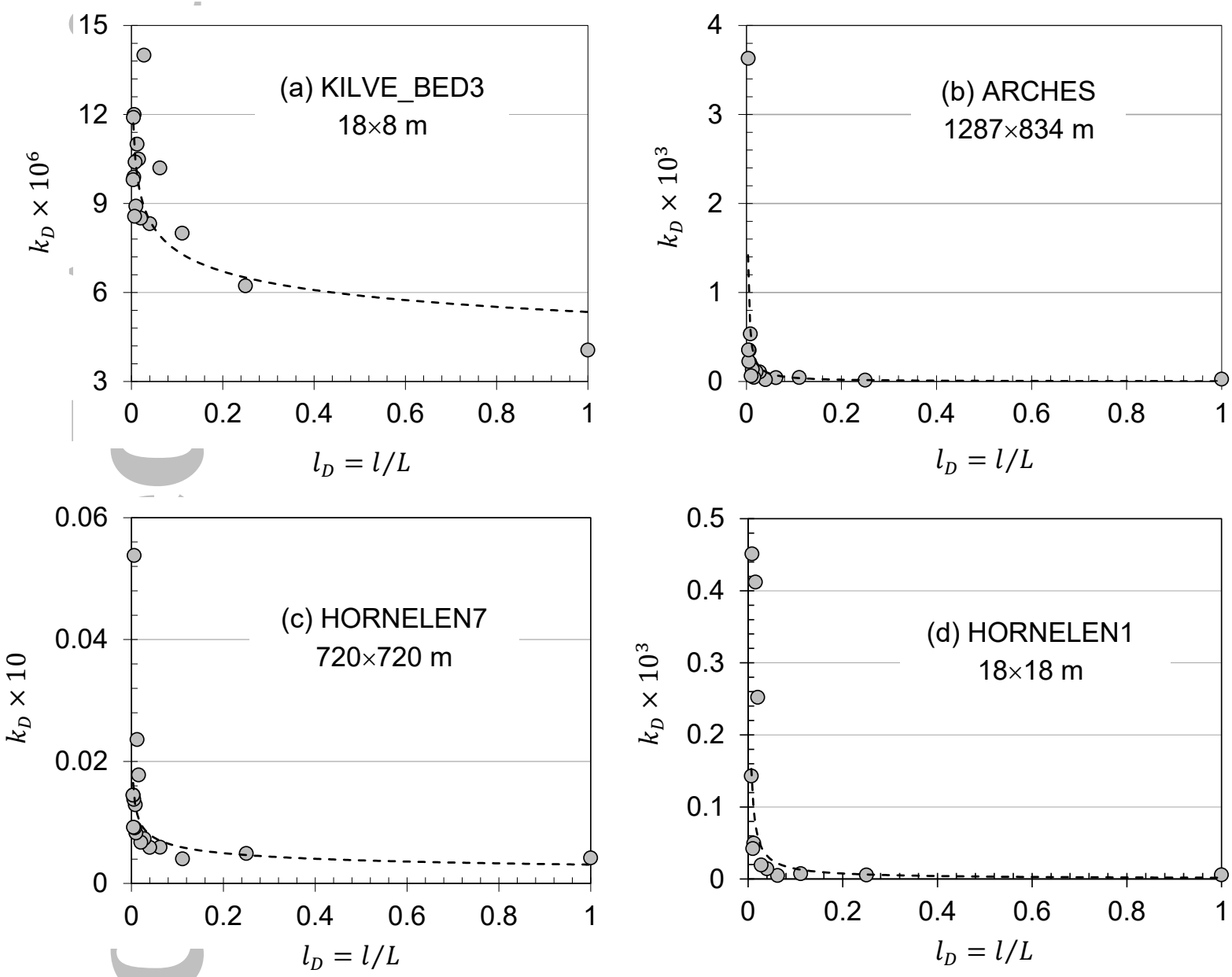

Figure 16. Variation of the dimensionless maximum principal component of the equivalent permeability tensor, $k_{D}=k_{\max }^{e q} / k_{m},\left(k_{m}\right.$ is matrix permeability) with dimensionless sample size, $l_{D}=l / L$ for (a) KILVE_BED3, (b) ARCHES, (c) HORNELEN7 and (d) HORNELEN1 models respectively using non-overlapping random square sampling method as described in the paper.

\subsection{Orientation of permeability tensor}

The permeability tensors obtained from square samples with different areas are displayed as ellipses plotted on the fracture maps in the center of the sampling locations (Figure 17- 
Figure 19). The axes of the ellipses scale with the principal permeability values (eigenvalues of $\mathbf{k}^{e q}$ ). Thus, even mildly elliptical glyphs indicate significant anisotropy.

\section{KILVE_BED3 $(18 \times 8 \mathrm{~m})$}
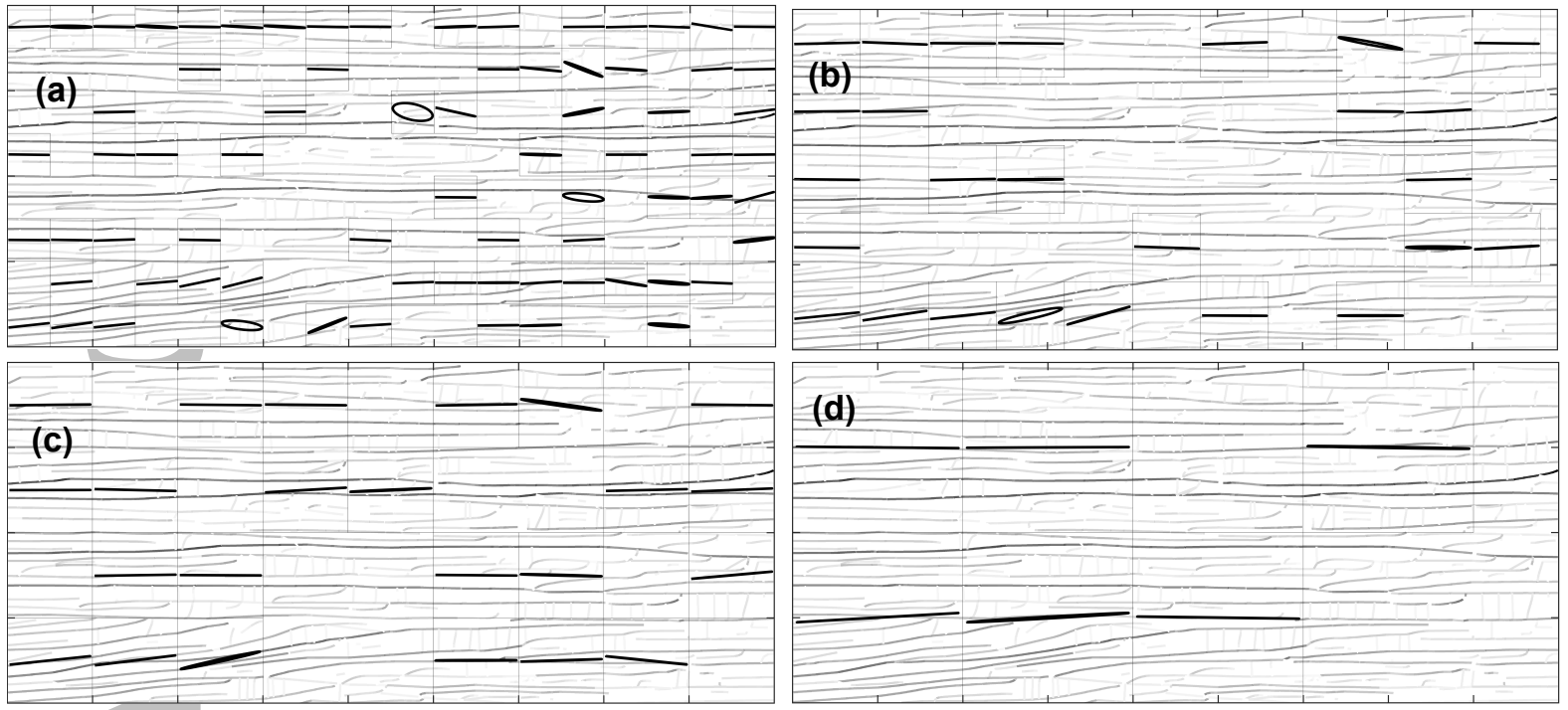

Figure 17. Visualization of the equivalent permeability tensor for KILVE_BED3 model at different length scales (inset gray squares depict the scale of interest): (a) $1 \mathrm{~m}$, (b) $1.6 \mathrm{~m}$, (c) $2 \mathrm{~m}$, and (d) $4 \mathrm{~m}$. Fracture permeability map of the model is shown in the background.

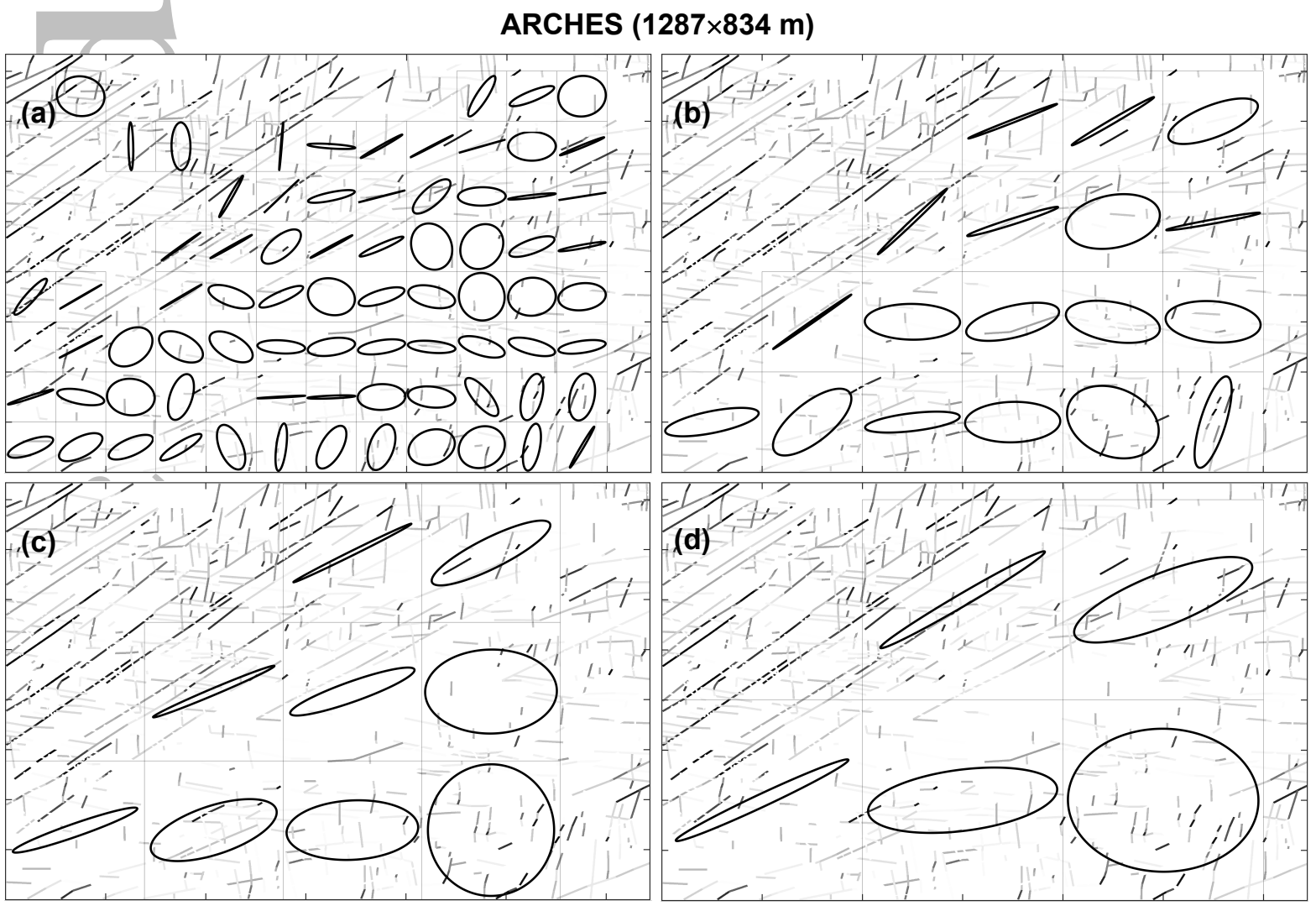

Figure 18. Visualization of the equivalent permeability tensor for ARCHES model at different length scales (inset gray squares depict the scale of interest): (a) $100 \mathrm{~m}$, (b) $200 \mathrm{~m}$, (c) $277 \mathrm{~m}$, and (c) $400 \mathrm{~m}$. Fracture permeability map of the model is shown in the background. 
HORNELEN7 $(720 \times 720 \mathrm{~m})$

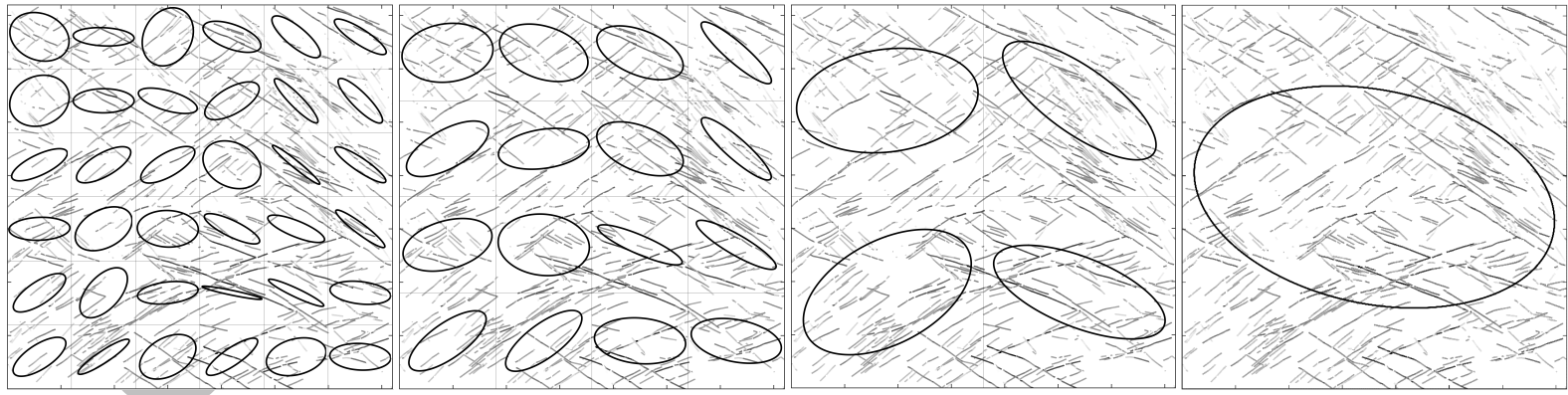

HORNELEN1 $(18 \times 18 \mathrm{~m})$

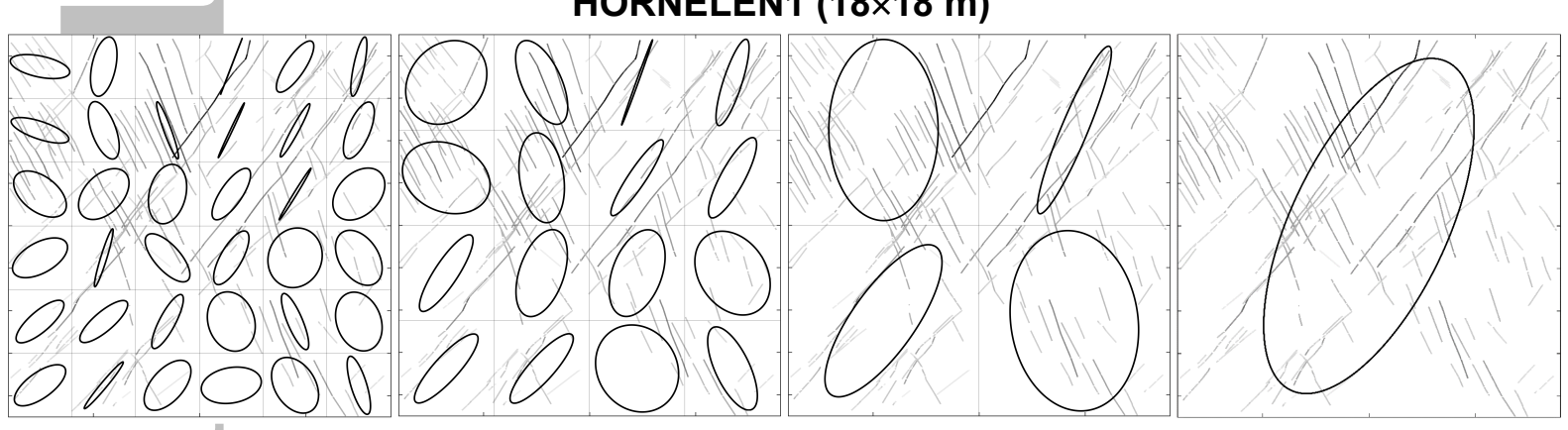

Figure 19. Visualization of the equivalent permeability tensor at different length scales (inset gray squares depict the scale of interest), top: HORNELEN7 model at $120 \mathrm{~m}, 180 \mathrm{~m}, 360 \mathrm{~m}$, and $720 \mathrm{~m}$ (entire model); bottom: HORNELEN1 model $3 \mathrm{~m}, 4.5 \mathrm{~m}, 9 \mathrm{~m}$, and $18 \mathrm{~m}$ (entire model). Fracture permeability map of the model is shown in the background.

These tensor maps demonstrate the spatial variability of the permeability anisotropy of the fracture patterns that is - in part - already visible in the fracture maps. With increasing sample size, a convergence of the degree of anisotropy occurs while tensor orientation varies widely across all sample scales.

These results highlight the importance of full tensor analysis for fractured porous media as opposed to methods that only determine permeability magnitude or even values along the axes of the coordinate system. A question of high relevance to subsurface engineering is whether the orientation of the permeability tensor can be inferred from the direction of the in situ stress in the fractured layer. The high degree of spatial variability of tensor orientation seen in our models in spite of the uniform and strongly anisotropic far-field stress acting on the models, indicates that this is not possible, although there are model subregions that show an alignment of the long axis of the permeability tensors (=maximum permeability) with the direction of the least principal stress. Instead, the tensor plots highlight how important it is to understand fracture geometry and the sequence of formation of different sets. If these are 
known in conjunction with the orientations of the in situ stress, a statement can be made about the degree of uncertainty in the tensor orientation. Thus, in the Kilve model, the earliest most continuous fracture set is dilated. This leads to a very high degree of anisotropy and very little variation in tensor orientation. Fractures of this set (and the second almost parallel one) are spaced so closely that they are contained almost in every sample. All tensors are aligned with this set. While the smaller fractures also enhance permeability, their effect is minor as compared with the earliest set. The results for Kilve are important also with regard to the analysis of the scale dependence of maximum fracture permeability: since the degree of anisotropy is strong and varies little with sampling scale, the lack of variation that is seen for the tensor magnitudes is genuinely indicative of scale invariance as opposed to a change in the level of anisotropy with sample size.

For the stress state applied to the Arches model, the shorter, younger fractures that terminate against the systematic earlier sets are dilated. From sample to sample a small number of longer fractures of intermediate age and variable orientation are also opened in shear contributing to the permeability. This leads to rather unpredictable tensor orientations and degrees of anisotropy of the tensor.

\section{Discussion}

Our findings support the results of Long et al. (1982), Min et al. (2004), and Bogdanov et al. (2007) who were able to find REVs for geostatistics-based stochastically generated fractured models with variable fracture aperture. However, our findings are at odds with those of Kiraly (1975), who observed a permeability increase with scale in his field study. Why? - to start with, our study only investigates 3 orders of magnitude of length scale, while Kiraly's of the Jura Mountains in Switzerland spans 5 orders of magnitude. Furthermore, we do not consider the core scale where a bias against samples with fractures yields only matrix permeabilities at that scale. This is touched on by Bisdom et al. (2016b), but was not the 
primary focus of their analysis. There also is a debate whether aperture-fracture length correlations seen on the 0.1-10 meter scale apply at scales above. Renshaw and Park (1997) present data that negate this. That the complex fracture interactions they invoke to explain deviations at the large scale have an effect on local aperture, is corroborated by the mechanical modeling of Zhang and Sanderson (1996, 1999). Their model takes into account the effects of local stress perturbations on aperture, but ignores fracture surface roughness. Incorporating the latter into a full-complexity mechanical model with frictional contacts, using the actual shear displacements as opposed to inferences made from shear stress as by the Bandis et al. (1985) model, appears as the next logical step towards physical realism, albeit a very challenging one (cf., Lei et al., 2016). The main difference between this and earlier studies is that we consider permeability anisotropy and matrix permeability. As there is anisotropy, we do not observe the often emphasized correlation between (bulk) fracture density (P21, Table 2) and permeability. Since the matrix is permeable, fracture connectivity is less important as also seen in the field-data based DFMs of Bisdom et al. (2016a, 2016b, 2016c). A gradual permeability increase from non-percolating to percolating model subdomains occurs. This was already simulated by Bogdanov et al. (2007), using stochastic fracture models. Since fracture aperture locally varies, matrix blocks surrounded by fractures are not necessarily stagnant as is commonly assumed in dual porosity modeling (e.g., AhmedElfeel and Geiger, 2012).

The anisotropy of the equivalent permeability $\mathbf{k}^{e q}$ complexifies the analysis of its scale dependence. Thus, the $\mathbf{k}^{e q}$ of the small-scale samples often is dominated by individual highly permeable fractures manifesting itself in an extreme $k_{\max }^{e q}$ and anisotropy values. This anisotropy decreases with sample size. Consequently, the maximum permeability only tells part of the story.

Due to the power law length-frequency distributions of the fractures in the investigated patterns, none of the outcrop maps studied herein are REVs on geometric grounds as the 
largest fractures mapped in the field extend beyond their bounding rectangles. Hence there is no separation of scales and fracture length mode is a function of model size (Table 1). However, our results indicate that, for the purpose of upscaling and continuum scale simulation of fluid flow through fractured rocks, reasonable estimates of $\mathbf{k}^{e q}$ can be made, but to utilize them in continuum scale simulation models, a full tensor representation of permeability is required. This result is corroborated by many studies in the literature, but hardly acted upon in engineering practice. We therefore would like to reemphasize that a full second-rank tensor representation of permeability is required when: (1) the principal directions of permeability are not aligned with the simulation coordinate system; (2) these directions gradually change within a flow model; (3) permeability upscaling is carried out (even if the fine-scale grid is isotropic and orthogonal, cf., Tarahhom et al., 2009).

There are two major limitations in 3D systems coming from (1) a lack of observability (3D data) and (2) a lack of 3D constitutive models. The conventional approach to model 3D fractured domains is to assume statistical distribution of apertures. Such results are not representative of the actual statistics of the natural system (cf., Pollard and Aydin, 1988). The REV analysis approach proposed here does not have any limitations with regard to application to 3D models.

\section{Conclusions}

We have analyzed the scale dependence and anisotropy of the equivalent permeability $\mathbf{k}^{e q}$, of layered fractured rocks with matrix permeability using fracture patterns mapped in outcrops. Plausible fracture aperture patterns for a buried state in the presence of differential stress were computed with the Barton and Bandis model, fracture segment by segment, using a constitutive mechanical model based on far-field stress. Resulting fracture apertures vary along curved fractures, are log-normally distributed, and depend on fracture orientation 
relative to the far-field stress. The discrete fracture and matrix models were analyzed with the finite-element method for $\mathbf{k}^{e q}$, varying sample size and strategy.

Although rather homogeneous fracture patterns were chosen, our analysis identifies a strong anisotropy imparted by the fractures that exhibits significant spatial variations, both of $\mathbf{k}^{e q}$ magnitude and direction. The variation of the maximum principal component of the $\mathbf{k}^{e q}$ tensor appears to decrease with increasing sample size, until a scale threshold is reached above which $k_{\max }^{e q}$ stays constant. This threshold is tracked by the standard deviation of $k_{D}=$ $k_{\text {max }}^{e q} / k_{m}$ and indicates the existence of a useful REV dependent on fracture density: $\sim 167 \mathrm{~m}$ for the Arches model, $\sim 144 \mathrm{~m}$ for the large-scale Hornelen model and $\sim 3.6 \mathrm{~m}$ for the smallscale one. These findings and the underpinning methodology are important because they allow to determine appropriate dimensions for fracture permeability upscaling to the continuum scale. This implies that, for the purpose of upscaling and continuum scale simulation of fluid flow through fractured rocks, the potential REV must be established first. If this REV is larger than the typical horizontal extent of reservoir simulation grid blocks, an additional downscaling step is required in the workflow.

The highly anisotropic nature of $\mathbf{k}^{e q}$ tensor implies that permeability is poorly correlated with fracture bulk density and that a detailed knowledge of fracture geometry is required to predict permeability. The axes of the $\mathbf{k}^{e q}$ tensor are neither aligned with the prominent fractures nor with the principal directions of the far-field stress. A full tensor representation of $\mathbf{k}^{e q}$ is therefore absolutely essential for modeling flow through fractured rock at the continuum scale.

\section{Acknowledgements}

We thank the sponsors of the UK industry-technology-facilitator (itf) consortium "Improved Simulation of Faulted and Fractured Reservoirs" ISF for their support of this study. Without the fracture trace maps of Dr. Mandefro Belayneh (Saudi Aramco) and Noelle Odling 
(University of Leeds, UK) who gave us the permission to use their original datasets, this work would not have been possible.

The fracture datasets used in this study may be obtained by contacting the first author via email (siroos.azizmohammadi@unileoben.ac.at).

\section{References}

Aguilera, R. (1995), Naturally Fractured Reservoirs, Tulsa, Oklahoma, PennWell.

Ahmed-Elfeel, M. and S. Geiger (2012), Static and Dynamic Assessment of DFN Permeability Upscaling, SPE 154369, presented at the EAGE Annual Conference \& Exhibition incorporating SPE Europec, Copenhagen, Denmark, 4-7 June.

Antonellini, M., and A. Aydin (1994), Effect of faulting on fluid flow in porous sandstones: Petrophysical Properties, AAPG Bulletin, 78, no. 3, 355-377.

Annewandter, R., S. Geiger, and I. Main (2013), High-Resolution Numerical Simulations of Capillary Trapping for Carbon Dioxide in Fractured Formations, SPE 166002, presented at SPE Reservoir Characterization and Simulation Conference and Exhibition, Abu Dhabi, UAE, 16-18 September.

Auriault, J. L., C. Boutin, and C. Geindreau (2009), Homogenization of Coupled Phenomena in Heterogeneous Media, London, ISTE Ltd.

Bandis, S. C., A. C. Lumsden, and N. R. Barton (1983), Fundamental of rock joint deformation: International Journal of Rock Mechanics and Mining Sciences \& Geomechanics Abstracts, v. 20, no. $6,249-268$.

Barton, N., and V. Choubey (1977), The shear strength of rock joints in theory and practice, Rock Mechanics, v. 10, no. 1-2, 1-54.

Barton, N., and S. Bandis (1982), Effects of block size on the shear behavior of jointed rock, Keynote Lecture, 23rd US Symposium on Rock Mechanics, Berkeley, California, 25-27 August.

Barton, N., S. Bandis, and K. Bakhtar (1985), Strength, Deformation and Conductivity Coupling of Rock Joints, International Journal of Rock Mechanics and Mining Sciences \& Geomechanics Abstracts, v. 22, no. 3, 121-140.

Bear, J. (1972), Dynamics of Fluids in Porous Media, New York, Elsevier.

Bear, J., A. H.-D. Cheng (2010), Modeling Groundwater Flow and Contaminant Transport, New York, Springer.

Beer, F. P., E. R. Johnston, J. T. Dewolf, and D. F. Mazurek (2011), Mechanics of Materials, New York, McGraw-Hill. 
Belayneh, M., S. Geiger, and S. K. Matthäi (2006a), Numerical simulation of water injection into layered fractured carbonate reservoir analogs, AAPG Bulletin, v. 90, no. 10, 1473-1493.

Belayneh, M., S. Masihi,, S. K. Matthäi, and P. R. King (2006b), Prediction of vein connectivity using the percolation approach: model test with field data, Journal of Geophysics and Engineering, v. 3, 219-229.

Belayneh, M., S. K. Matthäi, and J. W. Cosgrove (2007), The implications of fracture swarms in the Chalk of SE England on the tectonic history of the basin and their impact on fluid flow in highporosity, low-permeability rocks, Geological Society, London, Special Publication, v. 272, 499517

Bisdom, K., G. Bertotti, and H. M. Nick (2016a), The impact of in-situ stress and outcrop-based fracture geometry on hydraulic aperture and upscaled permeability in fractured reservoirs, Tectonophysics,

Bisdom, K., G. Bertotti, and H. M. Nick (2016b), The impact of different aperture distribution models and critical stress criteria on equivalent permeability in fractured rocks, Journal of Geophysical Research: Solid Earth, v. 121, 4045-4063.

Bisdom, K., G. Bertotti, and H. M. Nick (2016c), A geometrically based method for predicting stressinduced fracture aperture and flow in discrete fracture networks, AAPG Bulletin, v. 100, no. 7, 1075-1097.

Bisdom, K., H. M. Nick, and G. Bertotti (2017), An integrated workflow for stress and flow modelling using outcrop-derived discrete fracture networks, Computers \& Geosciences, v. 103, 2135. http://dx.doi.org/10.1016/j.cageo.2017.02.019

Bogdanov, I. I., V. V. Mourzenko, J. -F. Thovert, and P. M. Adler (2007), Effective permeability of fractured porous media with power-law distribution of fracture sizes, Physical Review E, v. 76, 036309.

Bonnet, E., O. Bour, N. E. Odling, P. Davy, I. Main, P. Cowie, and B. Berkowitz (2001), Scaling of Fracture Systems in Geological Media, Reviews of Geophysics, v. 39, no. 3, 347-383.

Bour, O., P. Davy, C. Darcel, and N, Odling (2002), A statistical scaling model for fracture network geometry, with validation on a multiscale mapping of a joint network (Hornelen Basin, Norway), Journal of Geophysical Research: Solid Earth, v. 107, no. B6, 2113.

Brace, W.F. (1984), Permeability of crystalline rocks: New in situ measurements, Journal of Geophysical Research, v. 89, no. B6, 4327-4330.

Chen, T., C. Clauser, G. Marquart, K. Willbrand, and D. Mottaghy (2015), A new upscaling method for fractured porous media, Advances in Water Resources, v. 80, 60-68. 
Clauset, A., C. Shalizi, and M. Newman (2009), Power-Law Distributions in Empirical Data. SIAM Review, v. 51, no. 4, 661-703. http://dx.doi.org/10.1137/070710111.

Cruikshank, K. M., G. Zhao, and A. M. Johnson (1991), Analysis of minor fractures associated with joints and faulted joints, Journal of Structural Geology, v. 13, no. 8, 865-886.

Darcel, C., O., Bour, and P. Davy (2003), Stereological analysis of fractal fracture networks, Journal of Geophysical Research: Solid Earth, v. 108, no. B9, 2451.

de Dreuzy, J. R., P. Davy, and O. Bour (2001), Hydraulic properties of two-dimensional random fracture networks following a power law length distribution: 1-Effective connectivity, Water Resources Research, v. 37, no. 8, 2065-2078.

Dershowitz, W.S., and H. H. Einstein (1988), Characterizing rock joint geometry with joint system models, Rock Mechanics and Rock Engineering, v. 21, no. 1, 21-51.

Durlofsky, L. J. (1991), Numerical Calculation of Equivalent Grid Block Permeability Tensors for Heterogeneous Porous Media, Water Resource Research, v. 27, no. 5, 699-708.

Elzinga, C. L., D. W. Salzer, J. W. Willoughby, and J. P. Gibbs (2001), monitoring PLANT and ANIMAL populations, Massachusetts, Wiley-Blackwell.

Geiger, S., and S. K. Matthäi (2012), What can we learn from high-resolution numerical simulations of single- and multi-phase fluid flow in fractured outcrop analogues?, Geological Society, London, Special Publications, 374(1), 125-144. http://dx.doi.org/10.1144/sp374.8

Gelhar, L. W. (1993), Stochastic subsurface hydrology, New Jersey, Prentice Hall, 390 p.

Gilman, J. (2003), Practical aspects of simulation of naturally fractured reservoirs, International Forum on Reservoir Simulation, Bühl, Baden-Baden Germany, June 23-27.

Hardebol, N. J., C. Maier, H. Nick, S. Geiger, G. Bertotti, and H. Boro (2015), Multiscale fracture network characterization and impact on flow: A case study on the Latemar carbonate platform, Journal of Geophysical Research: Solid Earth, v. 120, no. 12, 8197-8222.

Hsieh, P. A. (1998), Scale effects in fluid flow through fractured geologic media, in G. Sposito, Scale Dependence and Scale Invariance in Hydrology, Cambridge, Cambridge University Press, 335-353.

Johansen, T. E. S., and H. Fossen (2008), Internal geometry of fault damage zones in interbedded siliciclastic sediments, Geological Society, London, Special Publication, v. 299, 35-56.

Kamerling, P. (1979), The geology and hydrocarbon habitat of the Bristol Channel basin, Journal of Petroleum Geology, v. 2, no. 1, 75-93.

Kasap, E., and L. W. Lake (1979), Calculating the Effective Permeability Tensor of a Gridblock, SPE Formation Evaluation, v. 5, no. 2, 192-200. 
Kiraly, L. (1975), Rapport sur l'état actuel des connaissances dans le domaines des caractères physiques des roches karstiques, in Burger, A., L. Dubertret, Hydrogeology of Karstic Terrains, International Association of Hydrogeologists, Series B, no. 3, 53-67.

Lang, P. S., A. Paluszny, and R.W. Zimmerman (2014), Permeability tensor of three-dimensional fractured porous rock and a comparison to trace map predictions, Journal of Geophysical Research: Solid Earth, v. 119, no. 8, 6288-6307.

Lei, Q., X. Wang, J. Xiang, and, J.-P. Latham (2016), Influence of Stress on the Permeability of a Three-Dimensional Fractured Sedimentary Layer. American Rock Mechanics Association, ARMA 2016-586.

Limpert, E., W. A. Stahel, and M. Abbt (2001), Log-normal Distributions across the Sciences: Keys and Clues, BioScience, v. 51, 341-352.

Long, J. C. S., J. S. Remer, C. R. Wilson, and P. A. Witherspoon (1982), Porous media equivalents for networks of discontinuous fractures, Water Resources Research, v. 18, no. 3, 645-658.

Lorenz, J. C., and S. P. Cooper (2001), Interpreting Fracture Patterns in Sandstones Interbedded with Ductile Strata at the Salt Valley Anticline, Arches National Park, Utah, http://digitalcommons.usu.edu/cgi/viewcontent.cgi?article=1005\&context=govdocs (Accessed January 3,2015$)$.

Martinez-Landa, L., and J. Carrera (2005), An analysis of hydraulic conductivity scale effects in granite, Water Resources Research, v. 41, no. 3, W03006.

Matthäi, S. K., M. Belayneh (2004), Fluid flow partitioning between fractures and a permeable rock matrix, Geophysical Research Letters, v. 31, no. 7, L07602.

Matthäi, S. K., S. Geiger, S. G. Roberts, A. Paluszny, M. Belayneh, A. Burri. A. Mezentsev, H. Lu, D. Coumou, T. Driesner, and C. A. Heinrich (2007), Numerical simulation of multi-phase fluid flow in structurally complex reservoirs, Geological Society, London, Special Publications, v. 292, 405-429.

Matthäi, S. K., S. Bazrafkan, P. S. Lang, and C. Milliotte (2012), Numerical Prediction of Relative Permeability in Water Wet Naturally Fractured Reservoir Rocks, ECMOR XIII, 13th European Conference on the Mathematics of Oil Recovery, Biarritz, France, 10-13 September.

Meheust, Y., and J. Schmittbuhl (2003), Scale Effects Related to Flow in Rough Fractures, pure and applied geophysics, v. 160, no. 5-6, 1023-1050.

Min, K.-B., L. Jing, and O. Stephansson (2004), Determining the equivalent permeability tensor for fractured masses using a stochastic REV approach: Method and application to the field data from Sellafield U.K., Hydrogeology Journal, v. 12, no. 5, 497-510. 
Nelson, R. A. (1985), Geologic Analysis of Naturally Fractured Reservoirs, Woburn, Gulf Professional Publishing.

Nemcok, M., and R. Gayer (1996), Modeling paleostress magnitude and age in extensional basins: A case study from the Mesozoic Bristol Channel Basin U.K., Journal of Structural Geology, v. 18, no. $11,1301-1313$.

Neuman, S. P. (1994), Generalized scaling of permeabilities: Validation and effect of support scale, Geophysical Research Letters, v. 21, no. 5, 349-352.

Nick, H. M., A. Paluszny, M. J. Blunt, and S. K. Matthai (2011), Role of geomechanically grown fractures on dispersive transport in heterogeneous geological formations: Physical Review E, v. 84, no. 5,056301 .

Odling, N. E. (1997), Scaling and connectivity of joint systems in sandstones from western Norway, Journal of Structural Geology, v. 19, no. 10, 1257-1271.

Olson, J. E. (2003), Sublinear scaling of fracture aperture versus length: an exception or the rule? Journal of Geophysical Research, v. 108, no. B9, 2413.

Olson, J. E. (2007), Fracture aperture, length and pattern geometry development under biaxial loading: a numerical study with applications to natural, cross-jointed systems, Geological Society of London, Special Publications, v. 289, 123-142.

Olsson, R., and N. Barton (2001), An improved model for hydromechanical coupling during shearing of rock joints, International Journal of Rock Mechanics and Mining Sciences, v. 38, no. 3, 317-329.

Paluszny, A. and S. K. Matthai (2010), Impact of fracture development on the effective permeability of porous rocks as determined by 2D discrete fracture growth modeling, Journal of Geophysical Research: Solid Earth, v. 115, B02203.

Pirker, B., A. W. Harrer, and Z. E. Heinemann (2008), Reserve Estimation for Naturally Fractured Reservoirs Using Numerically Derived Recovery Curves, 11th European Conference on the Mathematics of Oil Recovery, Bergen, Norway, 8-11 September.

Pollard, D. D., and A. Aydin (1988), Progress in understanding jointing over the past century, Geological Society of America Bulletin, v. 100, no. 8, 1181-1204.

Pollard, D. D., and R. C. Fletcher (2005), Fundamentals of structural geology, New York, Cambridge University Press.

Qi, D., and T. Hesketh (2005), An analysis of upscaling techniques for reservoir simulation, Petroleum Science and Technology, v. 23, no. 7-8, 827-842.

Rawnsley, K. D., D. C. P Peacock, T. Rives, J. -P Petit (1998), Joints in the Mesozoic sediments around the Bristol Channel Basin, Journal of Structural Geology, v. 20, no. 12, 1641-1661. 
Renshaw, C. E., and J. C. Park (1997), Effect of mechanical interactions on the scaling of fracture length and aperture, Nature, v.386, no. 6624, 482-484.

Ringrose, P. S., A. S. Mathieson, I. W. Wrightb, F. Selamac, O. Hansena, R. Bissellb, N. Saoulaa, and J. Midgleyb (2013), The In Salah CO2 Storage Project: Lessons Learned and Knowledge Transfer, Energy Procedia, v. 37, 6226-6236.

Roedder, E. (1984), Reviews in mineralogy, Washington: Mineralogical Society of America.

Roehl, P. O., and P. W. Choquette (1985), Carbonate Petroleum Reservoirs, New York, Springer.

Sahimi, M. (2011), Flow and Transport in Porous Media and Fractured Rock: From Classical Methods to Modern Approaches, Weinheim, Germany, Wiley.

Schulze-Makuch, D., D. A. Carlson, D. S. Cherkauer, and P. Malik (1999), Scale dependency of hydraulic conductivity in heterogeneous media, Ground Water, v. 37, no. 6, 904-919.

Snow, D. T. (1969), Anisotropic Permeability of Fractured Media, Water Resources Research, v. 5, no. $6,1273-1289$.

Stüben, K. (2001), A review of algebraic multigrid, Journal of Computational and Applied Mathematics, v. 128, no. 1-2, 281-309.

Tarahhom, F., K. Sepehrnoori, and F. Marcondes (2009), A Novel Approach to Integrate Dual Porosity Model and Full Permeability Tensor Representation in Fractures, SPE 119001, presented at SPE Reservoir Simulation Symposium, Woodlands, Texas, USA, 2-4 February.

Taylor, W.L., D. P. Pollard, and A. Aydin (1999), Fluid flow in discrete joint sets: field observations and numerical simulations, Journal of Geophysical Research, v. 104, no. B12, 28983-29006.

Tran, N. H. (2009), Solving Complexity of Naturally Fractured Reservoirs: A Contemporary Application in Optimizing Production of Deep-Earth Resources, Proceedings of the 2nd WSEAS International Conference on Engineering Mechanics, Structures, and Engineering Geology, Rodos (Rhodes) Island, Greece, July 22-24.

Turcotte, D. L., E. M. Moores, and J. B. Rundle (2014), Super fracking, Physics Today, v. 67, no. 8, $34-39$.

Wu, H., and D. D. Pollard (1995), An experimental study of the relationship between joint spacing and layer thickness, Journal of Structural Geology, v. 17, no. 6, 887-905.

Wu, H., and D. D. Pollard (2002), Imaging 3-D fracture networks around boreholes, AAPG Bulletin, v. 86 , no. $4,593-604$.

Zhang, X., and D. J., Sanderson (1996), Effects of stress on the 2-D permeability tensor of natural fracture networks, Geophysical Journal International, v. 125, no. 3, 912-24. 
Zhang, X., and D. J., Sanderson (1999), Scale-up of two-dimensional permeability tensor for highly heterogeneous fracture networks, Engineering Geology, v. 53, no. 1, 83-99.

Zimmerman, R. W., and G. S. Bodvarsson (1996), Hydraulic conductivity of rock fractures, Transport in Porous Media, v. 23, no. 1, 1-30.

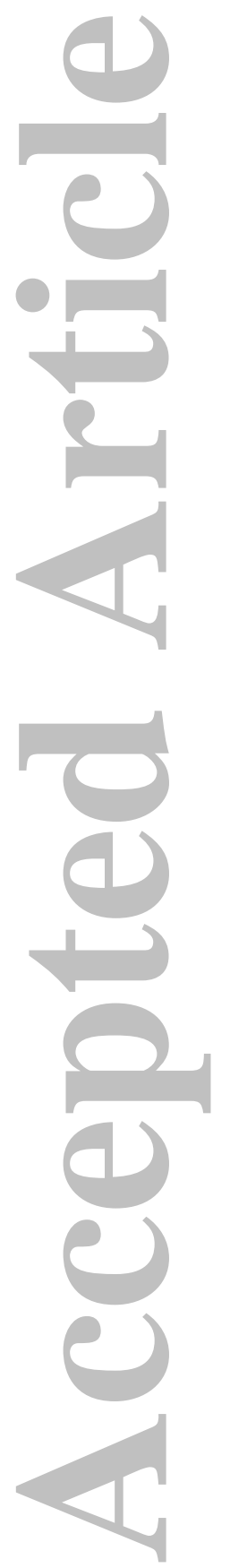




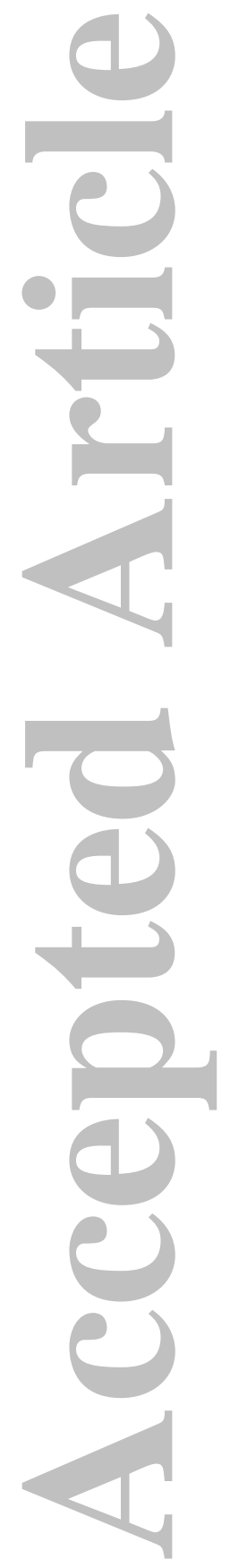

This article is protected by copyright. All rights reserved. 


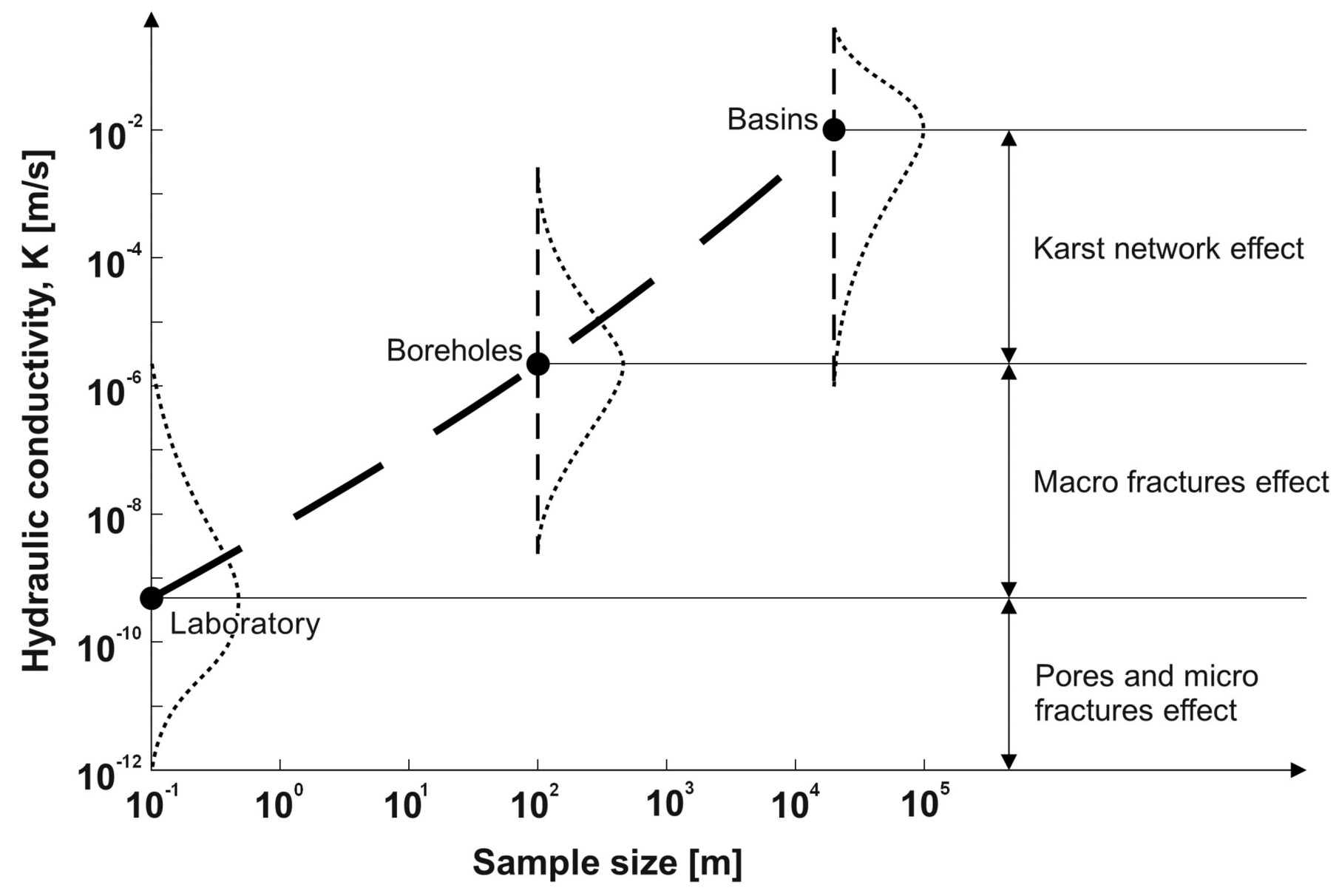

This article is protected by copyright. All rights reserved. 


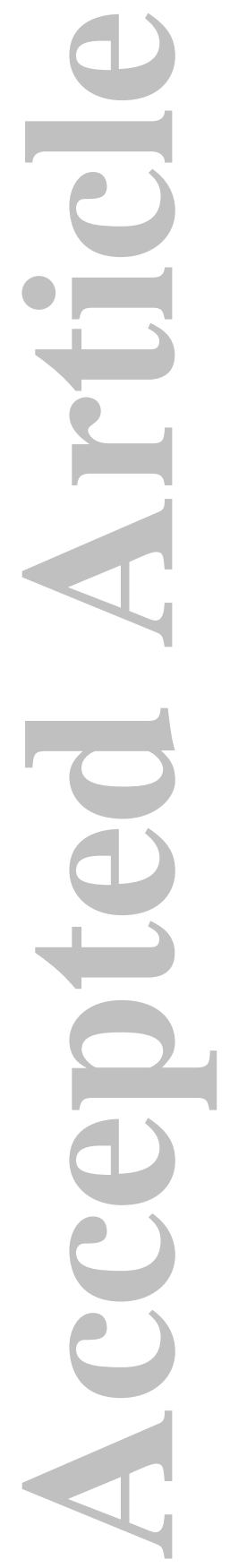

This article is protected by copyright. All rights reserved. 

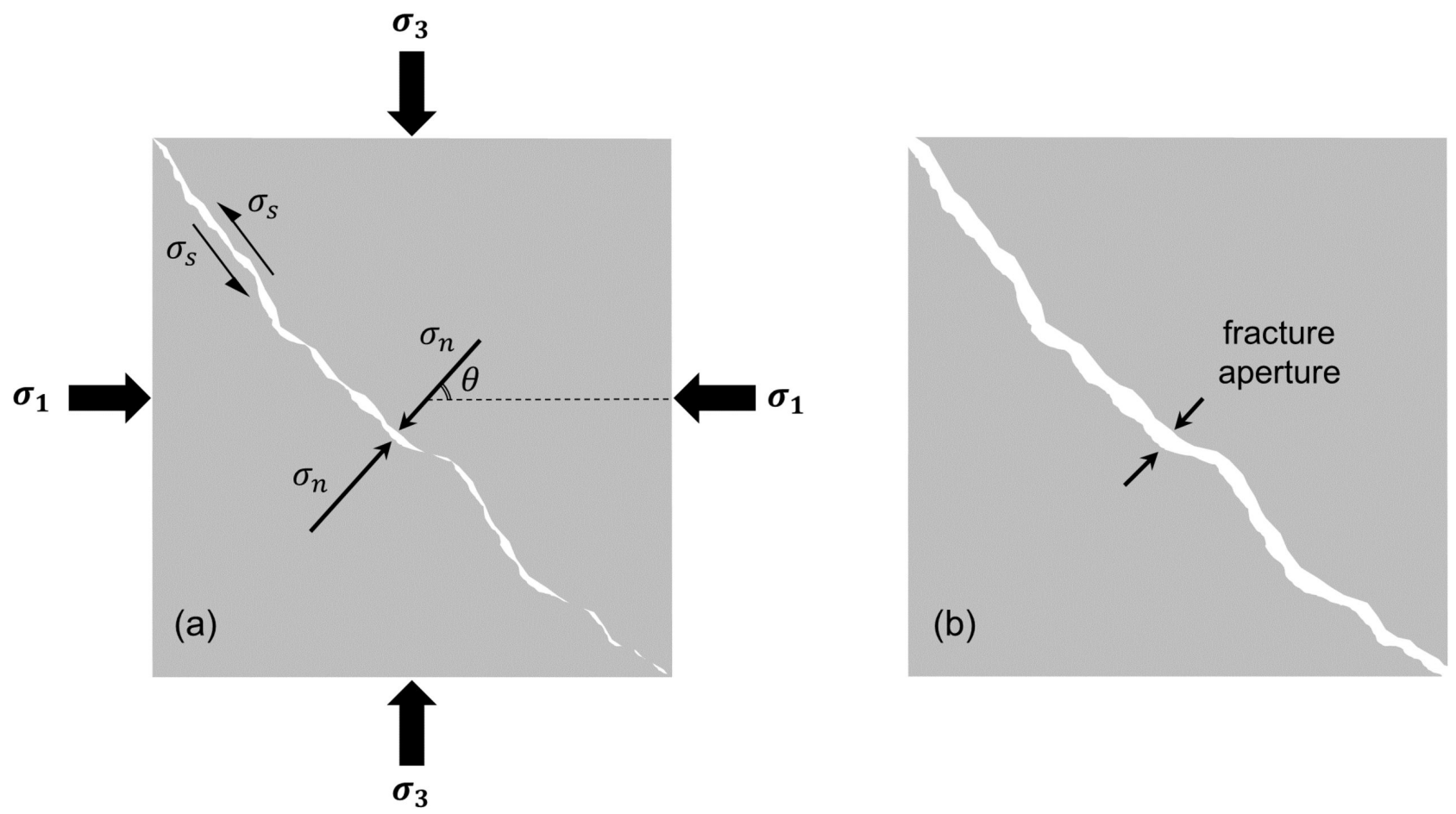

This article is protected by copyright. All rights reserved. 


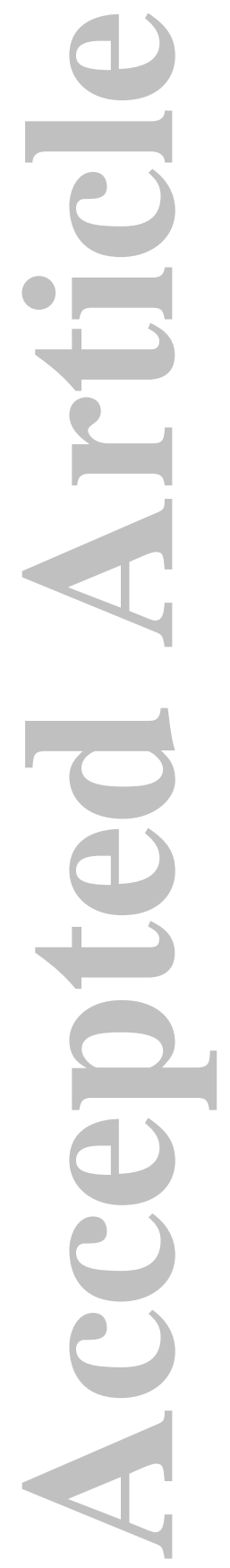

This article is protected by copyright. All rights reserved. 


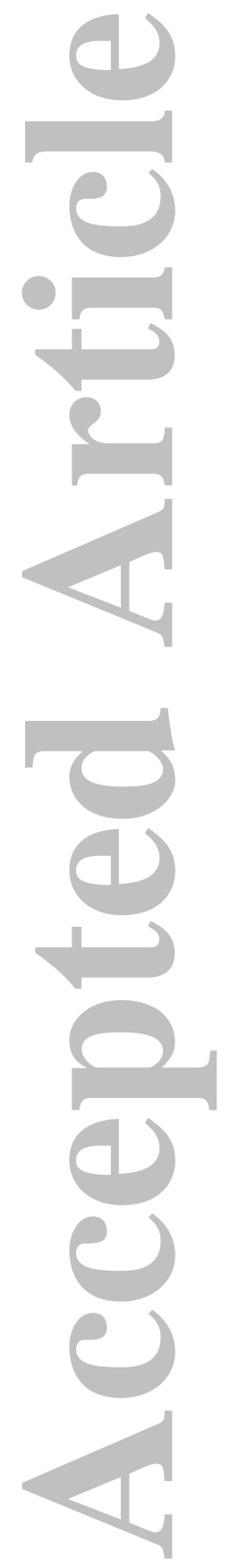

This article is protected by copyright. All rights reserved. 

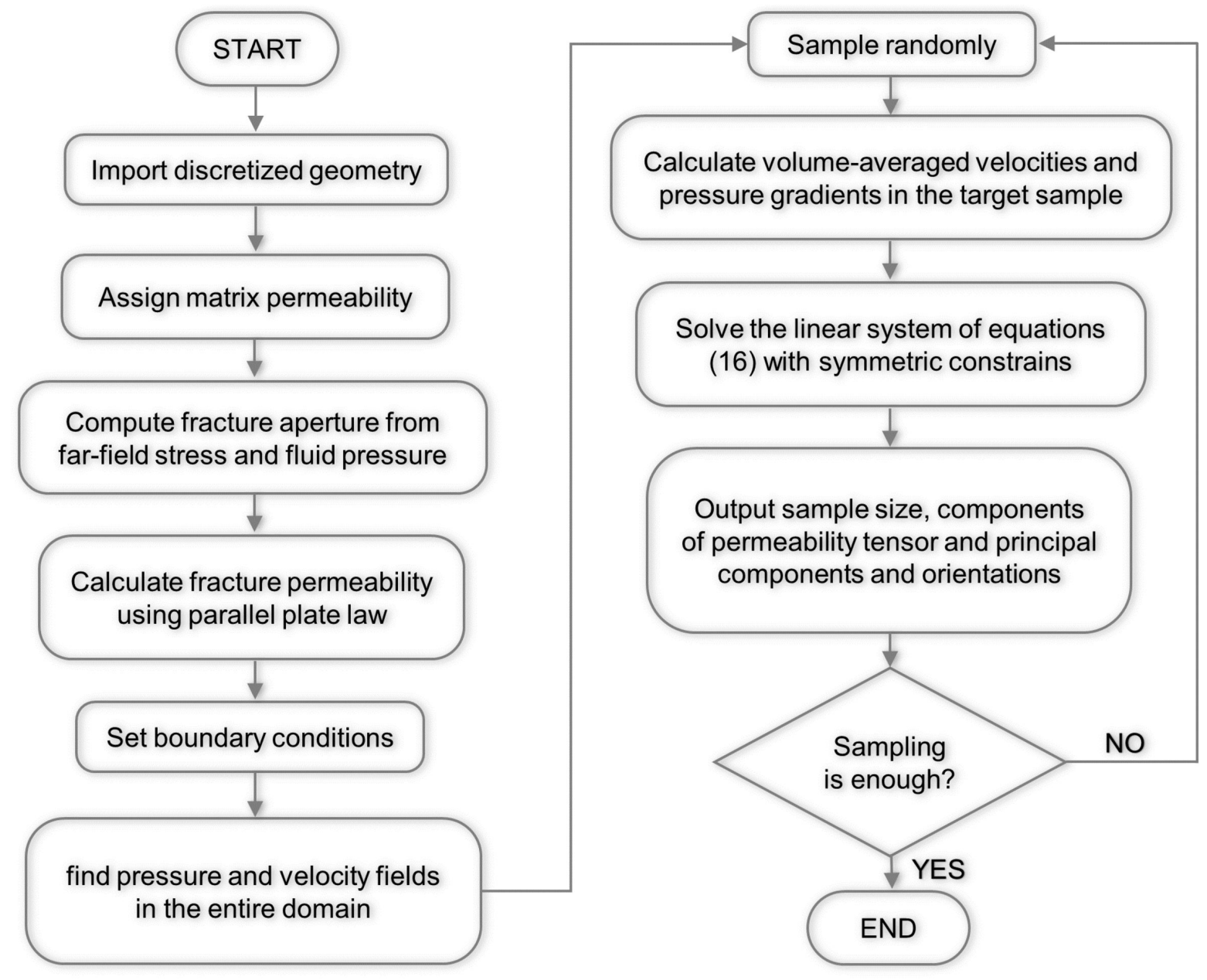

This article is protected by copyright. All rights reserved. 


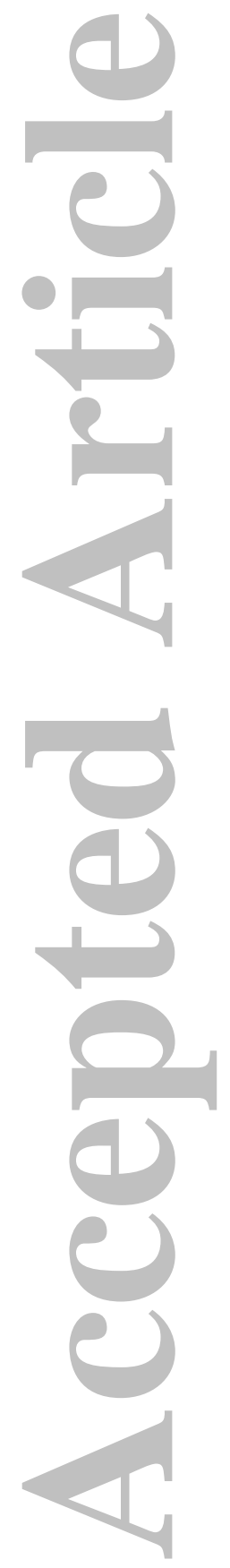

This article is protected by copyright. All rights reserved. 
(a)

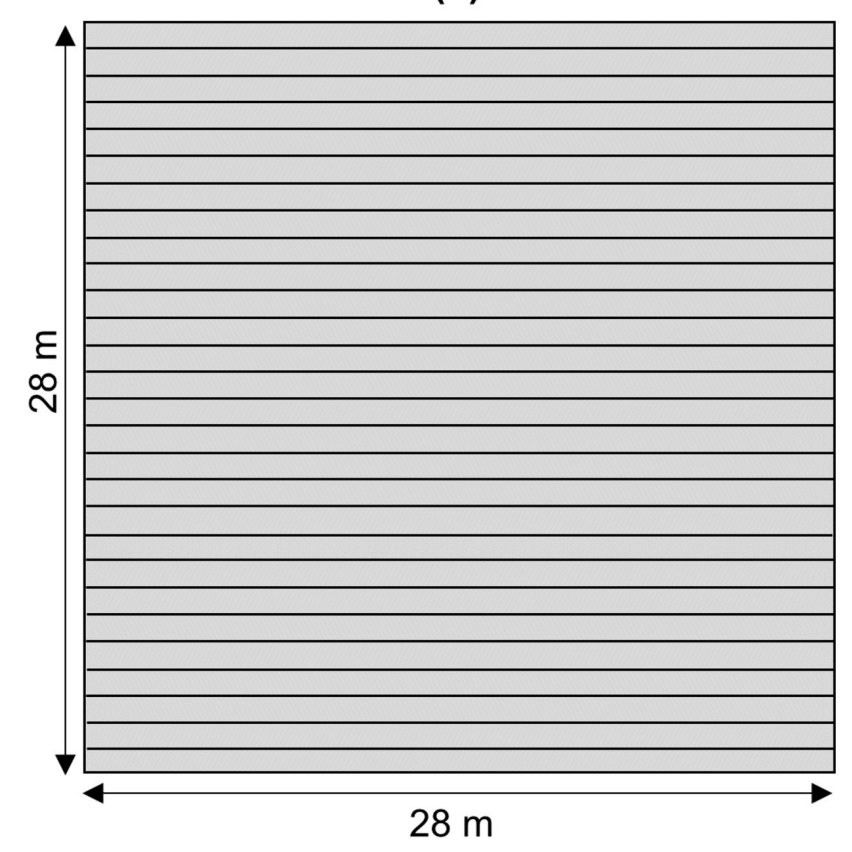

(b)

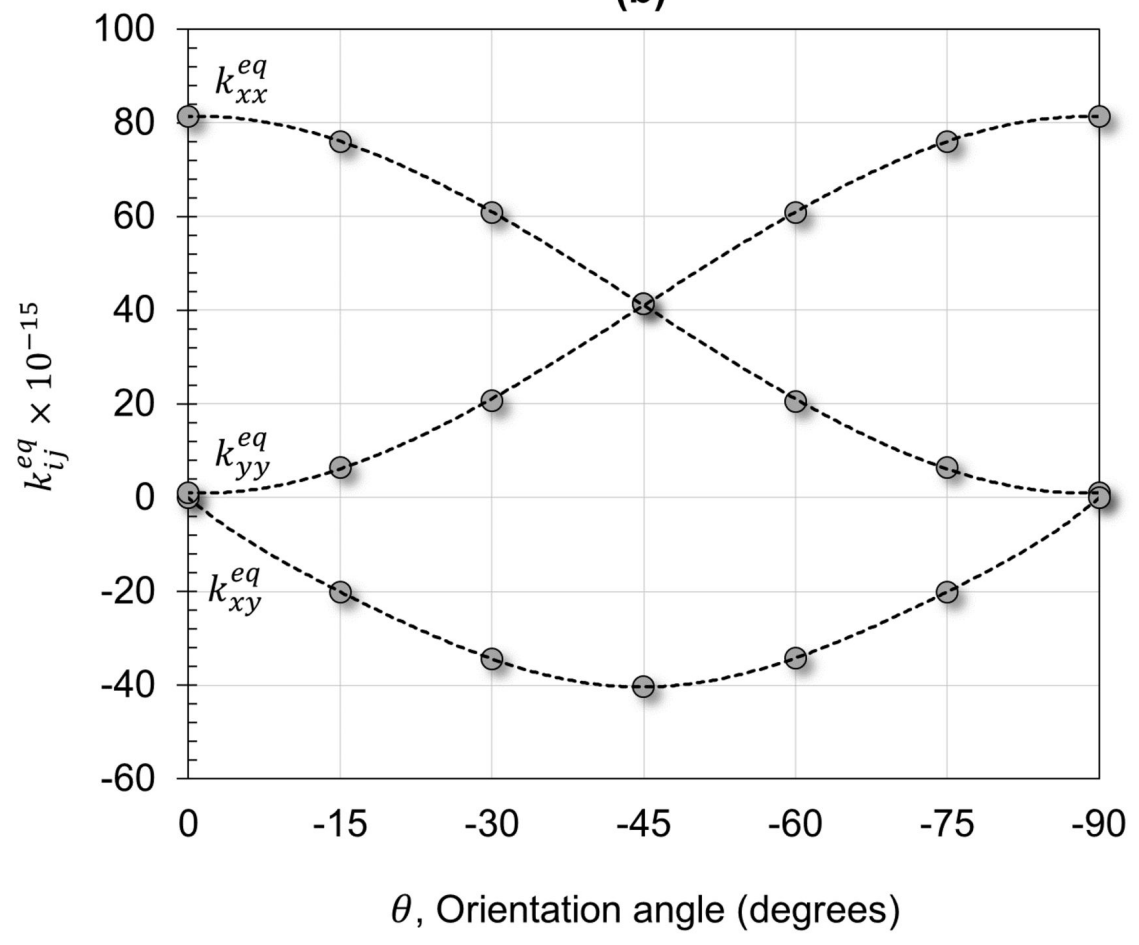




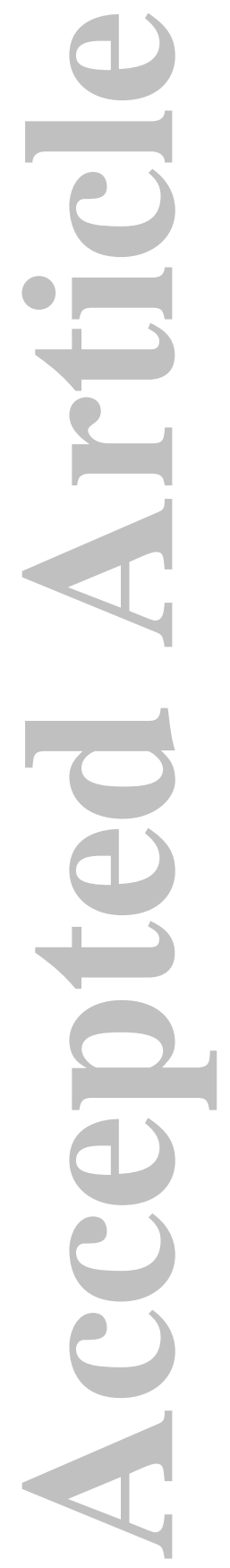

This article is protected by copyright. All rights reserved. 


\section{KILVE_BED3}

$\varepsilon$

(1)

$18 \mathrm{~m}$

\section{ARCHES}

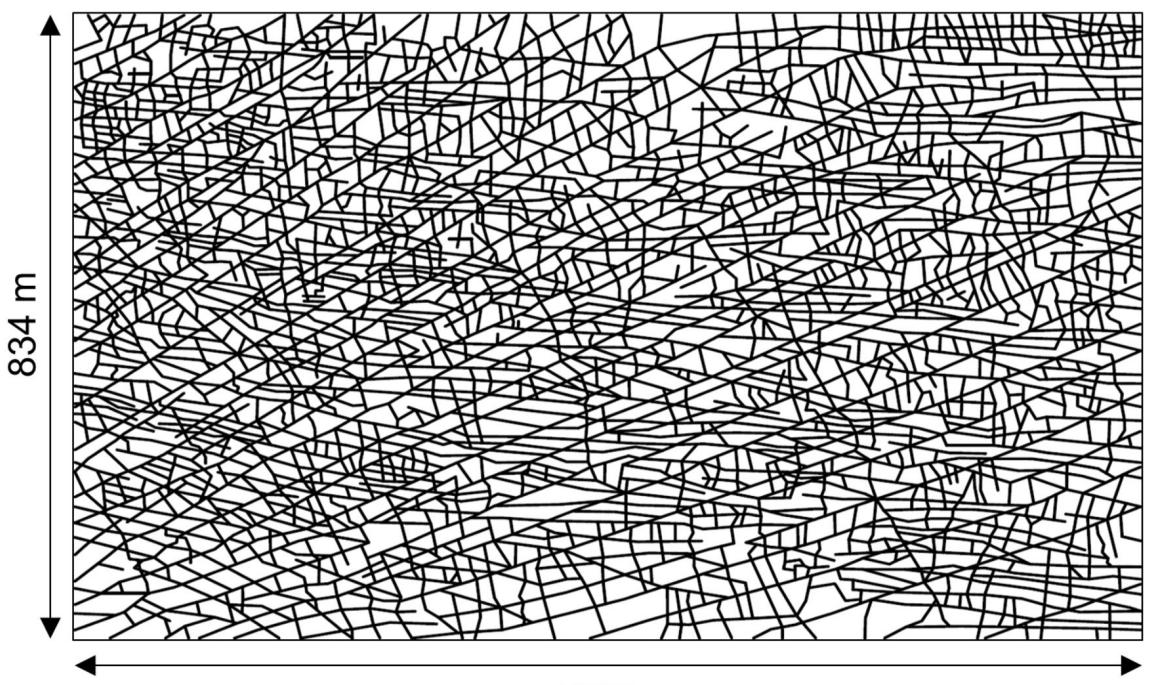

$1287 \mathrm{~m}$
HORNELEN7

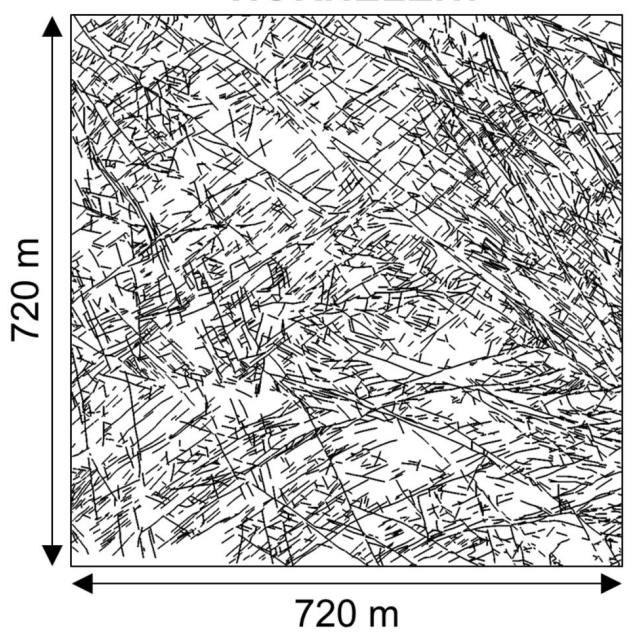

HORNELEN1

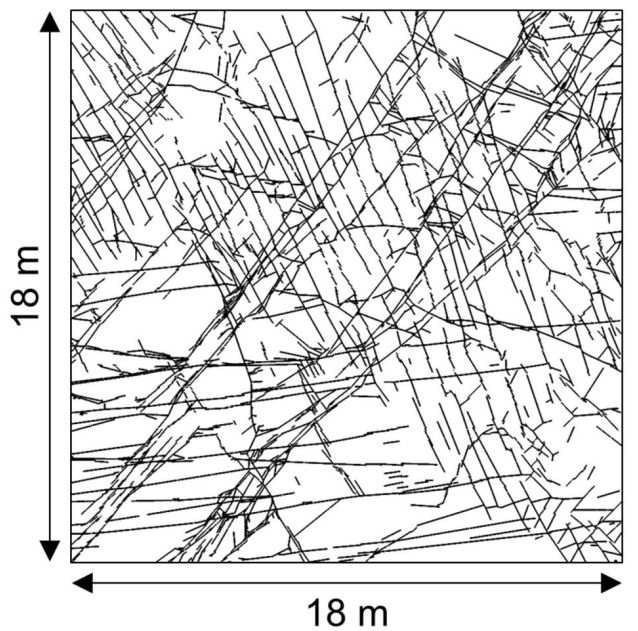




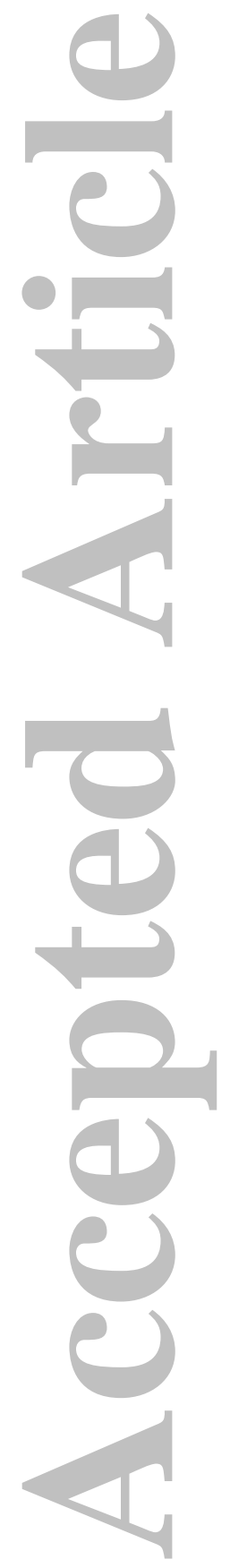

This article is protected by copyright. All rights reserved. 

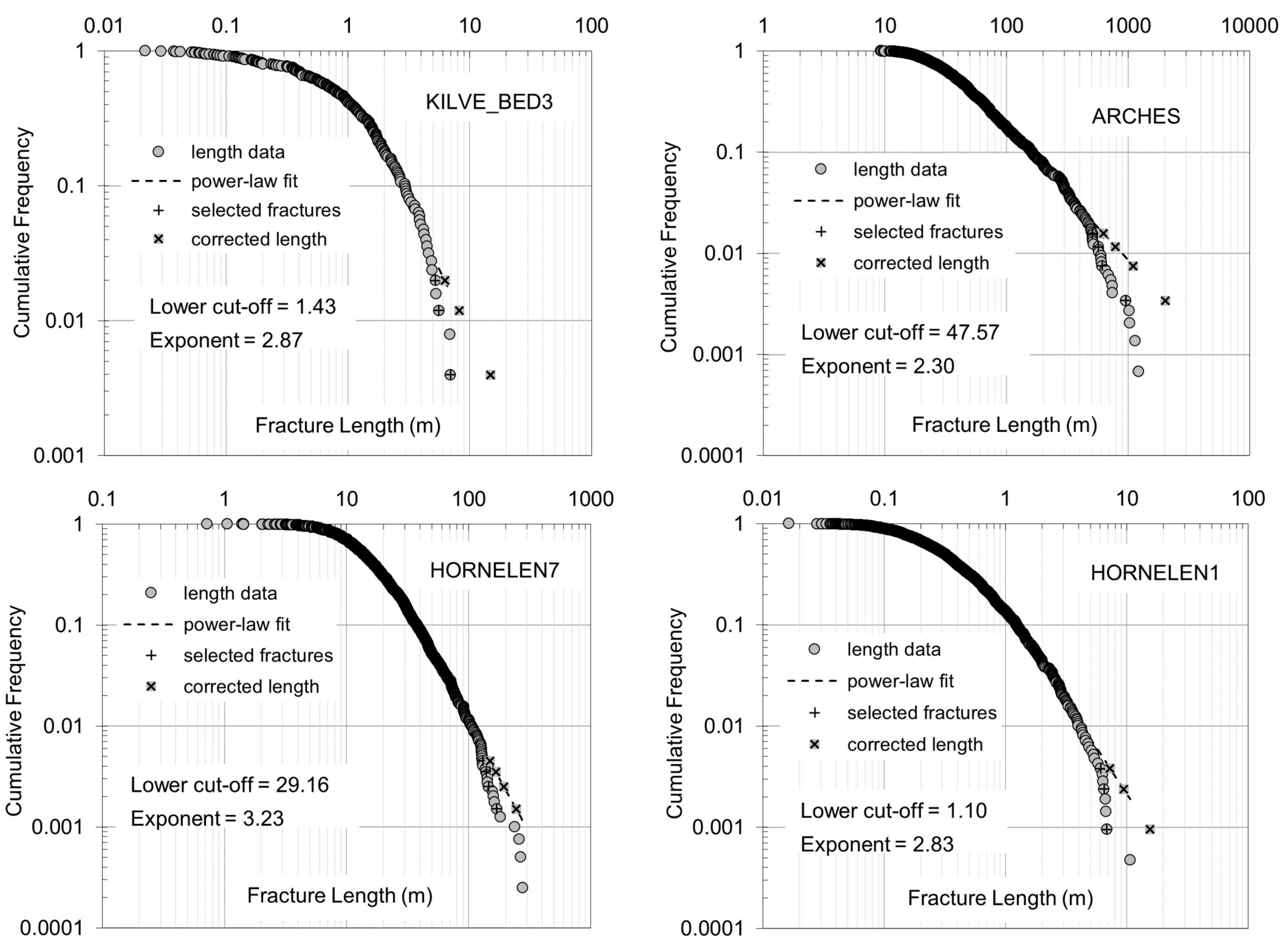

This article is protected by copyright. All rights reserved. 


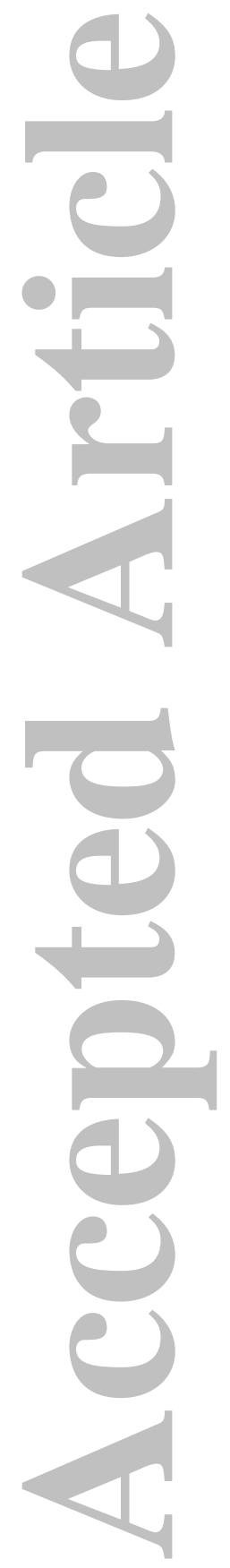

This article is protected by copyright. All rights reserved. 

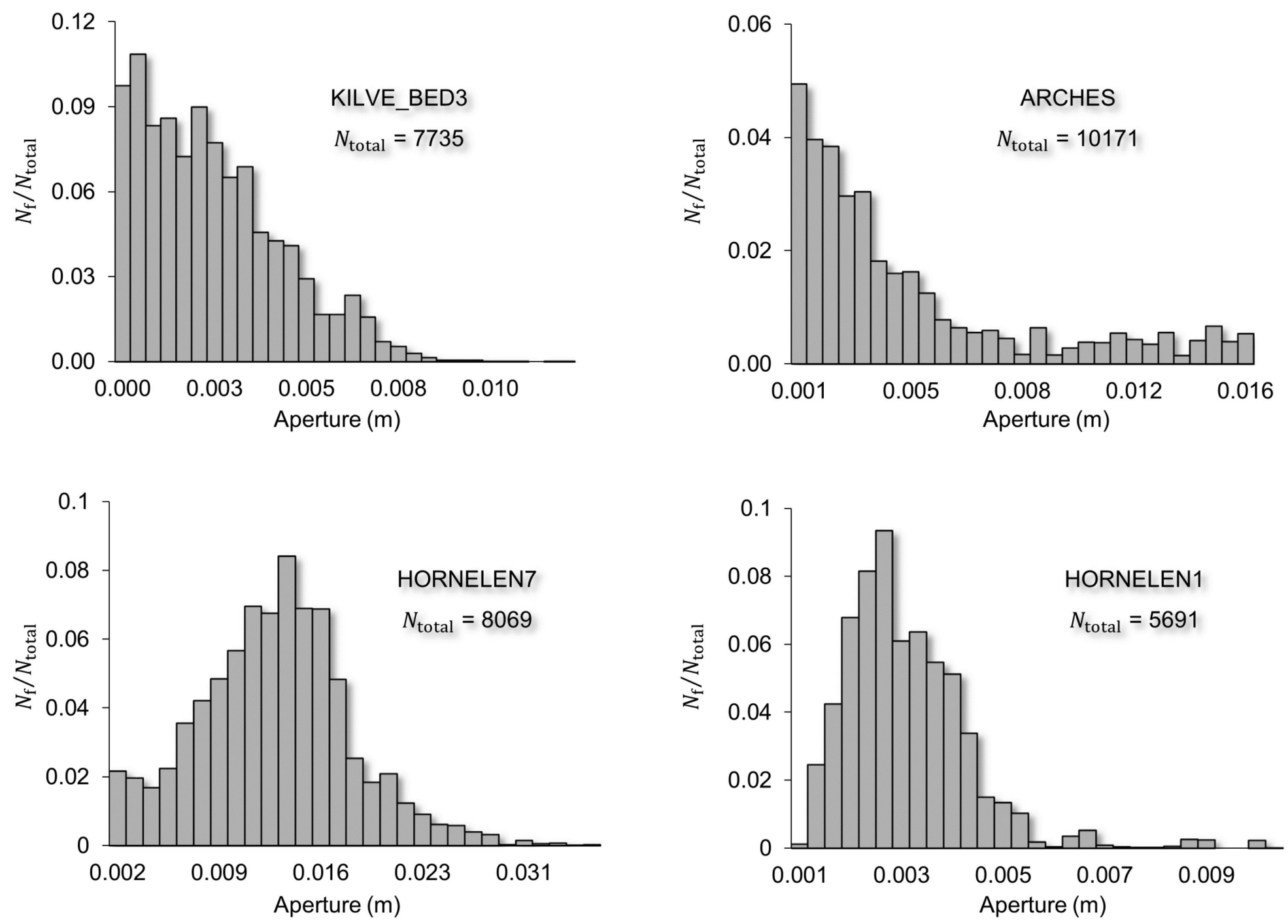

This article is protected by copyright. All rights reserved. 


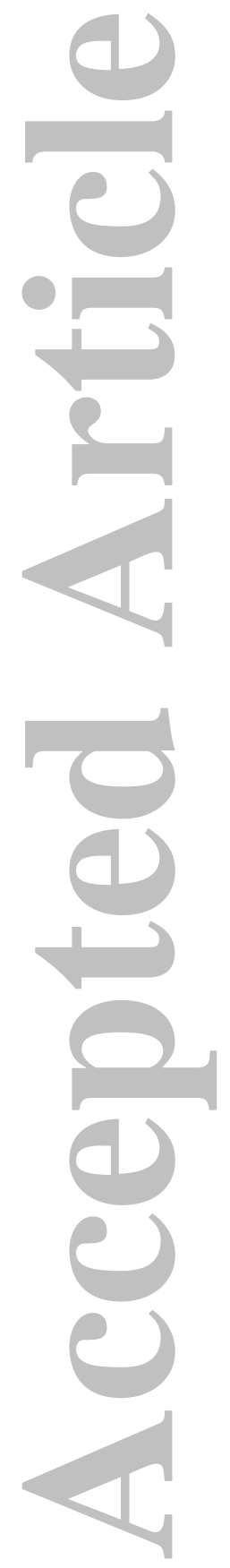

This article is protected by copyright. All rights reserved. 

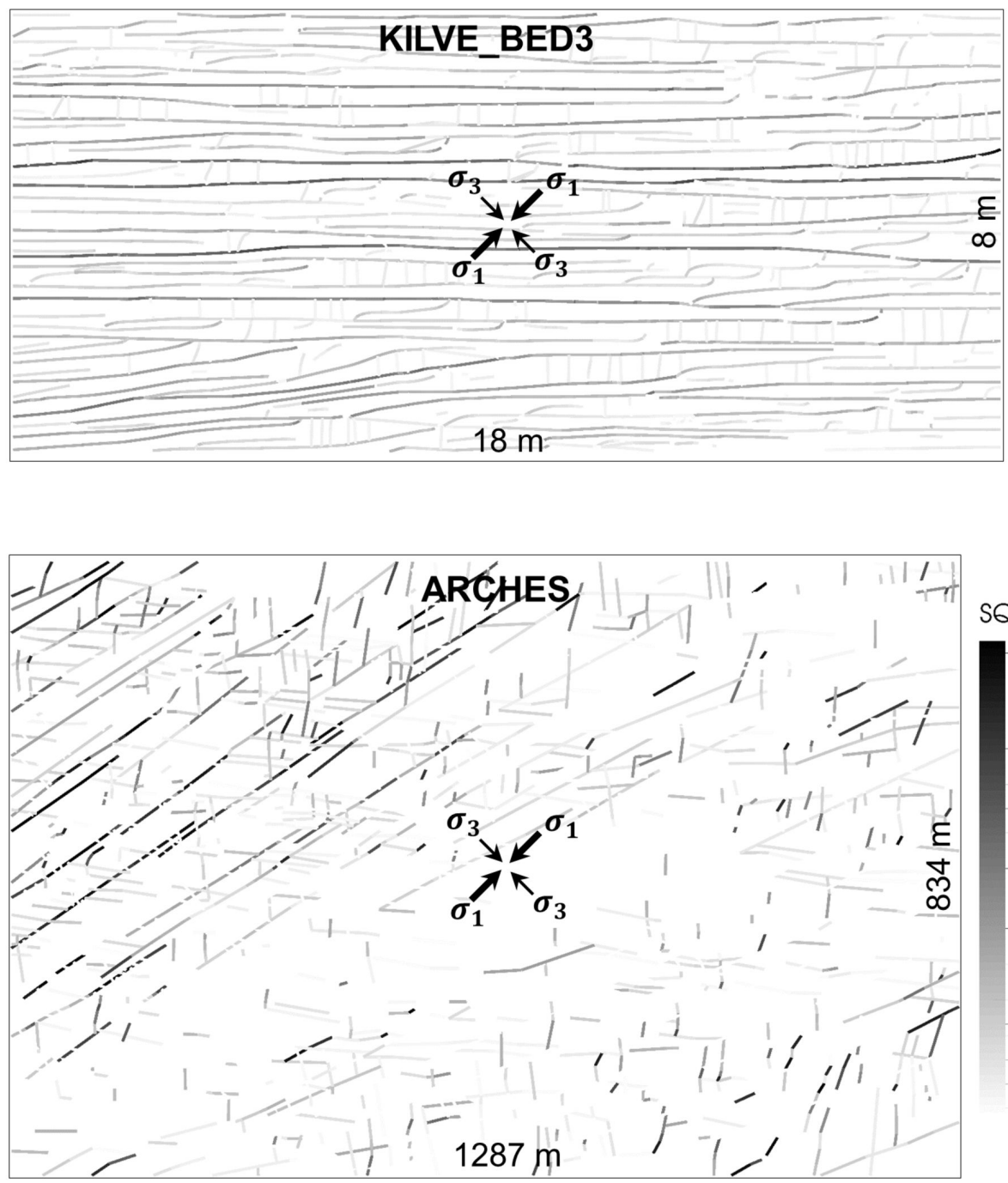

SQRT(Perm)
$3.5 \mathrm{e}-03$
0.0026
0.0018
$=$
0.00089
$=$
$5.8 \mathrm{e}-06$

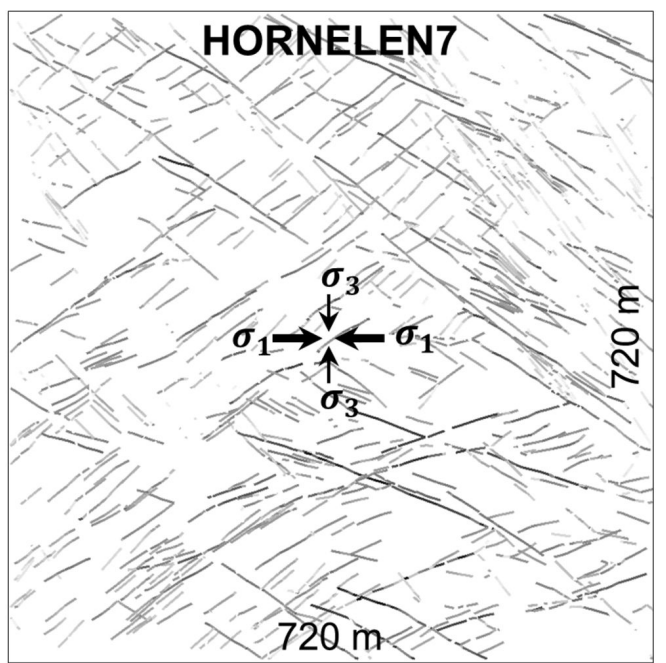

SQRT(Perm)

1.0e-02

0.0078

0.0052

0.0026

$5.8 \mathrm{e}-06$

\section{SQRT(Perm)}

$\mathbf{-}^{4.6 \mathrm{e}-03}$

0.0034

0.0023

0.0011

$5.8 \mathrm{e}-06$

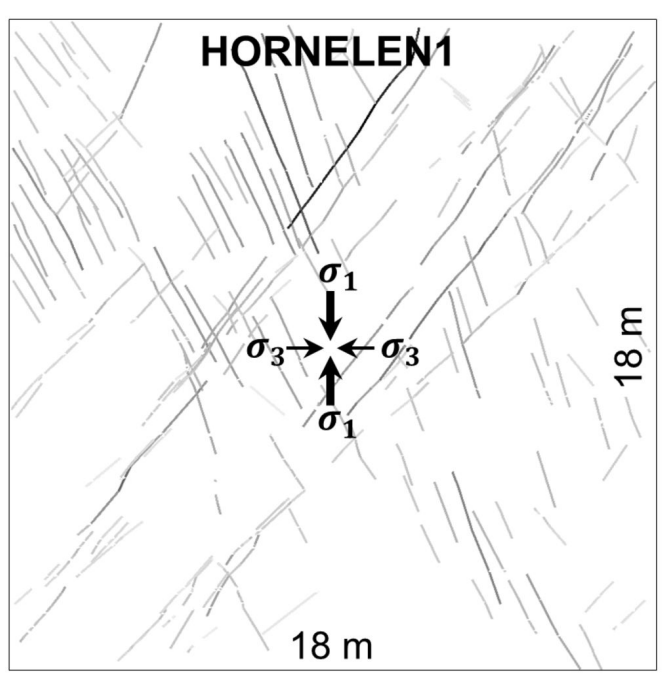

SQRT(Perm)

3. $1 \mathrm{e}-03$

0.0023

0.0015

0.00078

$5.8 \mathrm{e}-06$ 


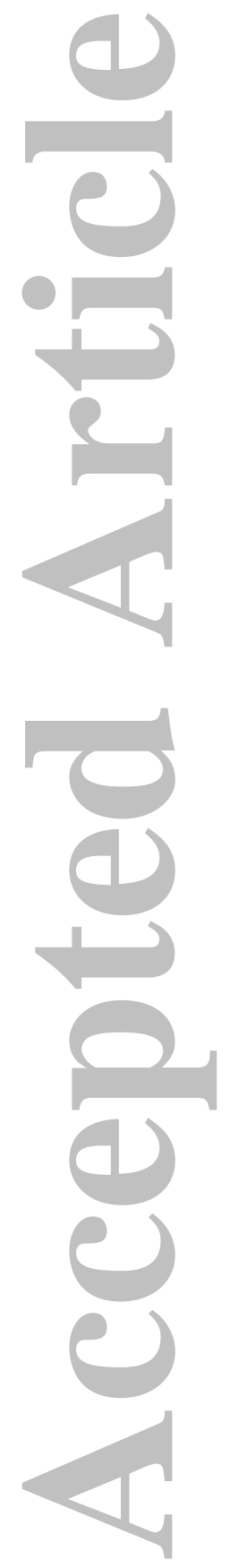

This article is protected by copyright. All rights reserved. 


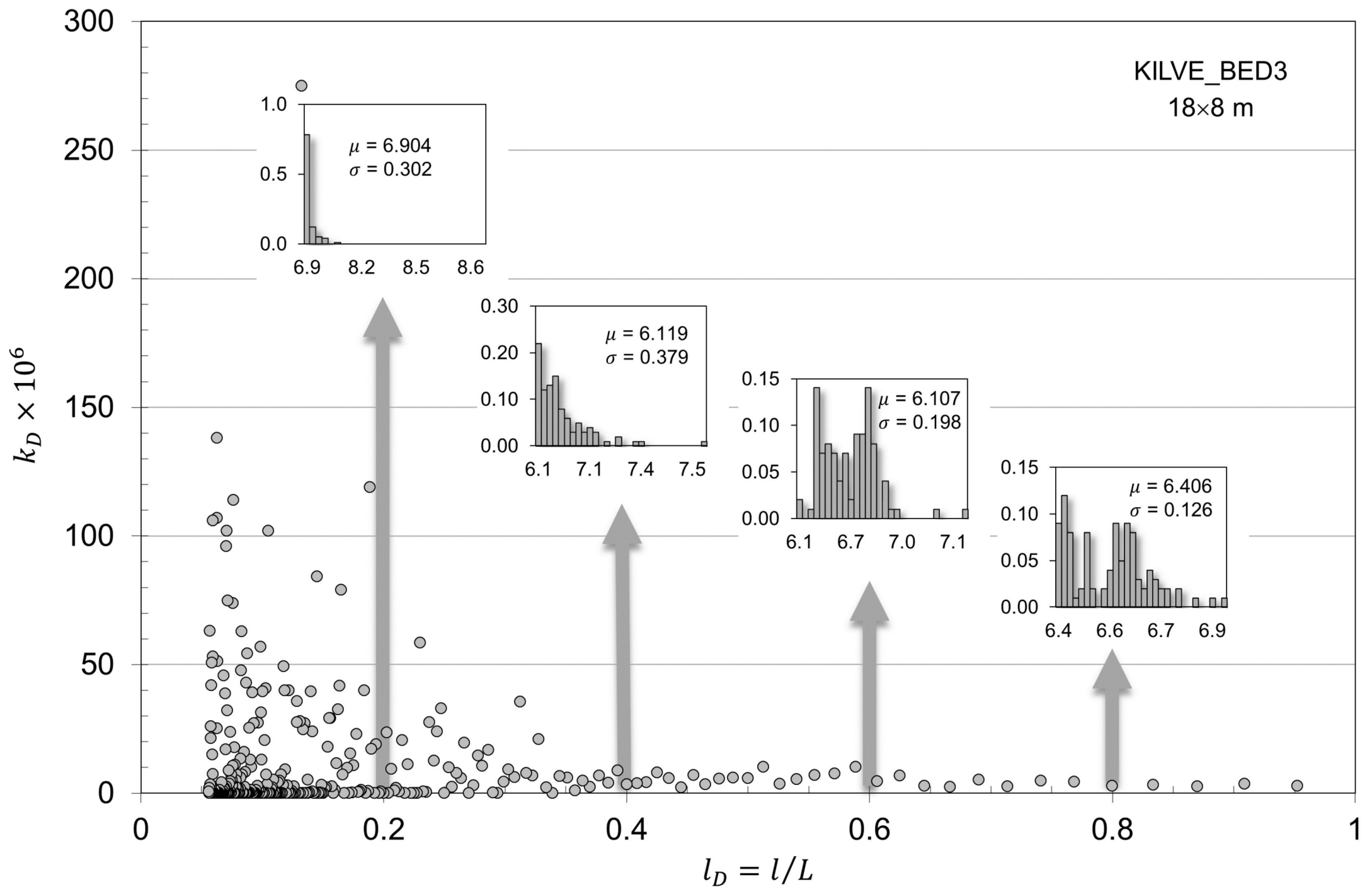

This article is protected by copyright. All rights reserved. 


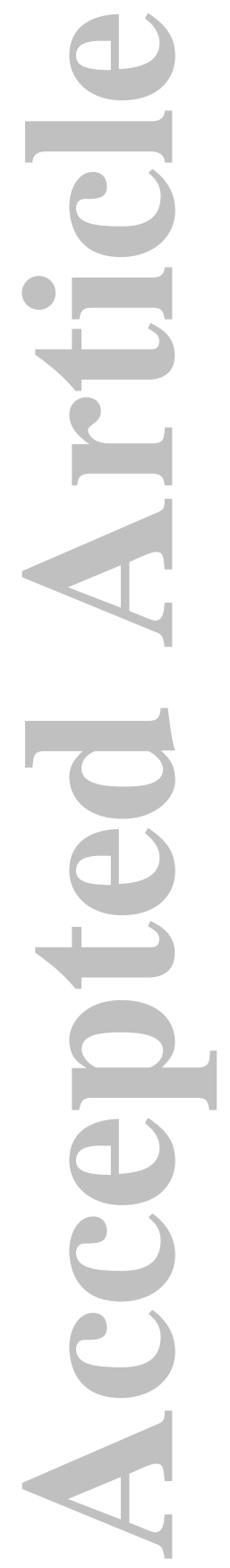

This article is protected by copyright. All rights reserved. 


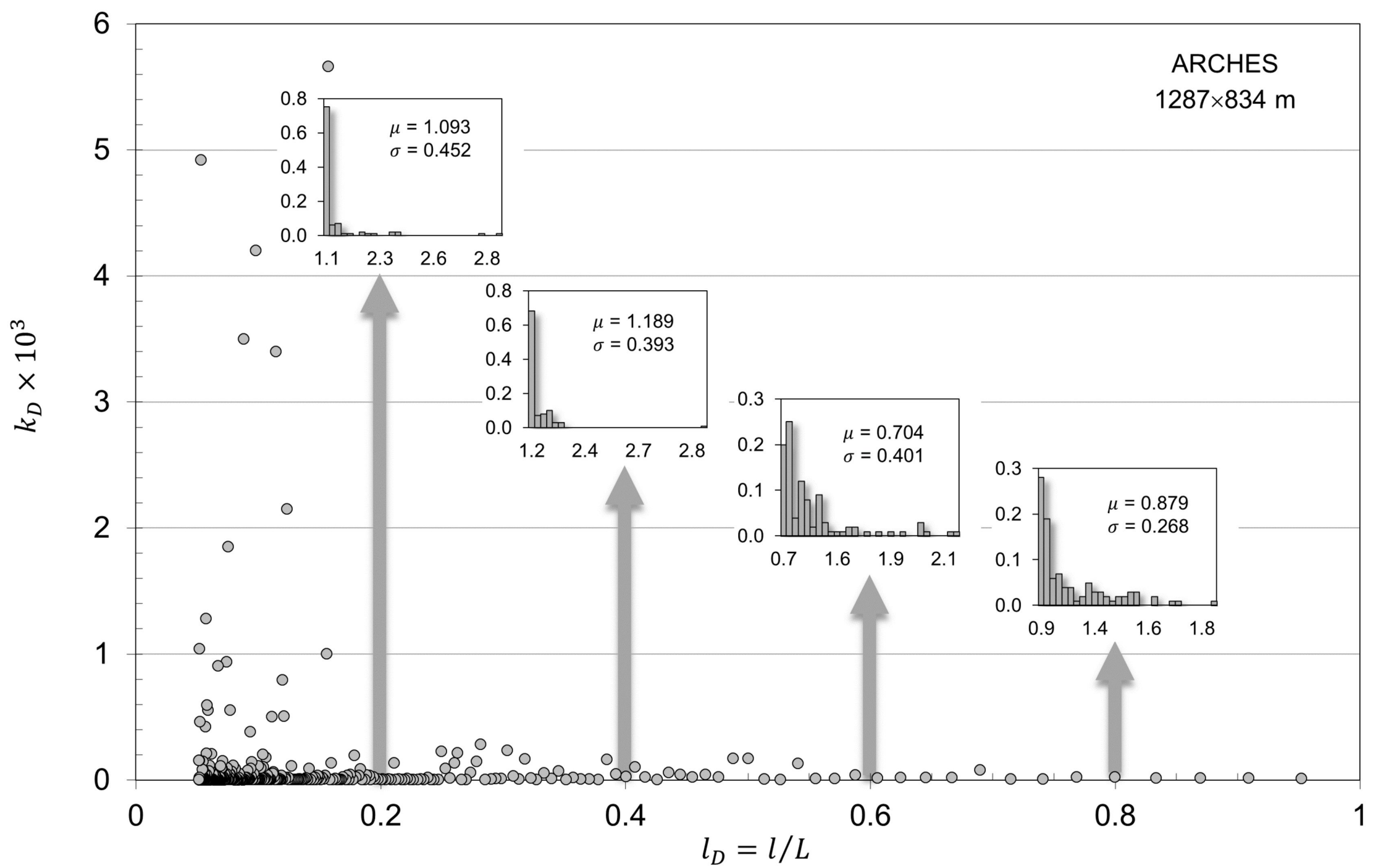

This article is protected by copyright. All rights reserved. 


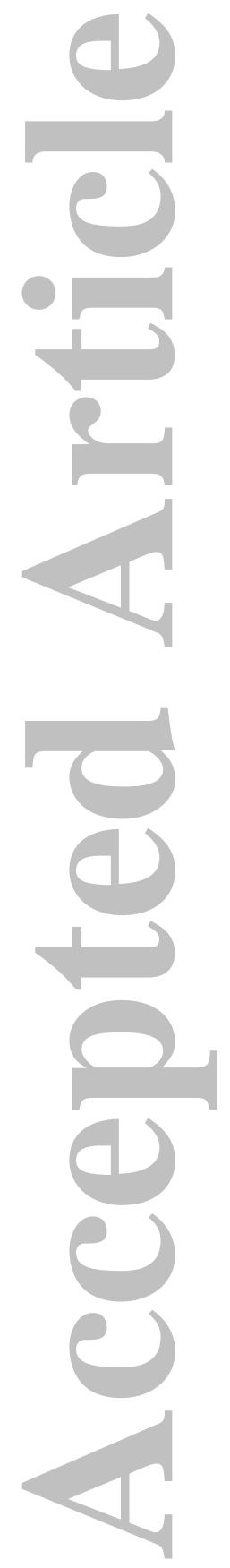

This article is protected by copyright. All rights reserved. 


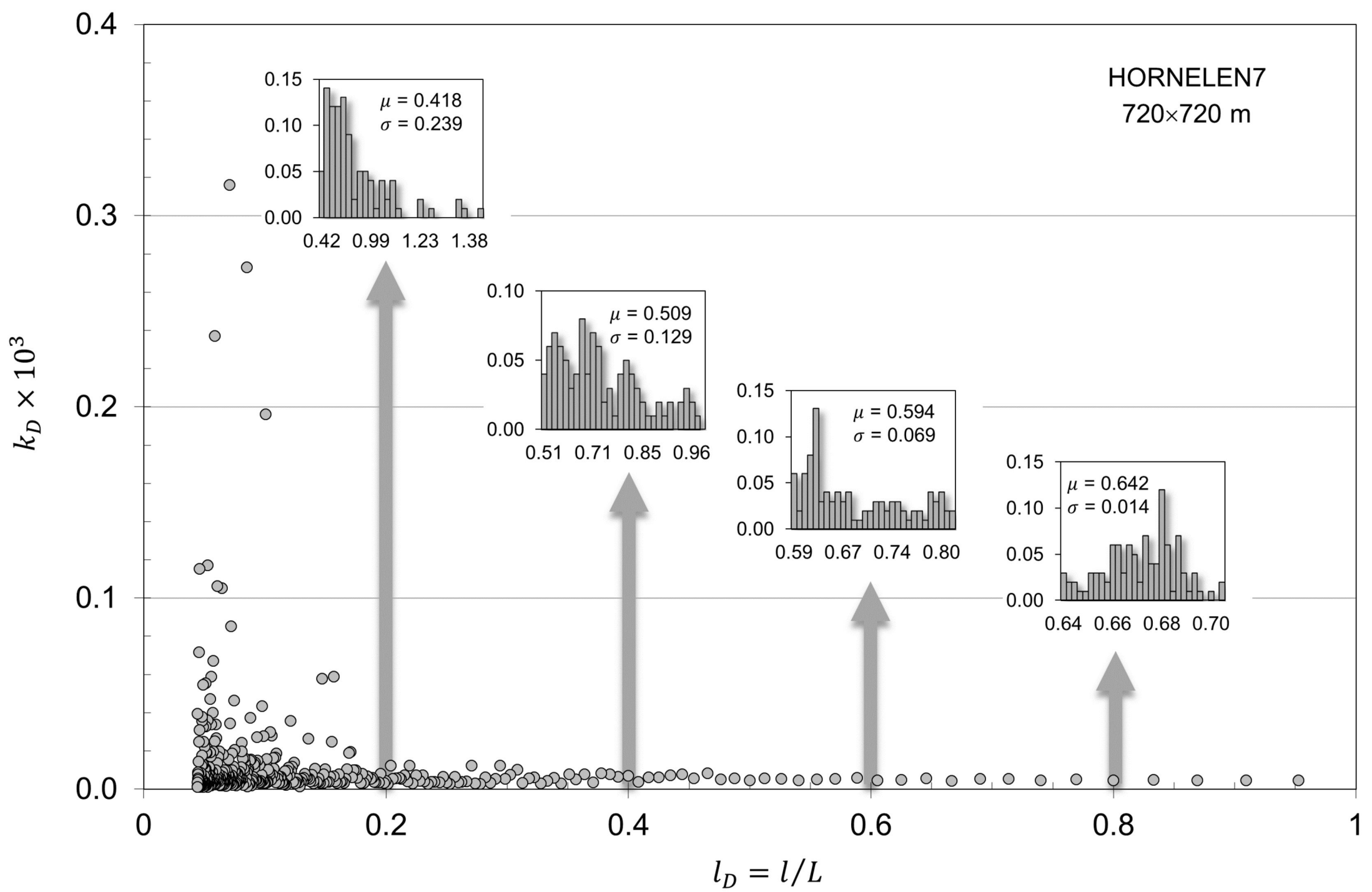

This article is protected by copyright. All rights reserved. 


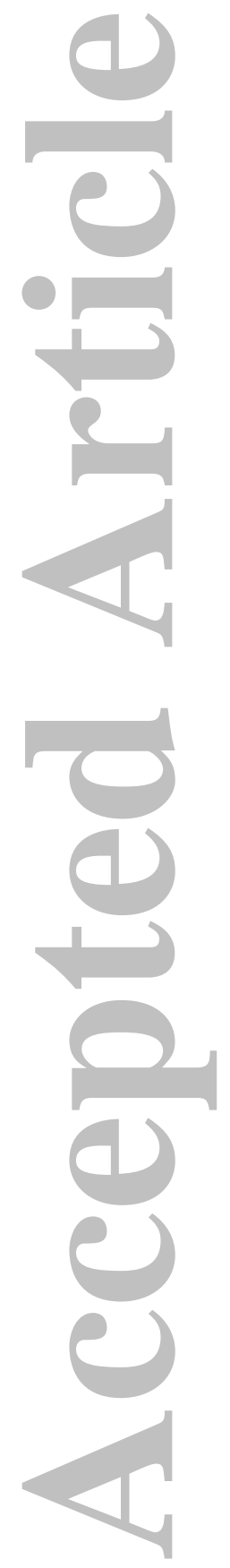

This article is protected by copyright. All rights reserved. 


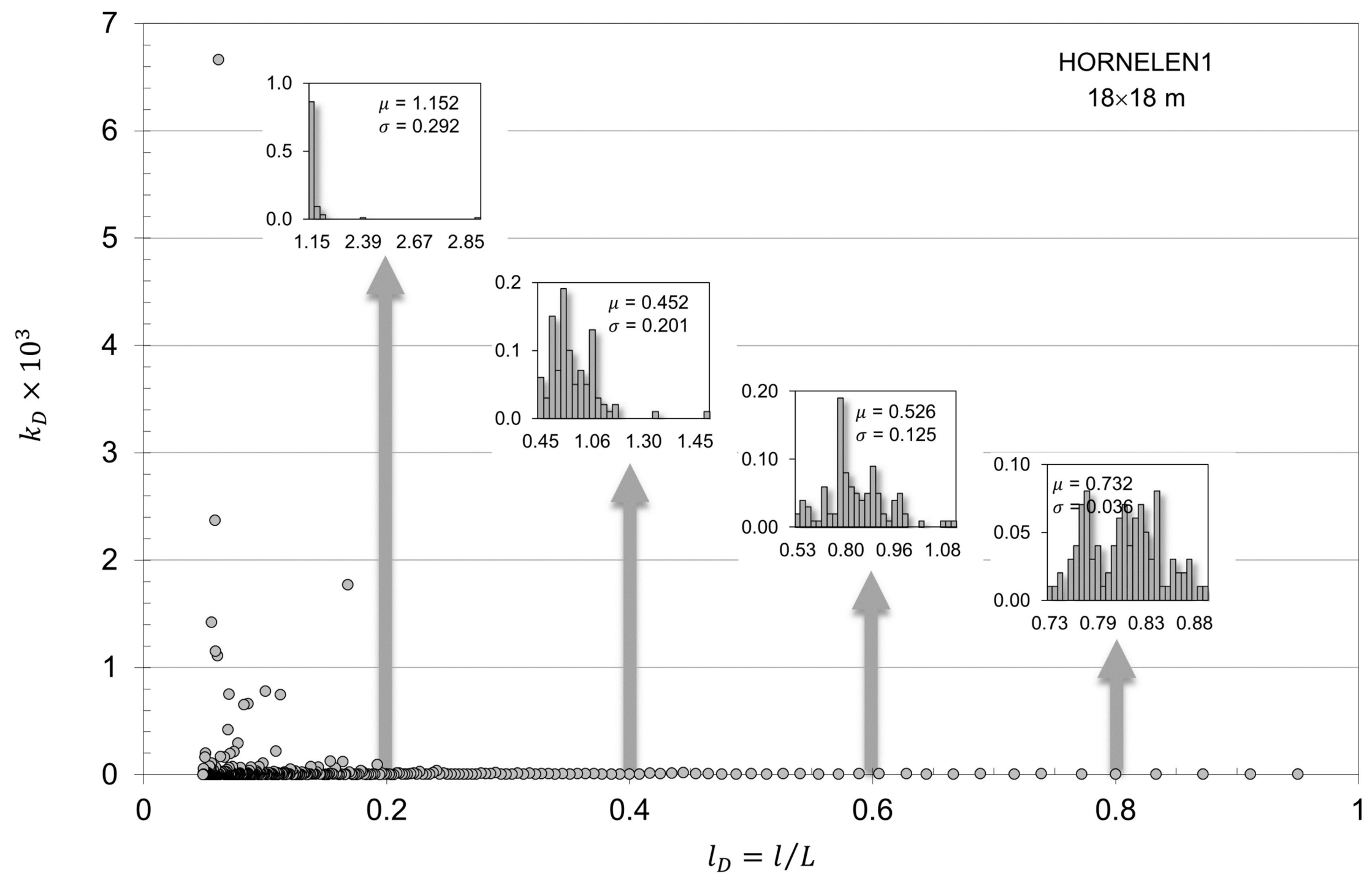

This article is protected by copyright. All rights reserved. 


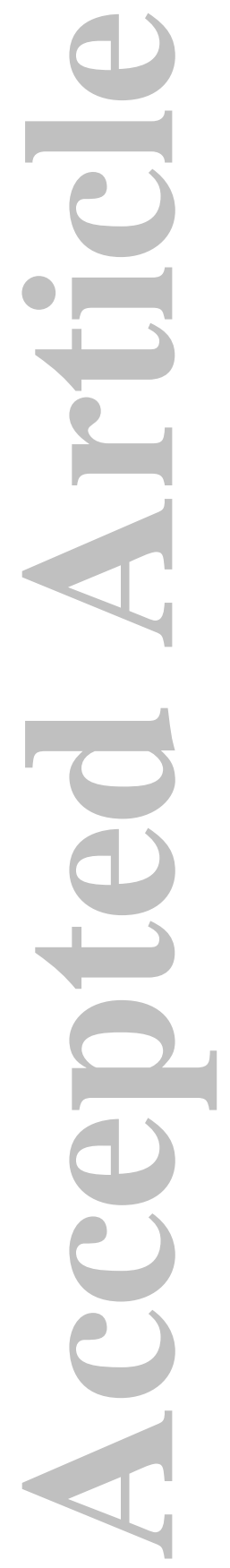

This article is protected by copyright. All rights reserved. 

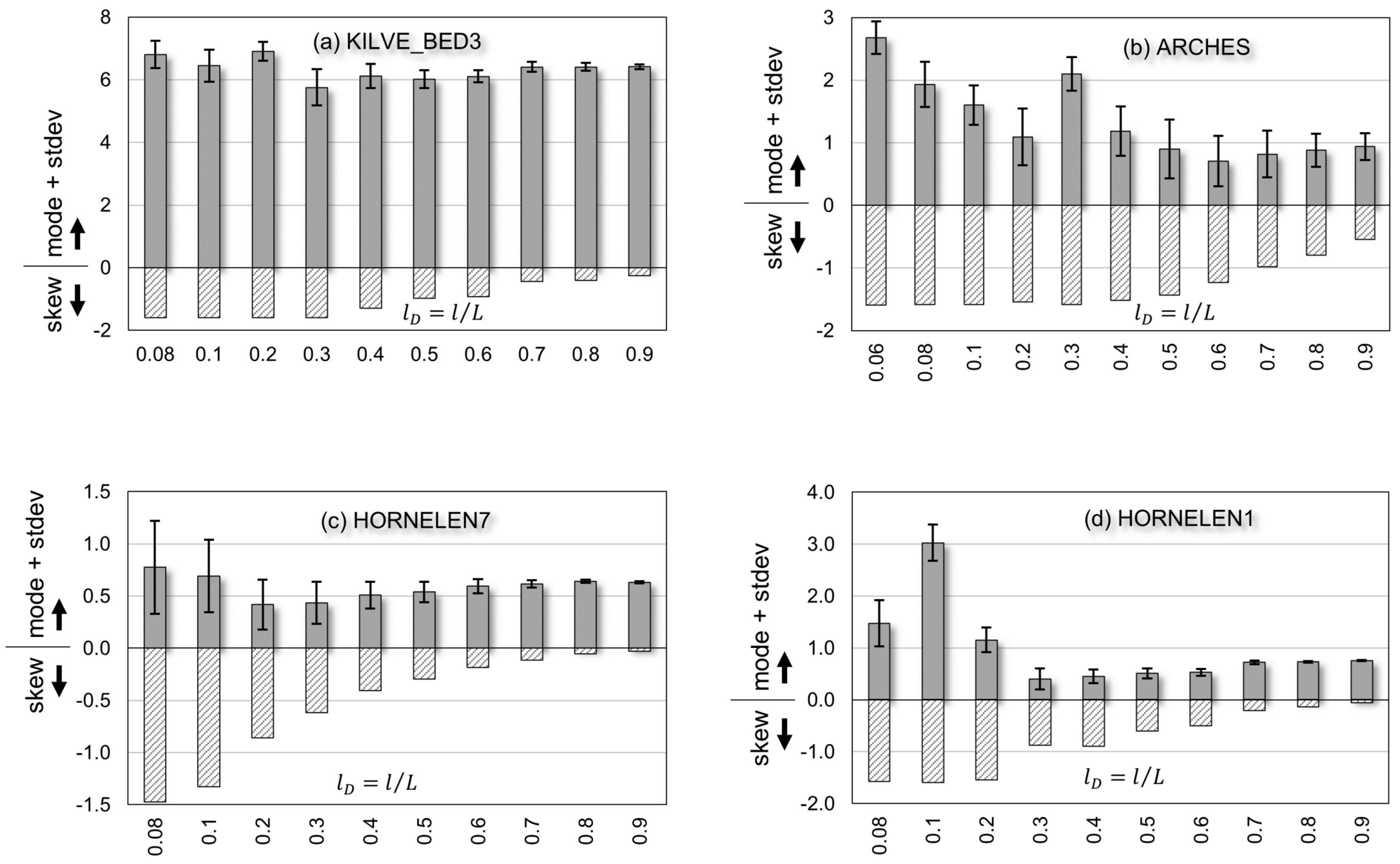


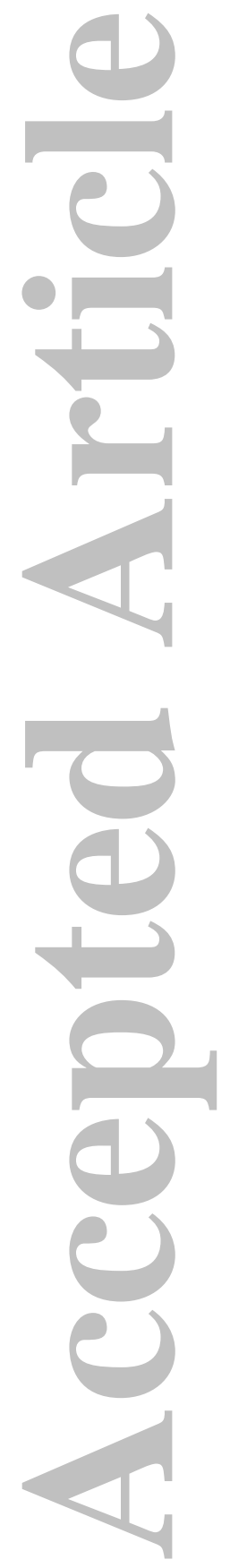

This article is protected by copyright. All rights reserved. 

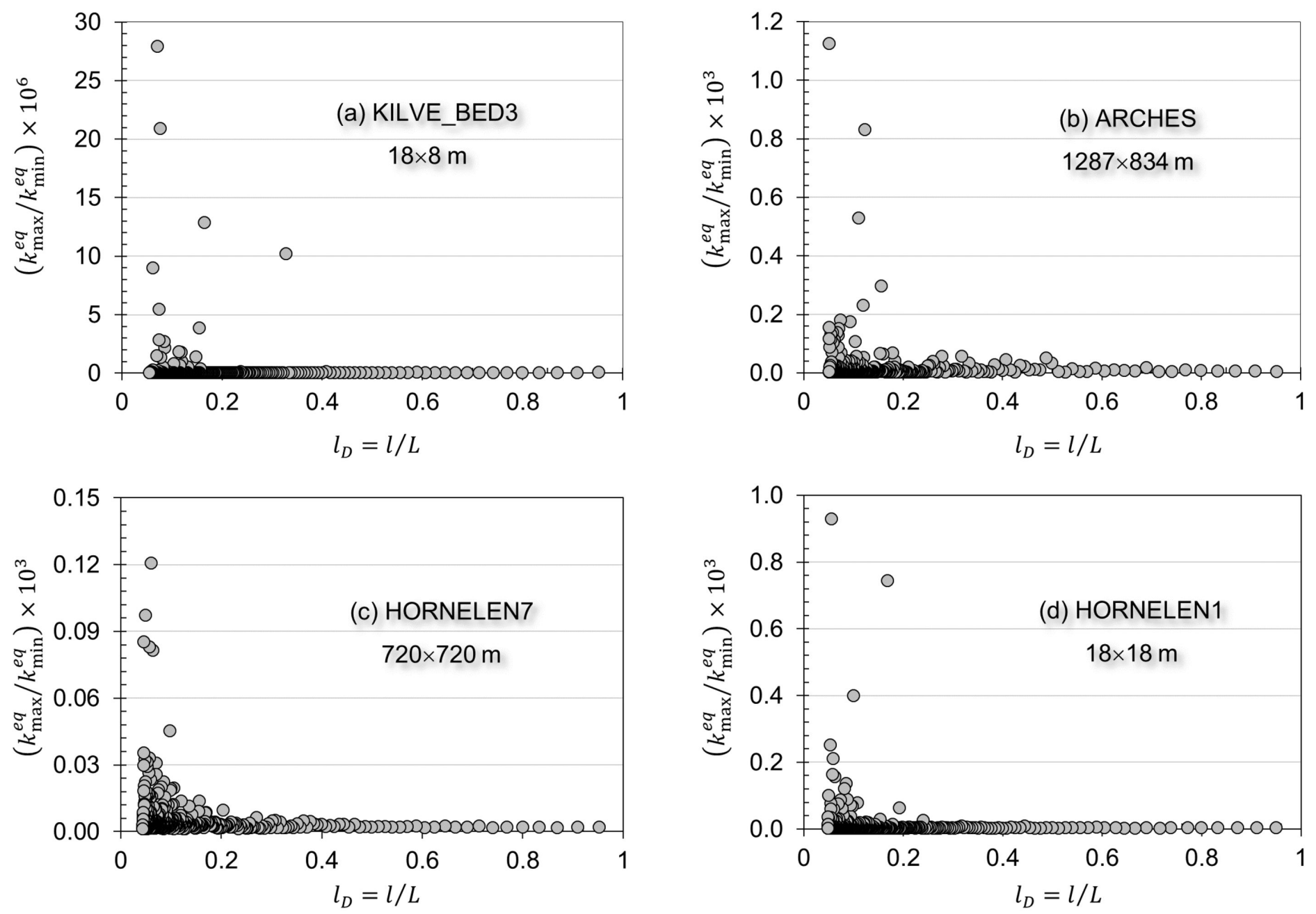

This article is protected by copyright. All rights reserved. 


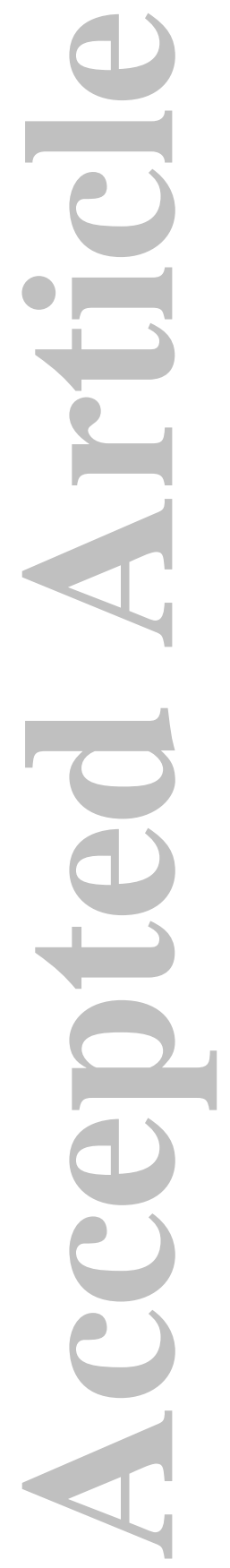

This article is protected by copyright. All rights reserved. 

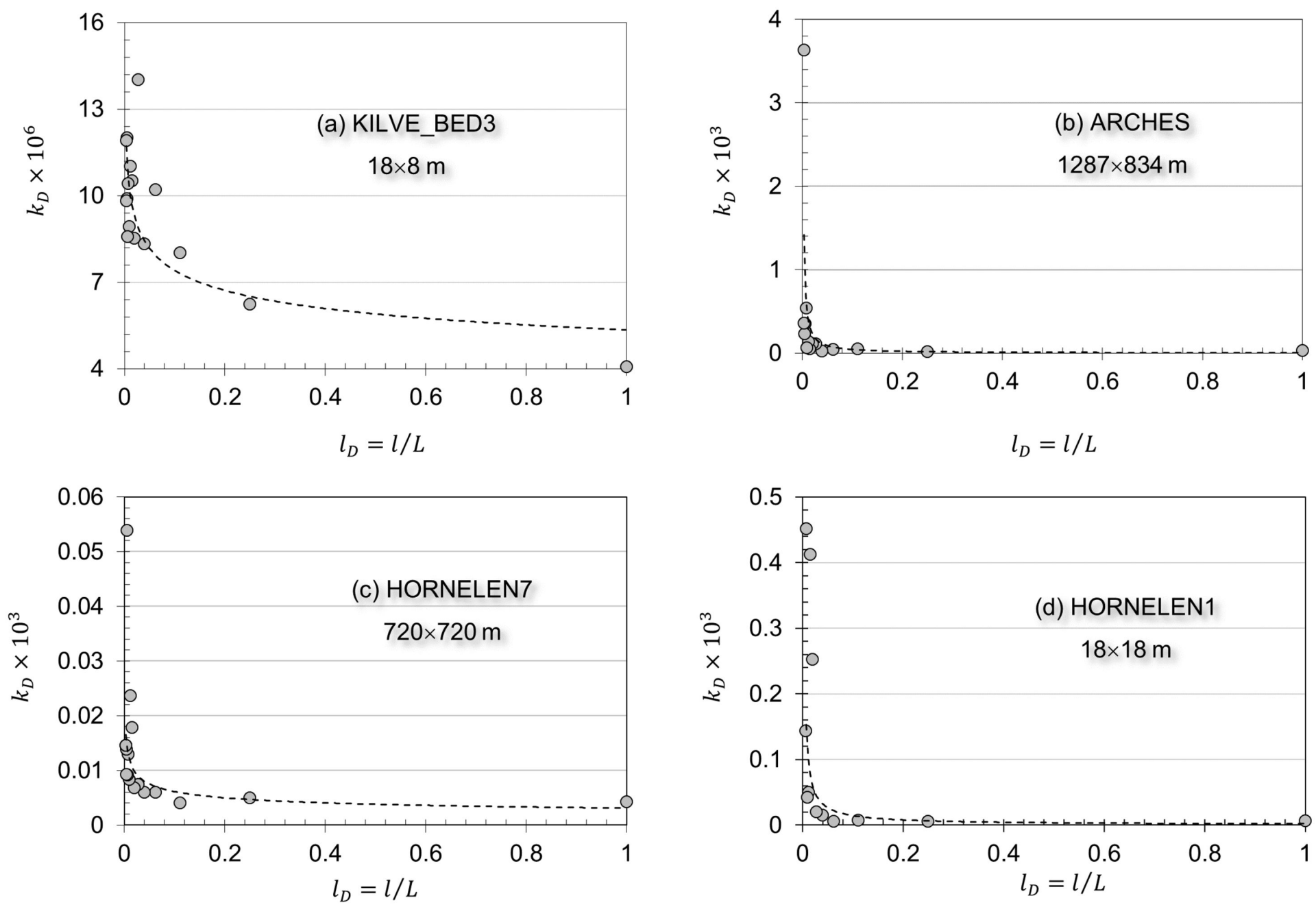

This article is protected by copyright. All rights reserved. 


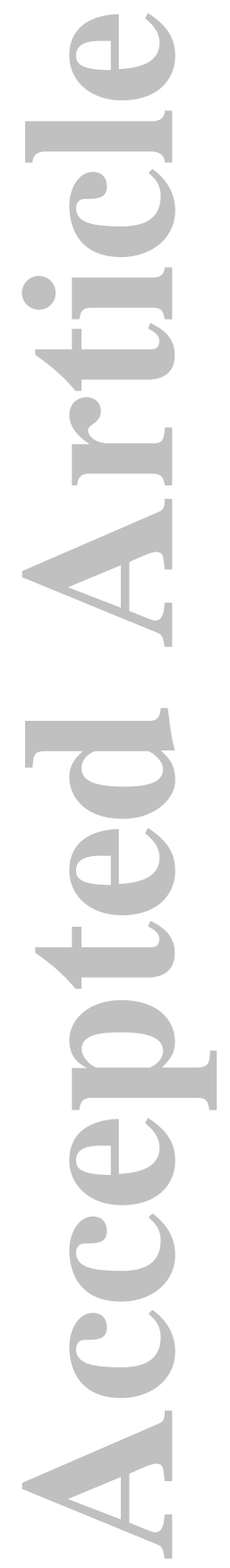

This article is protected by copyright. All rights reserved. 


\section{KILVE_BED3 $(18 \times 8 \mathrm{~m})$}

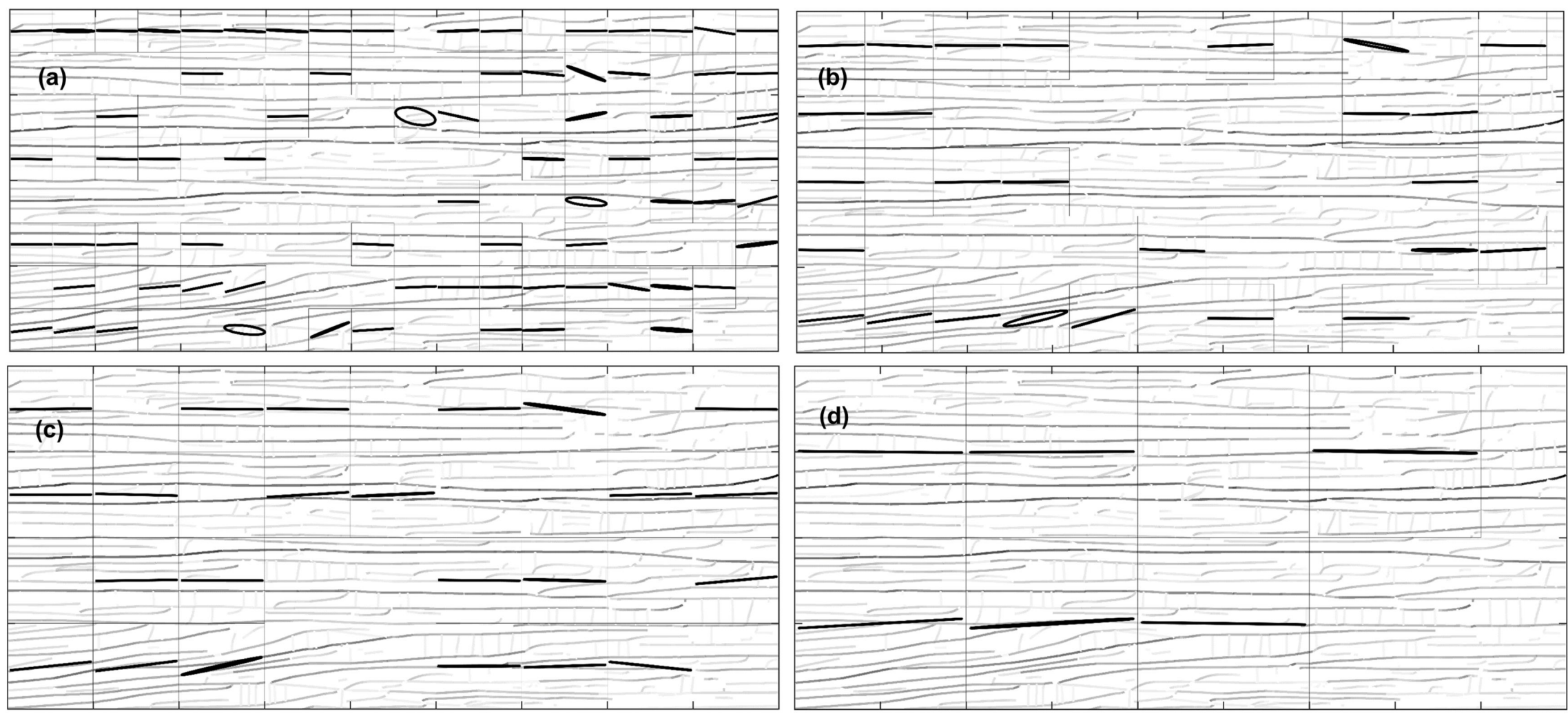

This article is protected by copyright. All rights reserved. 


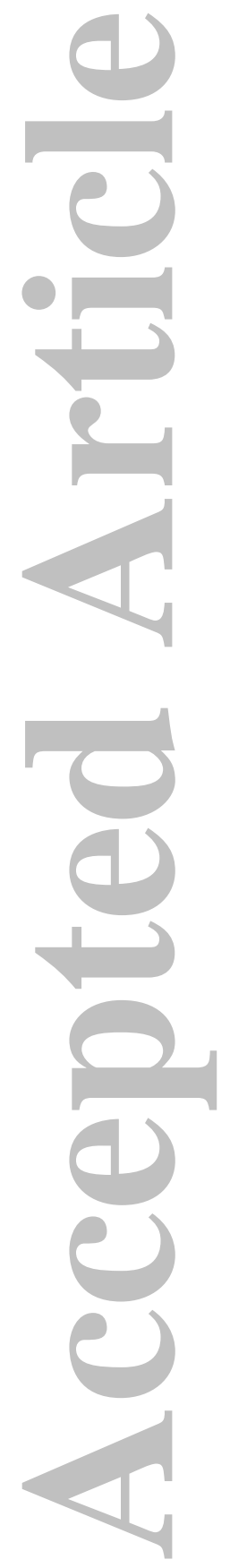

This article is protected by copyright. All rights reserved. 
ARCHES (1287×834 m)
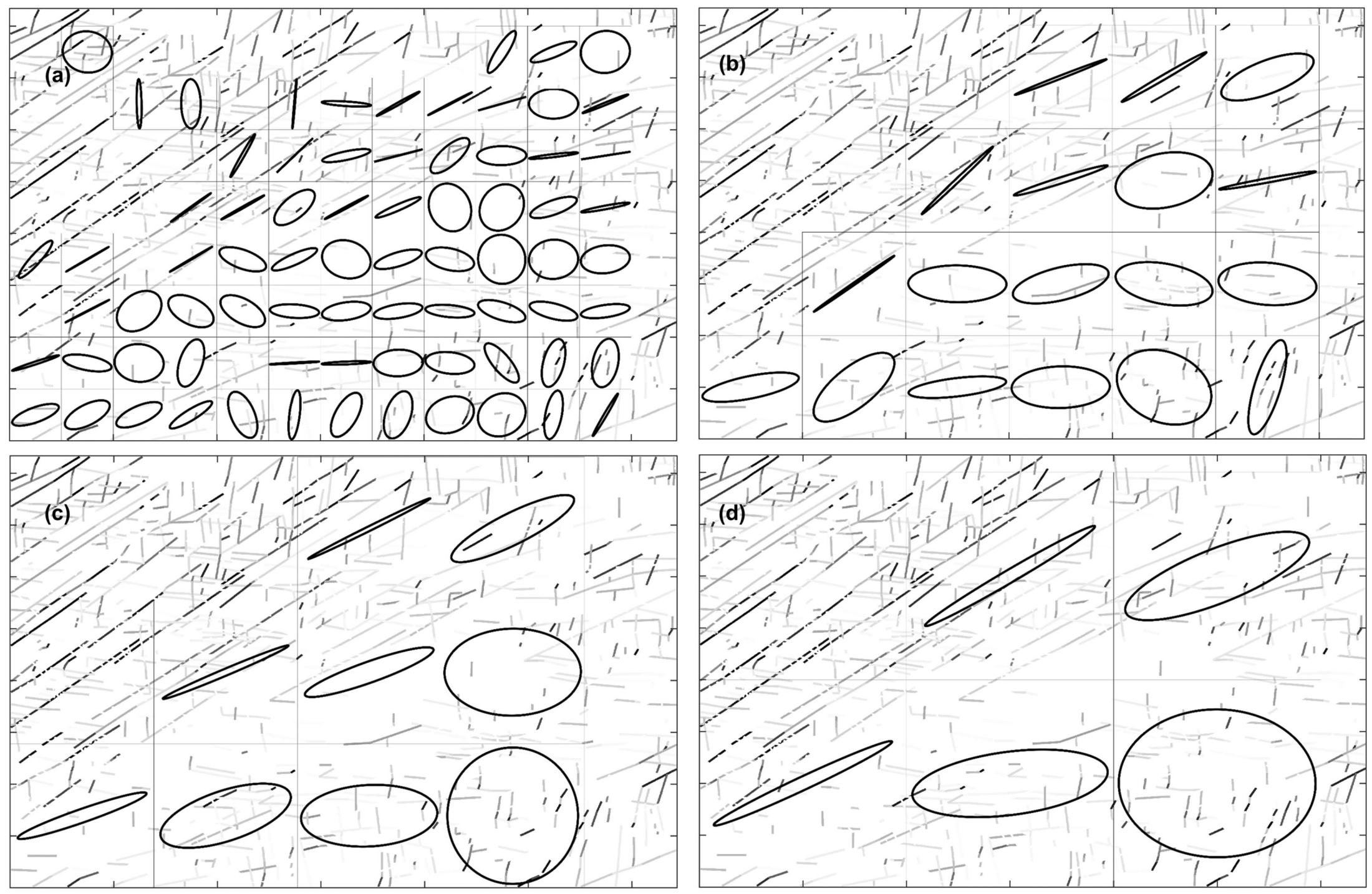

This article is protected by copyright. All rights reserved. 


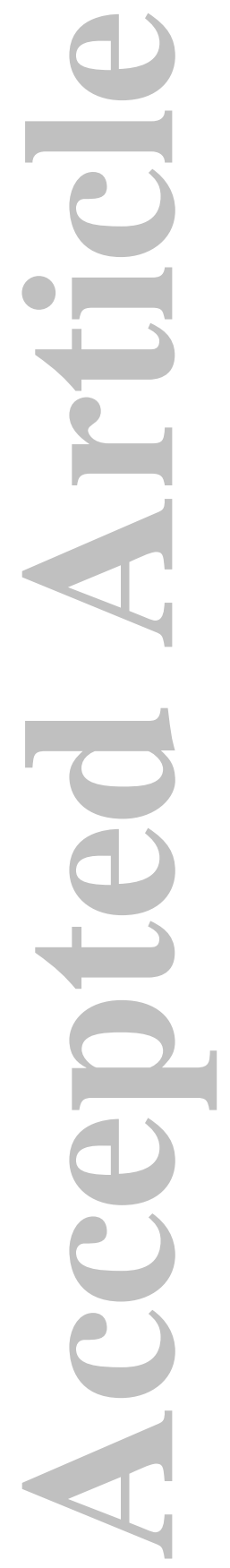

This article is protected by copyright. All rights reserved. 
HORNELEN7 $(720 \times 720 \mathrm{~m})$
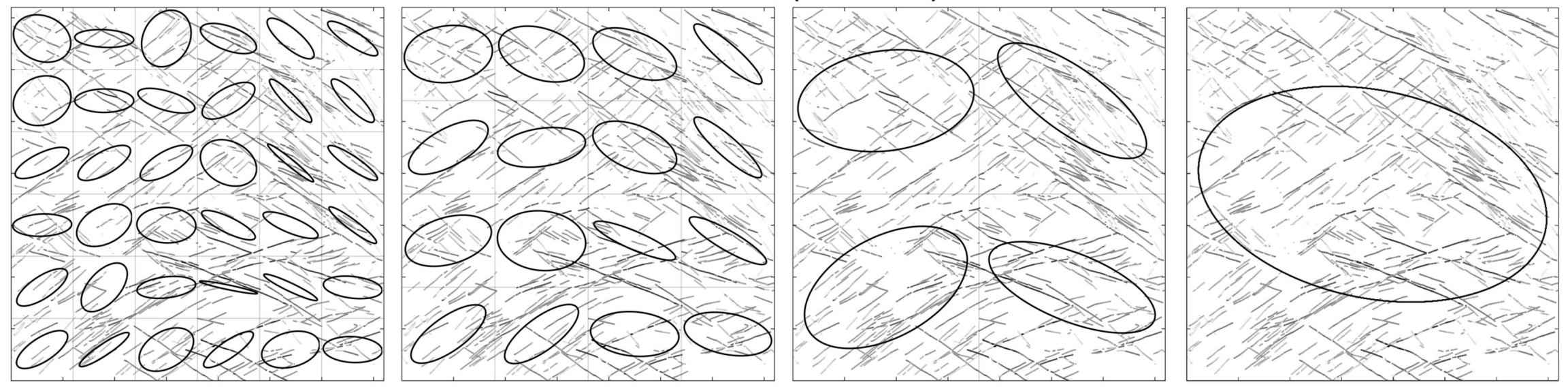

HORNELEN1 $(18 \times 18 \mathrm{~m})$
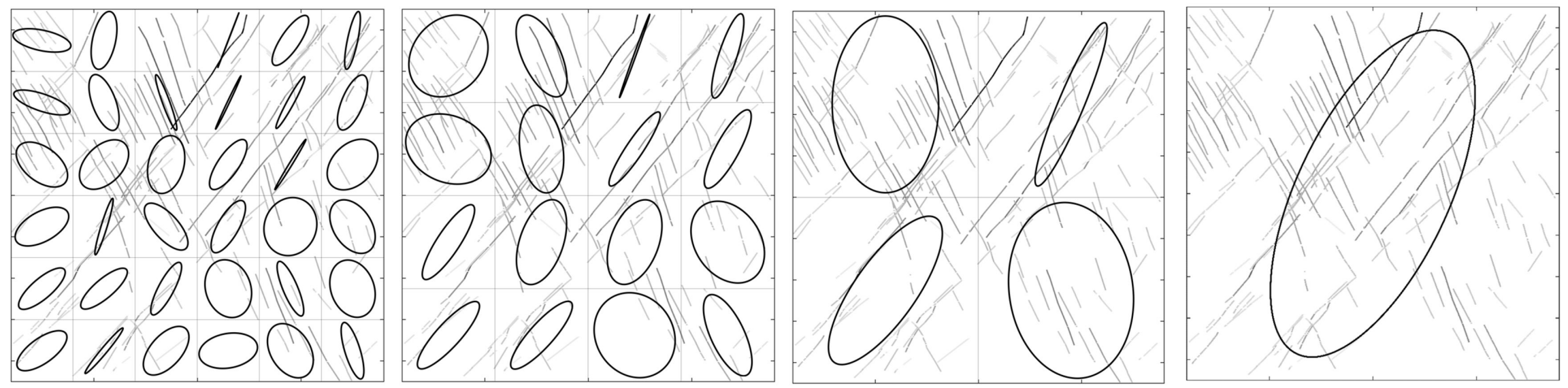